\title{
Revised Multi-Node Well (MNW2) Package for MODFLOW Ground-Water Flow Model
}

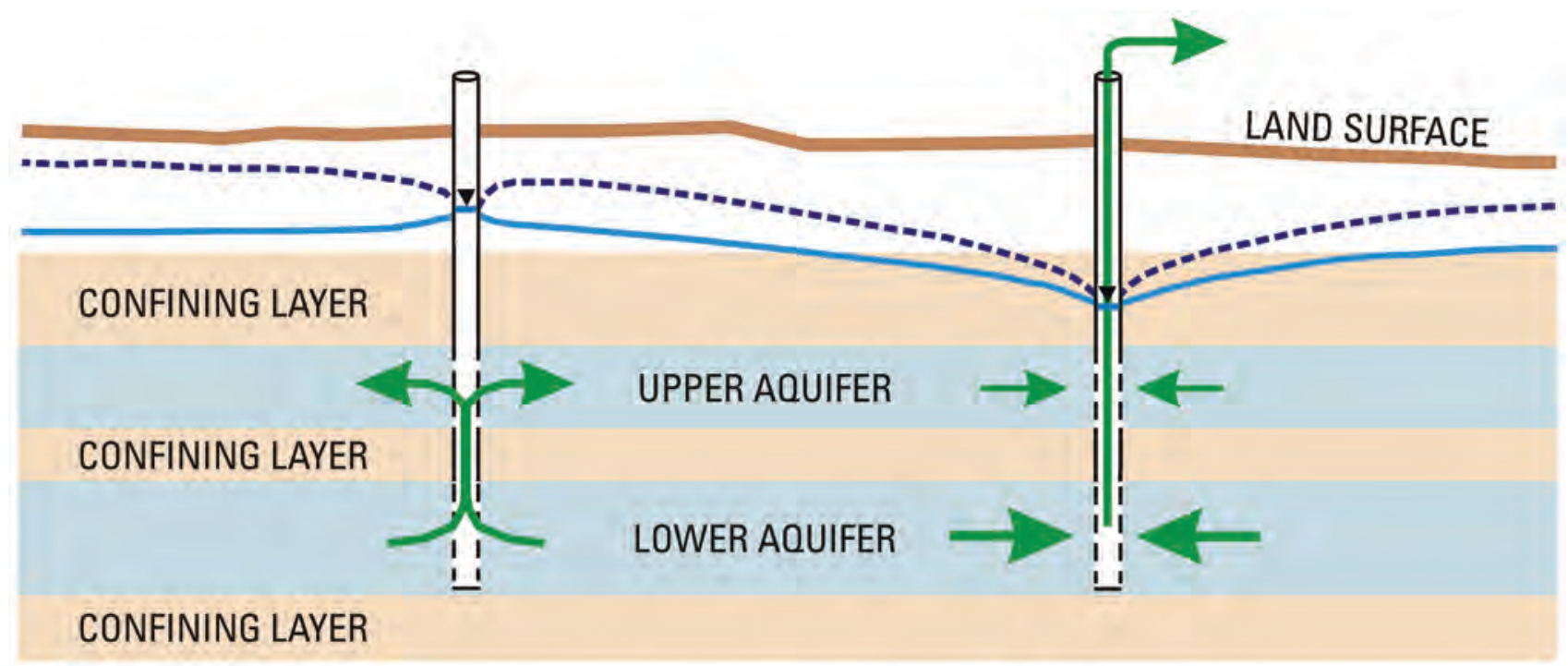

Techniques and Methods 6-A30 
Cover: Schematic cross section showing flow patterns that can be induced by well that is open to multiple aquifers (see figure 1 and related discussion for more details); modified from Halford and Hanson (2002). 


\section{Revised Multi-Node Well (MNW2) Package for MODFLOW Ground-Water Flow Model}

By Leonard F. Konikow, George Z. Hornberger, Keith J. Halford, and Randall T. Hanson

With a section by

Arlen W. Harbaugh

Techniques and Methods 6-A30 


\section{U.S. Department of the Interior \\ KEN SALAZAR, Secretary \\ U.S. Geological Survey \\ Suzette M. Kimball, Acting Director}

U.S. Geological Survey, Reston, Virginia: 2009

For more information on the USGS - the Federal source for science about the Earth, its natural and living resources, natural hazards, and the environment, visit http://www.usgs.gov or call 1-888-ASK-USGS

For an overview of USGS information products, including maps, imagery, and publications, visit http://www.usgs.gov/pubprod

To order this and other USGS information products, visit http://store.usgs.gov

Any use of trade, product, or firm names is for descriptive purposes only and does not imply endorsement by the U.S. Government.

Although this report is in the public domain, permission must be secured from the individual copyright owners to reproduce any copyrighted materials contained within this report.

Suggested citation:

Konikow, L.F., Hornberger, G.Z., Halford, K.J., and Hanson, R.T., 2009, Revised multi-node well (MNW2) package for MODFLOW ground-water flow model: U.S. Geological Survey Techniques and Methods 6-A30, 67 p.

ISBN 978-1-4113-2488-6 


\section{Preface}

This report describes a software package to allow the U.S. Geological Survey (USGS) MODFLOW ground-water flow model to simulate "long" wells that are connected to more than one node of the finite-difference grid. The software represents a revision to a previously published Multi-Node Well Package and is meant to replace the previous version. The modifications allow corrections for the effects of partially penetrating wells, improved treatment of non-vertical wells, and adjustments in discharge according to specified pump performance (head-capacity) curves, among other changes. Sample problems are included throughout the text. The revised code is compatible with MODFLOW-2000 and MODFLOW-2005.

In this report, any program variables, computer file names, input listings, and output files are printed in a nonproportional (or fixed width) font (for example, sample parameter). This helps clearly distinguish the nature and origin of these terms and items.

The code and documentation, including files for the sample test problem, are available for downloading at no cost on the Internet from a USGS software repository at http://water.usgs.gov/software/ground_water.htm?. When this code is revised or updated in the future, new versions or releases will be made available for downloading from this site.

Although extensive testing of the code indicates that this model will yield reliable calculations for a variety of field problems, the user is cautioned that the accuracy and efficiency of the model can be affected appreciably for certain combinations of parameter values. Users are encouraged to report any errors in this report or in the code to the contact listed on the appropriate software distribution Web page. 


\section{Contents}

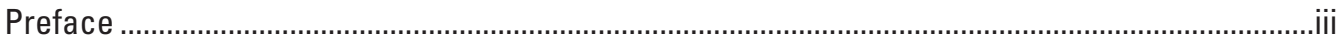

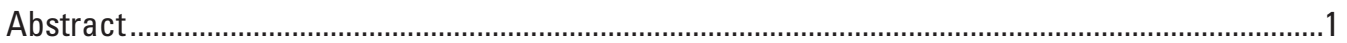

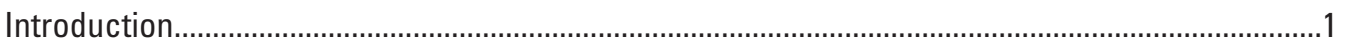

Conceptual Model and Numerical Implementation .........................................................................3

Simulation of Pumping and Nonpumping Wells .........................................................................

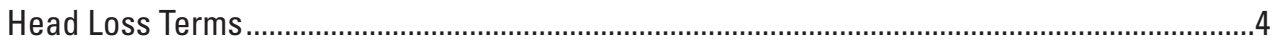

Calculation of Water Level and Flow in the Multi-Node Well ...................................................... 6

Specifying the Location of Multi-Node Wells ..........................................................................

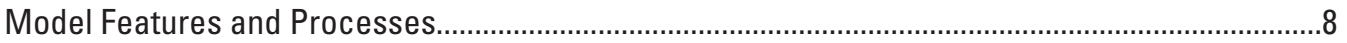

Description of Test Problems .......................................................................................................

Fully Penetrating Pumped Well in Ideal Confined Aquifer (Lohman Problem) ..................8

Long, Unpumped Observation Well (Reilly Problem) .........................................................8

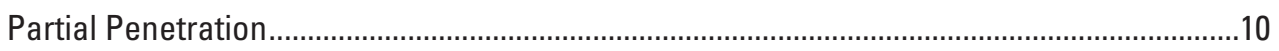

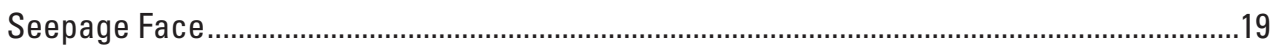

Constraints on Pumping Rate ....................................................................................................21

Flowing Wells: Special Application of Constraints on Pumping Rate ......................................27

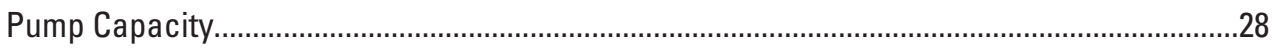

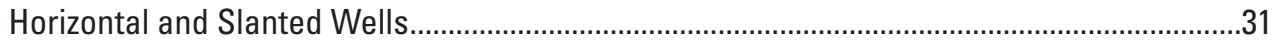

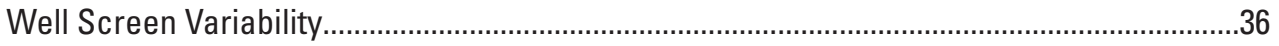

Flow Routing in Borehole ........................................................................................................39

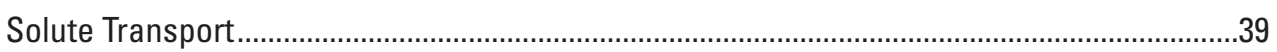

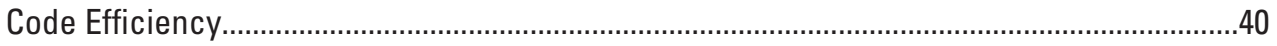

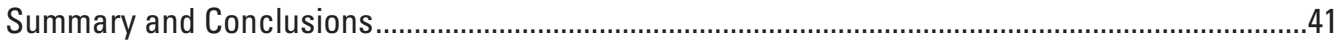

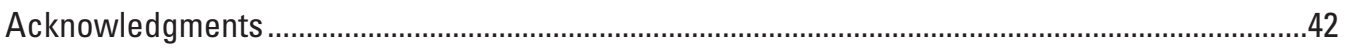

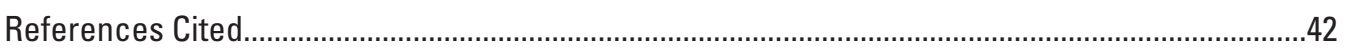

Appendix 1-Data Input Instructions for Multi-Node Well (MNW2) Package ...............................45

Appendix 2-Selected Input Data and Printed Results for Sample Problem...................................55

Appendix 3-Program to Convert MNW1 Input Data to MNW2 Input Data ....................................65

\section{Figures}

1. Schematic cross section showing flow patterns that can be induced by a multiaquifer well and simulated by the MNW2 Package.

2. Schematic horizontal cross section (plan view) through a vertical well in a finitedifference cell showing some of the factors affecting computed well loss.

3. Semilog plot showing comparisons between drawdowns computed numerically using MODFLOW and drawdowns computed using the Theis (1935) analytical solution

4. Conceptual diagram showing geometry and boundaries for three-dimensional test problem with a nonpumping multi-node well.

5. Map view of MODFLOW finite-difference grid showing location of fine grid area and of the nonpumping multi-node well in the Reilly test problem

6. Calculated head distribution in vertical section near well on plane of symmetry...........11 
7. Schematic cross-sectional diagram showing fully and partially penetrating wells in a nonleaky confined aquifer...

8. Semilog plots of dimensionless drawdown in a vertical pumping well with an open interval centered vertically in a nonleaky, homogeneous, isotropic, confined aquifer, showing the sensitivity of the analytical solution to the partial penetration fraction.

9. Plots showing the relation of dimensionless drawdown to penetration fraction for a vertical pumping well in a nonleaky, homogeneous, isotropic, confined aquifer, for wells located vertically in the middle of the aquifer and the edge of the aquifer .

10. Drawdown due to partial penetration effects in a vertical pumping well that is open to 33 percent of the saturated thickness of the aquifer, showing sensitivity to the vertical position of the well screen within the aquifer...

11. Plot showing comparisons of analytical and numerical solutions for dimensionless drawdown for selected cases for the Lohman problem.

12. Schematic cross-sectional diagram showing alternate vertical discretization possibilities for simulating a confined aquifer containing a partially penetrating well.

13. Plot showing comparisons of analytical and numerical solutions for dimensionless drawdown for the Lohman problem with a partial penetration fraction of 0.33 and the well screen located in the middle of the aquifer.

14. Schematic cross section of an unconfined aquifer simulated as a single "convertible" model layer showing the relation of the position of a partially penetrating well screen to the water table as the water table declines sequentially over time.

15. Schematic cross section of an unconfined aquifer represented by three model layers, showing the relation of a well screened in model layer 2 to the water table as the water table declines over time.

16. Plot showing the effect of variations in the penetration fraction for the uppermost node of the multi-node well in the Reilly problem on the computed water level in the well.

17. Plot showing sensitivity of total intraborehole flow to variations in the penetration fraction for the uppermost node of the multi-node well in the Reilly problem.

18. Plot showing flux into or out of each node of the borehole for penetration fractions of the top node of the well in the Reilly test problem

19. Schematic cross section of an unconfined aquifer showing a multi-node well open to parts of the uppermost five model layers.

20. Plot showing computed changes in head for the modified Reilly problem, both with and without correction for the development of a seepage face in the uppermost cell

21. Plot showing computed flow into the uppermost node of the multi-node well for the modified Reilly problem, both with and without correction for the development of a seepage face.

22. Plot showing computed flows into all nodes of the multi-node well during the 11th time-step for the modified Reilly problem, both with and without correction for development of seepage face.....

23. Hypothetical cross section illustrating limitations on well discharge rates....................23

24. Plot showing relation between computed net discharge from a multi-node well and computed head in the well for case in which well is subject to a constraint 
25. Plot showing relation between computed net discharge from a multi-node well and computed head in the well for case in which well is subject to a constraint and additional nearby pumping wells cause additional drawdown in the multinode well

26. Variations in nodal flux between the multi-node well and aquifer for modified Reilly problem with three additional single-node pumping wells nearby. .26

27. Plot showing relation between computed net discharge from a multi-node well and computed head in the well for case in which well is subject to a constraint and the minimum allowable pumping rate is set at $-2,000$ cubic feet per day

28. Plot showing relation between computed net discharge from a multi-node well and computed head in the well for case with multiple stress periods

29. Plot showing relation between computed net discharge from a nonpumping, free-flowing, single-node well located close to the downgradient boundary in a variation of the Reilly problem

30. Hypothetical but representative performance curves for three models of vertical turbine pump

31. Hypothetical performance curves for three models of vertical turbine pumps, showing points defined for linear interpolation.

32. Plot showing results of applying the pump-capacity relations to the modified Reilly problem in which the desired discharge equals $-7,800$ cubic feet per day for a 300-day transient stress period.

33. Plot showing results of applying the pump-capacity relations to the modified Reilly problem for two 365-day transient stress periods with three nearby wells pumping during the first transient stress period

34. Schematic three-dimensional perspective drawing of a representative finitedifference cell connected to a nonvertical multi-node well passing through the block-centered node.

35. Schematic cross-sectional view of a finite-difference cell containing a horizontal well aligned with the $y$-direction of the grid.

36. Schematic cross-sectional view to the west of part of a MODFLOW grid containing a multi-node well that changes orientation from a vertical well at the surface to a horizontal well at depth.

37. Depiction of orientation and alignment of a nonvertical well on the basis of two characteristic angles

38. Schematic cross-sectional view of part of a MODFLOW grid containing a multinode well that changes direction

39. Schematic cross-sectional view through a MODFLOW grid showing a mostly horizontal multi-node well.

40. Schematic cross section of an unconfined aquifer, showing the relation of the open and closed intervals to the position of the water table.

41. Diagrammatic cross section showing wells with complex well screens or open intervals within a model layer.

42. Schematic cross section of an unconfined aquifer showing a multi-node well and the relation of multiple screens.

43. Schematic cross section illustrating components of flow into and out of well segments comprising a representative node of a multi-node well. 


\section{Tables}

1. Properties of the confined aquifer system analyzed in the Lohman test problem ............8

2. Selected physical parameters used in MODFLOW simulation of ground-water flow in a three-dimensional, steady-state flow system containing a multi-node well .............9

3. Modified parameters in Reilly problem for evaluating seepage face calculation in

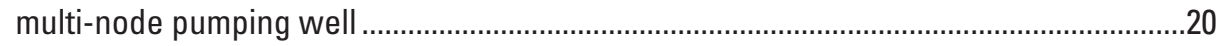

4. Computational effort for range of variations of Reilly test problem ................................41

A1-1. Summary of parameter definition requirements for available well-loss options.............48

A3-1. Inferred equivalence in MNW1to2 of LOSSTYPE options in MNW1 to those in MNW2.

\section{Conversion Factors}

\begin{tabular}{lcl}
\hline \multicolumn{1}{c}{ Multiply } & By & To obtain \\
\hline & Length & \\
\hline foot $(\mathrm{ft})$ & 0.3048 & meter $(\mathrm{m})$ \\
\hline square inch $\left(\mathrm{in}^{2}\right)$ & Area & \\
\hline & 6.452 & square centimeter $\left(\mathrm{cm}^{2}\right)$ \\
\hline cubic foot $\left(\mathrm{ft}^{3}\right)$ & Volume & \\
\hline & 0.02832 & cubic meter $\left(\mathrm{m}^{3}\right)$ \\
\hline foot per day $(\mathrm{ft} / \mathrm{d})$ & Flow rate & \\
cubic foot per second $\left(\mathrm{ft}^{3} / \mathrm{s}\right)$ & 0.3048 & meter per day $(\mathrm{m} / \mathrm{d})$ \\
cubic foot per day $\left(\mathrm{ft}^{3} / \mathrm{d}\right)$ & 0.02832 & cubic meter per second $\left(\mathrm{m}^{3} / \mathrm{s}\right)$ \\
& 0.02832 & cubic meter per day $\left(\mathrm{m}^{3} / \mathrm{d}\right)$ \\
\hline foot per day $(\mathrm{ft} / \mathrm{d})$ & Hydraulic conductivity & \\
\hline & 0.3048 & meter per day $(\mathrm{m} / \mathrm{d})$ \\
\hline
\end{tabular}





\title{
Revised Multi-Node Well (MNW2) Package for MODFLOW Ground-Water Flow Model
}

\author{
By Leonard F. Konikow, George Z. Hornberger, Keith J. Halford, and Randall T. Hanson
}

\begin{abstract}
Wells that are open to multiple aquifers can provide preferential pathways to flow and solute transport that shortcircuit normal fluid flowlines. Representing these features in a regional flow model can produce a more realistic and reliable simulation model. This report describes modifications to the Multi-Node Well (MNW) Package of the U.S. Geological Survey (USGS) three-dimensional ground-water flow model (MODFLOW). The modifications build on a previous version and add several new features, processes, and input and output options. The input structure of the revised MNW (MNW2) is more well-centered than the original verion of MNW (MNW1) and allows the user to easily define hydraulic characteristics of each multi-node well. MNW2 also allows calculations of additional head changes due to partial penetration effects, flow into a borehole through a seepage face, changes in well discharge related to changes in lift for a given pump, and intraborehole flows with a pump intake located at any specified depth within the well. MNW2 also offers an improved capability to simulate nonvertical wells. A new output option allows selected multi-node wells to be designated as "observation wells" for which changes in selected variables with time will be written to separate output files to facilitate postprocessing. MNW2 is compatible with the MODFLOW-2000 and MODFLOW-2005 versions of MODFLOW and with the version of MODFLOW that includes the Ground-Water Transport process (MODFLOW-GWT).
\end{abstract}

\section{Introduction}

Wells that have relatively long open (uncased) intervals or screens may be hydraulically connected to multiple aquifers or to different parts of a single aquifer where the hydraulic heads differ. Such wells (or boreholes) can provide preferential pathways to flow and solute transport that short-circuit natural predevelopment fluid flowlines, whether the well is pumped or unpumped (such as a long-screen observation well). Although the hydraulic head in the aquifer can vary along the length of the borehole, there would only be a single water level within the well itself. Flow can occur within these wells in response to the varying differences in hydraulic head between the well and the aquifer along the length of the borehole in addition to flow caused by pumping stresses. Although the net pumpage from a well may be known, the flow between the aquifer and the borehole can vary substantially along the length of the borehole, and that distribution is generally unknown.

If a nonpumping well has a relatively long open interval or well screen and (or) is open to multiple aquifers, then the borehole may be adjacent to materials having a range of hydraulic heads. This can (and will) induce flow within a nonpumping well. This phenomenon has long been recognized, and much effort has been directed towards the development and use of geophysical methods to measure the flow in the borehole (for example, see Izbicki and others, 1999; Paillet and others, 2002) and methods to simulate and characterize the flow (for example, see Giddings, 1987; Kaleris, 1989; Reilly and others, 1989; Hanson and Nishikawa, 1996). It is also recognized that long-screen wells or long open boreholes with intraborehole flow potentially provide pathways for contaminants to move from one location to another in a ground-water flow system (Konikow and Hornberger, 2006a).

Examples of flow through long boreholes are illustrated in figure 1, which shows a two-aquifer system in which the transmissivities of the two aquifers are identical but their head distributions are different. Well A is a nonpumping well open to both the upper and lower aquifers. Because the head in the lower aquifer is higher than the head in the upper aquifer, the head in the well will equilibrate to some intermediate value between the two aquifer heads at the location of the well. Consequently, the head in the well will be lower than that in the lower aquifer, and there will be flow into the well at that horizon. Likewise, because the head in the well will be higher than that in the upper aquifer, there will be flow out of the well and into the upper aquifer. Even though it is a nonpumping well, there is upwards flow through the borehole and this flow transfers water between the two aquifers.

Well $\mathrm{B}$ in figure 1 is a pumping well that is also open to both the upper and lower aquifers. Because of the pumpage, the head in the well is lower than in either aquifer. However, more flow enters the well in the lower aquifer than in the upper aquifer, even though the transmissivities are identical, because the head gradient between the aquifer and the well is greater in the lower aquifer than in the upper aquifer. 


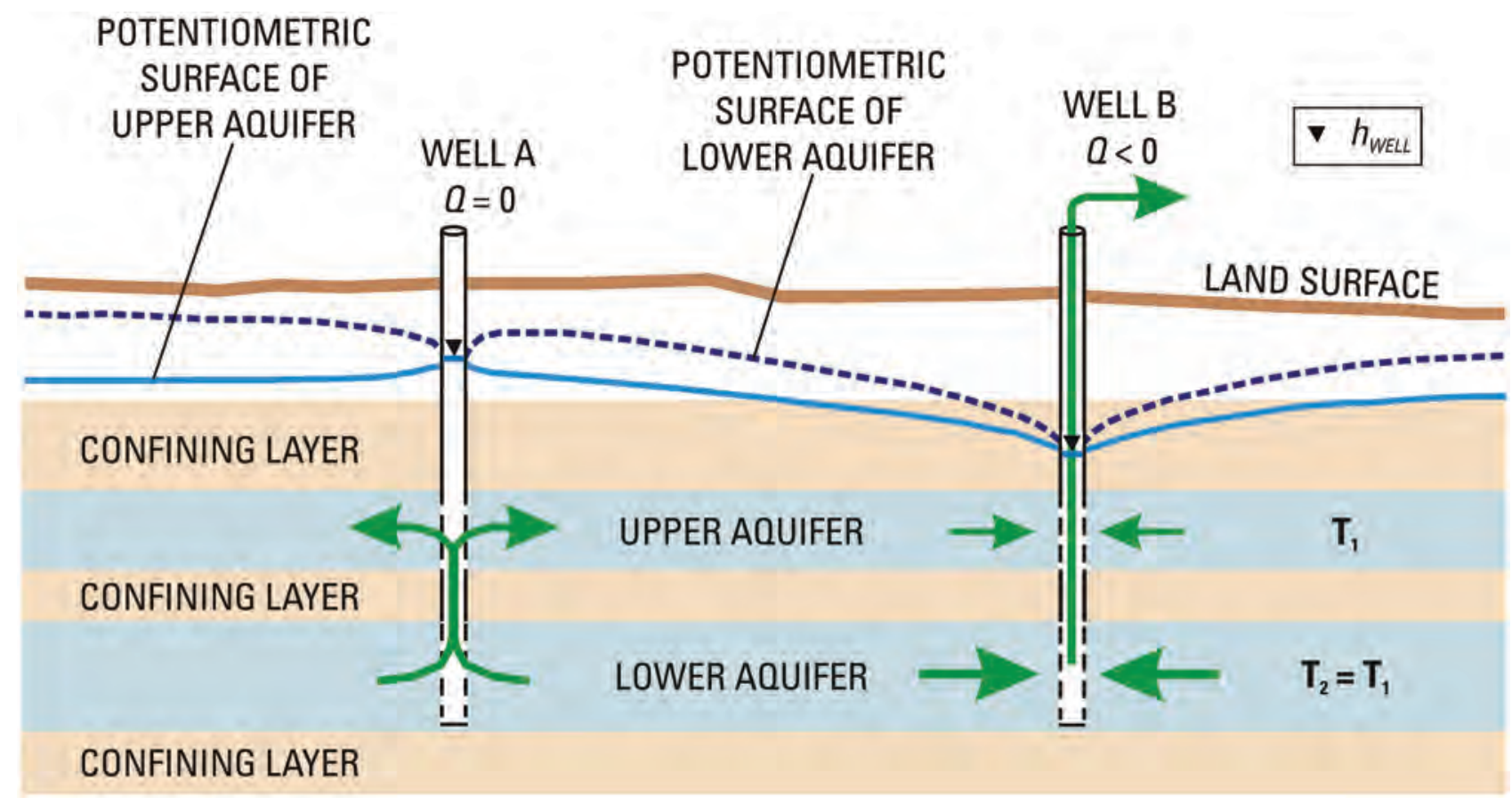

Figure 1. Schematic cross section showing flow patterns that can be induced by a multiaquifer well and simulated by the MNW2 Package (modified from Halford and Hanson, 2002). Well A is a nonpumping well, well $B$ is a pumping well, $T$ is transmissivity, $h_{\text {WELL }}$ is the water level in the well, and $Q$ is discharge rate from the well (in MODFLOW convention, discharge has a negative sign).

In a numerical ground-water simulation model, long wells, which are connected to more than one node of the grid, must be represented and simulated accurately to understand and predict their effects on the local and regional flow fields. Traditional approaches for simulating wells in numerical models, such as the Well (WEL) Package of MODFLOW (McDonald and Harbaugh, 1988; Harbaugh and McDonald, 1996; Harbaugh and others, 2000; Harbaugh, 2005) assume that the well is connected to a single node of the grid representing the ground-water flow system and that the water level in the well is identical to the head at the connected node. For a long well, however, flow rates between the well and each node are unknown, and the numerical method must be able to calculate the single water level in the well, whether the well is pumping or nonpumping and calculate the contribution of each model node to the total flow rate (or net discharge) of the well (such as described in Bennett and others, 1982; Neville and Tonkin, 2004).

Neville and Tonkin (2004) reviewed several alternative numerical methods to represent multiaquifer wells with the widely used U.S. Geological Survey (USGS) ground-water simulation model MODFLOW (McDonald and Harbaugh, 1988; Harbaugh and McDonald, 1996; Harbaugh and others, 2000; Harbaugh, 2005). They demonstrated that the MultiAquifer Well (MAW1) Package (McDonald, 1984) closely matched exact analytical solutions for pumping and nonpumping conditions, and noted that the MNW Package (Halford and Hanson, 2002; hereafter referred to as MNW1) expanded on the capabilities of the earlier MAW1 Package to simulate flow between a long well and the adjacent ground-water system. The value and importance of the MNW1 Package has been illustrated by its application and use in the simulation of many aquifer systems. For example, Hanson and others (2004) applied the package in their model of the Santa Clara Valley, Calif.

The MNW1 Package was designed for maximum compatibility with the original WEL Package of MODFLOW (McDonald and Harbaugh, 1988). However, the input data structure to enable this compatibility was relatively complex and required the user to develop a single long list of all nodes contained in all multi-node wells. Use of this type of nodeoriented structure also therefore required the redundant specification of well properties for each node, sometimes entailing unnecessary duplication of effort and information. The MNW1 Package was also designed to be as general as possible and included a number of features, processes, and parameters that would only be used in a limited number of very special cases. Although this generality has value, it also increases the complexity and difficulty of the input structure and data preparation for most users.

The purpose of this study was to develop a new MNW Package, MNW2, that would be simpler and easier to use (primarily through a restructured input data format), to add new features and processes that would be applicable in common situations, to eliminate rarely used or highly specialized features, and to improve the efficiency of the code. This report describes the underlying theory of the processes that are implemented in the MNW2 Package, provides detailed 
instructions for preparing the input file necessary for a simulation that includes the MNW2 Package, and gives examples of the application of the package for hypothetical conditions. Because of the large number of changes that have been made in the transition from the MNW1 to the MNW2 Packages and because the input file for the MNW2 Package is not backwards compatible with that for the MNW1 Package, the MNW2 Package supersedes the MNW1 Package. This report provides documentation for the MNW2 Package.

The main features added to the MNW2 Package include:

- Restructured input formats, including the separate specification of properties associated with individual wells, an option to specify vertical locations of open intervals (or well screens) by their top and bottom elevations, and an option to define skin effects in terms of the hydraulic conductivity of the well skin.

- The option for the model to calculate additional head changes due to partial penetration effects in vertical pumping wells.

- The capability to calculate flow into a borehole through a seepage face that develops when the water level in the well drops into a cell below the layer containing the water table.

- Improved capability to simulate slanted and horizontal wells.

- The option to adjust pumpage for changes in lift over time using pump performance (head-capacity) curves.

- The option to specify the pump intake at any depth.

- Additional output options, including the development of a Multi-Node Well Information (MNWI) Package, which includes options for writing data to separate output files. For example, a well may be designated as an "observation well," for which changes in selected variables with time are recorded in a separate output file.

\section{Conceptual Model and Numerical Implementation}

The MNW1 Package (Halford and Hanson, 2002) allows MODFLOW to simulate wells that extend beyond a single model node, and the model user has to specify a group of nodes that are associated with a single well. This allows the simulated well to penetrate more than one model layer, more than one aquifer, or to represent a slanted or horizontal well. The net flux in or out of the well can be negative (representing a withdrawal well), positive (representing an injection well), or zero (representing a nonpumping well or a longscreened observation well). The net flux represents the addition or removal of water from the ground-water system and corresponds with the flow at the wellhead. MNW2 follows the same basic conceptual model and numerical equation-solving implementation as documented for MNW1.

Regardless of the net flux, when a well is linked to multiple nodes of the finite-difference grid, then the flow between the model domain and the well can vary greatly in magnitude (and perhaps in direction) among the various nodes linked to the single well. As in MNW1, the MNW2 Package assumes that the hydraulic head within the well will equilibrate to a single representative value. Because the heads in the aquifer at various model nodes encompassing a multi-node well will vary depending on local and regional aquifer properties and boundary conditions, a well can have nonuniform borehole flow (or intraborehole flow), and the maximum borehole flow rate can exceed the net withdrawal or injection rate specified for the well. The MNW2 Package partitions the flux among the various nodes connected to a multi-node pumping well on the basis of relative heads and hydraulic conductances (the product of hydraulic conductivity and cross-sectional area of flow divided by the length of the flow path).

The conceptual model for flow through a long borehole that is connected to multiple nodes of the model grid represents a substantial simplification of the actual hydrodynamics of such a system. A rigorous representation of the flow dynamics within the borehole, such as analyzed by Cooley and Cunningham (1979), is neither developed nor applied. In fact, for simplicity and computational efficiency, it is assumed that there are no head gradients within the borehole and that a single value of hydraulic head (and water level) is effective over the entire length of the borehole (Bennett and others, 1982; Fanchi and others, 1987), although Rutledge (1991) discusses some hypothetical examples in which he calculates head differences within a borehole of several feet [for example, a range of about 7 feet (ft) relative to a mean drawdown of about $21 \mathrm{ft}]$.

Under the simplifying assumptions of the MNW1 and MNW2 Packages, at any level of the open or screened borehole, the flow between the well and the adjacent porous media would be controlled by the head difference and the hydraulic conductance between the well and the porous media for any particular location (grid cell) where the well and porous media are connected. When a well is open to two or more different intervals in which the aquifer heads are different from each other, as illustrated in figure 1, the well provides a pathway for flow between the aquifers, and flow will occur in the borehole, even in a nonpumped well, in response to head gradients in the aquifer (and not to head gradients within the borehole, which are not computed).

\section{Simulation of Pumping and Nonpumping Wells}

In MODFLOW's standard WEL Package, the discharge of a well $(Q)$ must be specified explicitly by the user (where $Q$ has dimensions of $\mathrm{L}^{3} / \mathrm{T}$ and is assumed to be negative in sign for discharge). Also, a WEL Package well can only be 
connected to a single node of the grid. If a well is known to discharge from a length of aquifer equivalent to more than one model node or layer, then the user must determine an approach for allocating the total discharge among the multiple model nodes or layers such that the total flow (or net discharge) from all model layers equals $Q_{N E T}$ :

$$
Q_{N E T}=\sum_{m=1}^{n} Q_{m}
$$

where $n$ is the total number of model nodes open to the well, and $m$ is the index of sequential node numbers of the multinode well.

In the MNW2 Package, however, the user specifies the net discharge rate for the multi-node well, and the code then determines the layer-by-layer (or node-by-node) flow rates between the well and the aquifer using methods described in the next section of this report. The total flow or discharge from a well at the land surface is referred to as a "net" discharge because, in complex hydrogeological settings, a single well can have inflow in some parts of its open interval and outflow at other parts, with the difference being equal to the net discharge. $Q_{N E T}$ can be negative (a pumping well), positive (an injection well), or zero (an unpumped well or observation well).

The total flow rate of a well (or net discharge) that is specified in MNW2 is referred to in the input file as variable Qdes, or the maximum desired flow rate for the well. This designation is used because the actual flow rate at the wellhead can be constrained by user-specified maximum and minimum water levels at the well and by possible pump-capacity constraints, as described in later sections of this report. If constraints are not specified, then the actual net discharge for the well will equal the specified value of Qdes.

In constructing a well and installing a pump, the actual location of the pump intake may be located at a depth or position determined for the conditions of that specific well. Therefore, the model allows the user to specify where within the length of the borehole the pump intake is located. This is set using the input variable PUMPLOC in input dataset $2 \mathrm{~b}$ (appendix 1) and related variables in optional dataset 2 e. If the user does not specify a pump intake location, then the model will assume that it is located above the uppermost node associated with the well (that is, above the node located closest to the land surface or wellhead). Specifying the location of the pump intake will not affect the net discharge from the well, nor the inflows and outflows at any particular node. Instead, it will only affect the routing of flow and solute within the borehole.

\section{Head Loss Terms}

MODFLOW computes the head at a block-centered node of a finite-difference grid on the basis of a fluid mass balance for fluxes into and out of the volume of the cell of interest, including flow in or out of a well located within the surface area (and volume) of that cell. However, because of differences between the volume of a cell and the volume of a wellbore, as well as differences between the average hydraulic properties of a cell and those immediately adjacent to a well, it is not expected that the computed head for the node of a finitedifference cell will accurately reproduce or predict the actual head or water level in a well at that location. Furthermore, if the length of the open interval or screen of a vertical well is greater than the thickness of the cell, then the head in the well would be related to the head in the ground-water system at multiple levels (and at multiple locations for a nonvertical well). Thus, if the user needs to estimate the head or water level in a well, rather than just the head at the nearest node, then additional calculations are needed to correct for the several factors contributing to the difference between the two.

Following the development and discussion of Jacob (1947), Rorabaugh (1953), Prickett (1967), and Bennett and others (1982), the difference between the head in the cell and the head in the well (the cell-to-well drawdown) can be calculated with a general well-loss equation as:

$$
h_{W E L L}-h_{n}=A Q_{n}+B Q_{n}+C Q_{n}^{P},
$$

where $h_{W E L L}$ is the composite head (or water level) in the well (L), $n$ is the index of nodes in a multi-node well, $h_{n}$ is the head in the $n^{\text {th }}$ cell associated with the well (L), $Q_{n}$ is the flow between the $n^{\text {th }}$ cell and the well $\left(\mathrm{L}^{3} / \mathrm{T}\right)$ (negative for flow out of the aquifer and into the well), $A$ is a linear aquifer-loss coefficient $\left(\mathrm{T} / \mathrm{L}^{2}\right), B$ is a linear well-loss coefficient $\left(\mathrm{T} / \mathrm{L}^{2}\right), C$ is a nonlinear well-loss coefficient $\left(\mathrm{T}^{P} / \mathrm{L}^{(3 P-1)}\right)$, and $P$ is the power (exponent) of the nonlinear discharge component of well loss. Equation 2 can alternatively be expressed in terms of the water level in the well as:

$$
h_{W E L L}=h_{n}+\left[A Q_{n}+B Q_{n}+C Q_{n}^{P}\right]
$$

Equation 3 states that the head in the well is equal to the head in the node in which the well is located $\left(h_{n}\right)$ plus several head-loss terms (noting again that for a pumping well, all of the $Q$ terms would be negative in sign). The head at the node, $h_{n}$, is calculated by the finite-difference solution to the partial differential equation of ground-water flow. The first head-loss term $\left(A Q_{n}\right)$ accounts for head losses in the aquifer resulting from the well having a radius less than the horizontal dimensions of the cell in which the well is located (that is, cell-towell head losses); the second term $\left(B Q_{n}\right)$ accounts for head losses that occur adjacent to and within the borehole and well screen (that is, skin effects); and the third term $\left(C Q_{n}^{P}\right)$ accounts for nonlinear head losses due to turbulent flow near the well.

Most previous approaches for simulating head losses have included only the aquifer-loss term $\left(A Q_{n}\right)$ (see, for example, Prickett, 1967; Trescott and others, 1976; Bennett and others, 1982; Anderson and Woessner, 1992; Planert, 1997; Neville and Tonkin, 2004). This common approach assumes that aquifer losses can be calculated on the basis of the Thiem (1906) steady-state flow equation and that head loss 
due to skin and local turbulence effects are negligible, such that equation 3 becomes:

$$
h_{W E L L}=h_{n}+\frac{Q_{n}}{2 \pi T} \ln \frac{r_{o}}{r_{w}}
$$

where $T$ is transmissivity of the aquifer $\left(\mathrm{L}^{2} / \mathrm{T}\right), r_{o}$ is the effective (or equivalent) radius of a finite-difference cell (L), and $r_{w}$ is the actual radius of the well (L).

The effective radius of the cell is equivalent to the radius of a vertical pumping well that would have the same head as that calculated for the node of the cell. Because $r_{o}$ is typically much greater than $r_{w}$, the head in a pumping (withdrawal) well will typically be lower than the model-computed head for the cell. Several assumptions underlie the use of the Thiem (1906) equation for estimating the aquifer loss, including that the aquifer is confined; the well is vertical and the screen fully penetrates a cell; the well causes radially symmetric drawdown; the well causes no vertical flow in the aquifer containing the well or from units above and below the aquifer; the transmissivity is homogeneous and isotropic in the cell containing the well and in the neighboring cells; and flow between the cell and well is at steady state for the time period used to solve the general ground-water flow equations in MODFLOW.

Peaceman (1983) indicates that the effective external radius of a rectangular finite-difference cell for isotropic porous media is given by

$$
r_{o}=0.14 \sqrt{\Delta x^{2}+\Delta y^{2}}
$$

where $\Delta x$ is the grid spacing in the $x$ - (column-) direction, and $\Delta y$ is the grid spacing in the $y$ - (row-) direction. If the grid is square, then this is simplified to

$$
r_{o} \approx 0.2 \Delta x
$$

However, if the porous medium is anisotropic, then the directional hydraulic conductivities must be considered, and Peaceman (1983) indicates that, in this general case, $r_{o}$ is given by

$$
r_{o}=0.28 \frac{\left[\left(\frac{K_{y}}{K_{x}}\right)^{0.5} \Delta x^{2}+\left(\frac{K_{x}}{K_{y}}\right)^{0.5} \Delta y^{2}\right]^{0.5}}{\left(\frac{K_{y}}{K_{x}}\right)^{0.25}+\left(\frac{K_{x}}{K_{y}}\right)^{0.25}},
$$

where $K_{x}$ and $K_{y}$ are the values of hydraulic conductivity in the $x$ - and $y$-directions. The definition of $r_{o}$ given in equation 7 is used in MNW2.

For general anisotropic conditions, transmissivity $(T)$ can be written $b \sqrt{K_{x} K_{y}}$, where $b$ is the saturated thickness of the cell (L). The constant term $(1 /(2 \pi T)) \ln \left(r_{o} / r_{w}\right)$ in equation 4 is the aquifer-loss coefficient $(A)$ for a vertical well, which can be written for anisotropic conditions as

$$
A=\frac{\ln \left(\frac{r_{o}}{r_{w}}\right)}{2 \pi b \sqrt{K_{x} K_{y}}},
$$

where $r_{o}$ is calculated by MNW2 using equation 8 on the basis of a user-specified value of $r_{w}$ and values of $\Delta x, \Delta y, K_{x}$, and $K_{y}$ specified in the MODFLOW discretization and internal-flow packages [Block-Centered Flow (BCF), Layer-Property Flow (LPF), or Hydrogeologic-Unit Flow (HUF) Packages].

The linear well-loss coefficient $(B)$ collectively defines head loss from flow through formation damaged during well drilling, the gravel pack (representing a possible increased hydraulic conductivity relative to the aquifer), and the well screen. The geometry of the problem and some of the relevant terminology are illustrated in figure 2. The coefficient $B$ can be used directly to define head loss or it can be recast in terms of a dimensionless skin coefficient (Skin), as defined by Earlougher (1977) and Halford and Hanson (2002). The skin coefficient represents a zone of affected hydraulic properties close to the wellbore or well screen. The value of Skin for a model cell depends on the hydraulic conductivity of the skin, the length of the borehole, and the thickness of the skin (which equals $r_{S K I N}-r_{w}$ ), among other factors, as

$$
\text { Skin }=\left(\frac{K_{h} b}{K_{\text {SKIN }} b_{w}}-1\right) \ln \left(\frac{r_{\text {SKIN }}}{r_{w}}\right),
$$

where $b$ is the saturated thickness of the cell (L), $b_{w}$ is the saturated (or active) length of the borehole in the cell $\left(b_{w}=b\right.$

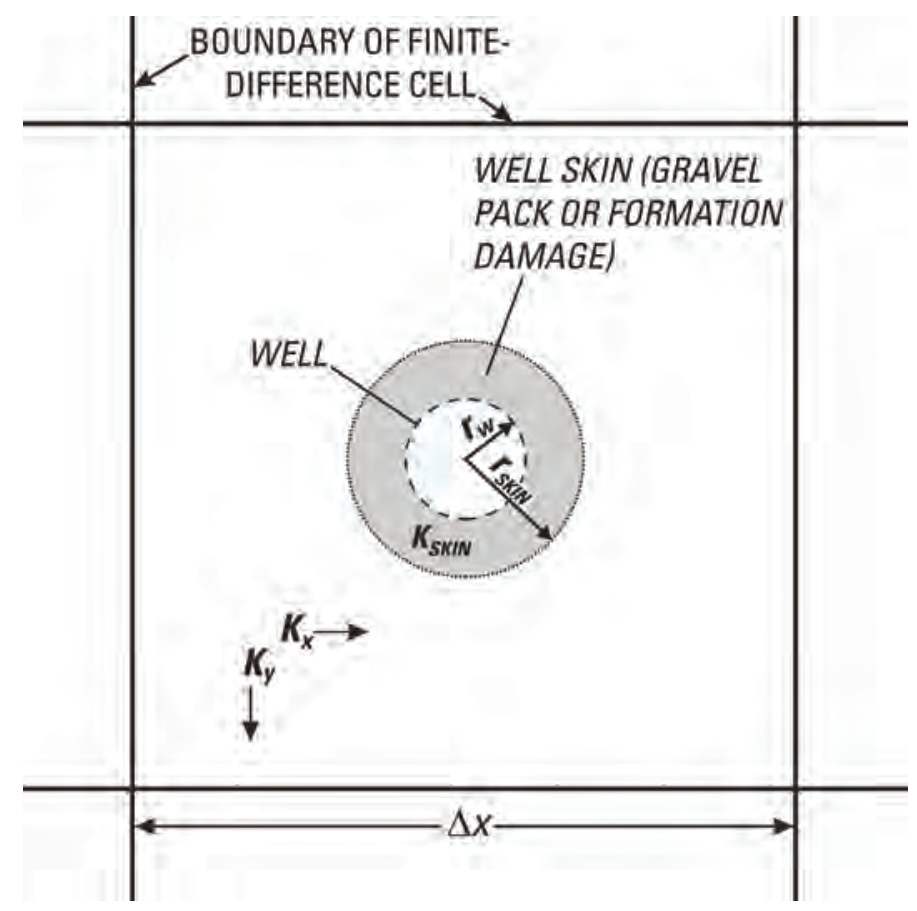

Figure 2. Schematic horizontal cross section (plan view) through a vertical well in a finite-difference cell showing some of the factors affecting computed well loss. $K$ is hydraulic conductivity and $r$ is radius. 
for a fully penetrating vertical well), and $K_{h}$ is the effective horizontal hydraulic conductivity of the cell $(\mathrm{L} / \mathrm{T})$ when horizontal anisotropy is present, wherein $K_{h}=\sqrt{K_{x} K_{y}}$.

The skin effect can be pictured as flow occurring across a cylinder having a hydraulic conductance that differs from (and is typically less than) the hydraulic conductance of the media comprising the finite-difference cell in which the well is located. The value of Skin would be negative if $K_{S K I N}$ is larger than $K_{h}$. Halford and Hanson (2002) relate the coefficient $B$ to Skin as

$$
B=\frac{\text { Skin }}{2 \pi b \sqrt{K_{x} K_{y}}} .
$$

The user has the option of directly specifying a value of $B$ (by setting input parameter LOSSTYPE in dataset $2 \mathrm{~b}$ equal to "GENERAL") or specifying the characteristics of the skin (if LOSSTYPE is set equal to "SKIN"). In the latter case, MNW2 will automatically calculate a value of Skin and subsequently a value of $B$ using equations 9 and 10 .

The nonlinear well-loss coefficient $(C$, with dimensions $\left.\mathrm{T}^{P} / \mathrm{L}^{(3 P-1)}\right)$ defines head loss from any turbulent flow near the well (Rorabaugh, 1953). The coefficient $C$ and power term $(P$, dimensionless) typically are estimated at specific wells through the application of step-drawdown tests. There remains some disagreement in the literature about the nonlinear well-loss terms (see, for example, the review by Ramey, 1982). Jacob (1947) states that "the loss of head that accompanies the flow through the screen ... is proportional approximately to the square of the discharge." Rorabaugh (1953) argues that the power $(P)$ is an empirical exponent that "may be unity at very low rates of discharge or it may be in excess of 2" where turbulent flow occurs in or near the well; he provides examples from several field cases for which $P$ varied between 2.4 and 2.8. The higher the value of $P$, the more likely that the numerical solution will have difficulty converging. If that happens, then the user can reduce the value of $P$. Because this additional nonlinear term $\left(C Q_{n}^{P}\right)$ may cause numerical problems or may not be needed, the user has the option of not including the nonlinear well-loss term in any multi-node well (for example, if LOSSTYPE = GENERAL, then set $C=0.0$ in dataset 2c).

Equation 2 can be rewritten in terms of the flow rate to each node $\left(Q_{n}\right)$. For the simplest case in which only the aquifer-loss term $A Q_{n}$ applies, the resulting equation is

$$
Q_{n}=\left[\frac{2 \pi b \sqrt{K_{x} K_{y}}}{\ln \left(r_{o} / r_{w}\right)}\right]\left(h_{W E L L}-h_{n}\right) .
$$

The expression in brackets has dimensions of $\left(\mathrm{L}^{2} / \mathrm{T}\right)$ and can be viewed as a hydraulic conductance term, which Halford and Hanson (2002) refer to as the cell-to-well conductance $\left(C W C_{n}\right)$.

A more general expression for $Q_{n}$ can be analogously derived from equation 2 by incorporating all of the head-loss terms into the cell-to-well conductance term. The flow to the $n^{\text {th }}$ node of the multi-node well is thus defined by the head difference between the cell and the well times a cell-to-well hydraulic conductance as

$$
Q_{n}=\left(h_{W E L L}-h_{n}\right) C W C_{n}
$$

where $C W C_{n}$ is the $n^{\text {th }}$ cell-to-well hydraulic conductance $\left(\mathrm{L}^{2} / \mathrm{T}\right)$. After substituting the right side of equation 2 for the term in parentheses, equation 12 can be rewritten to solve for $C W C_{n}$ as

$$
C W C_{n}=\frac{Q_{n}}{\left(A Q_{n}+B Q_{n}+C Q_{n}^{P}\right)}
$$

This can be further simplified by dividing through by $Q_{n}$ to yield:

$$
C W C_{n}=\left[A+B+C Q_{n}^{(P-1)}\right]^{-1}
$$

The $C W C_{n}$ term can be defined more explicitly by substituting the right sides of equations 8 and 10 for the $A$ and $B$ terms in equation 14 , resulting in

$$
C W C_{n}=\left[\frac{\ln \left(\frac{r_{o}}{r_{w}}\right)}{2 \pi b \sqrt{K_{x} K_{y}}}+\frac{\left(\frac{b K_{h}}{b_{w} K_{S K I N}}-1\right) \ln \left(\frac{r_{S K I N}}{r_{w}}\right)}{2 \pi b \sqrt{K_{x} K_{y}}}+C Q_{n}^{(P-1)}\right]^{-1}
$$

The value of $C W C_{n}$ can be specified directly by the user (if LOSSTYPE is specified as "SPECIFYCWC" in dataset 2b), otherwise it will be calculated automatically by the model using equation 15 (for cases when LOSSTYPE is specified as "THIEM," "SKIN," or "GENERAL" in dataset 2b).

The nature of the linear well-loss term indicates that, if the well is less than fully penetrating, the linear well-loss coefficient $(B)$ would change inversely proportional to the fraction of penetration $\left(\alpha=b_{w} / b\right)$, and the cell-to-well conductance would be reduced accordingly. Also note that in an unconfined (convertible) cell, MODFLOW assumes that the saturated thickness changes as the water table rises or falls. Therefore, when the head changes in an unconfined cell containing a multi-node well, the value of $C W C_{n}$ must be updated by solving equation 15 again because both $b$ and $b_{w}$ will have changed.

\section{Calculation of Water Level and Flow in the Multi-Node Well}

The basic numerical solution process is described by Bennett and others (1982), Halford and Hanson (2002), and Neville and Tonkin (2004). It consists of an iterative process with three basic steps:

1. solve the system of finite-difference equations for heads at each node of the grid, 
2. solve for the composite head (water level) in the well, $h_{W E L L}$, and

3. solve for the flow rate at each node $\left(Q_{n}\right)$ and the net discharge from the well $\left(Q_{\text {net }}\right)$.

The net flow to a multi-node well is simulated by summing the flow component to each node (Bennett and others, 1982; Fanchi and others, 1987; Halford and Hanson, 2002), which is defined by equation 12 and the common head in each node of the well. After the terms are collected and rearranged, the net flow rate between a multi-node well and the groundwater system is

$$
Q_{n e t}=\sum_{n=1}^{m}\left(C W C_{n} h_{W E L L}-C W C_{n} h_{n}\right),
$$

where $m$ is the total number of nodes in a multi-node well, and $Q_{\text {net }}$ is the net flow between the well and the ground-water system $\left(\mathrm{L}^{3} / \mathrm{T}\right)$ and is equivalent to the flow at the wellhead (negative in sign for a discharge or withdrawal well). Because $h_{W E L L}$ is common to all nodes in a multi-node well, equation 16 can be rewritten as

$$
Q_{n e t}=h_{W E L L} \sum_{n=1}^{m} C W C_{n}-\sum_{n=1}^{m} C W C_{n} h_{n}
$$

The value of $h_{W E L L}$ is not known explicitly but is needed to estimate the flow rate between each well node and connected grid cell for a given multi-node well and to test that the drawdown does not exceed user-specified limits. Rearranging equation 17 gives the head in the well (Halford and Hanson, 2002):

$$
h_{W E L L}=\frac{Q_{n e t}+\sum_{n=1}^{m} C W C_{n} h_{n}}{\sum_{n=1}^{m} C W C_{n}}
$$

In solving the governing ground-water flow equation, estimates of $h_{W E L L}$ and $Q_{n}$ lag an iteration behind estimates of $h_{n}$ because equations 17 and 18 are solved explicitly assuming that $h_{n}$ is known. Halford and Hanson (2002) note that this causes slow convergence of the solver if the MNW cells are represented in MODFLOW as a general-head boundary (see McDonald and Harbaugh, 1988). Convergence is accelerated by alternately incorporating the MNW cells as specified-flux boundary conditions in odd iterations and as general-head boundaries in even iterations. That is, while solving the governing flow equation numerically, during odd numbered iterations the values of $Q_{n}$ and $Q_{n e t}$ are specified from the latest known values and the head in the well is calculated using equation 18 , and during even numbered iterations the head in the well is specified from the most recent known value and the values of $Q_{n}$ and $Q_{n e t}$ are calculated using equations 12 and 17.

\section{Specifying the Location of Multi-Node Wells}

In MODFLOW, a multi-node well must be linked to one or more nodes of the grid. The user has two options to accomplish this through the input datasets. One does not have to apply the same option to all wells.

In the first approach, the user can specify the number of nodes of the grid that a particular well is associated with (by specifying the value of NNODES in dataset 2a). Then the layer-row-column location of each node (or cell) of the grid that is open to the multi-node well must be listed sequentially in dataset $2 \mathrm{~d}$. The order of the sequence must be from the first node that is located closest to the land surface or wellhead to the last node that is furthest from the wellhead. This ordering is required so that the model can properly route flow [and solute if the ground-water transport (GWT) process is active] through the borehole. There are no restrictions on locations of nodes, other than they be located in the active part of the grid. Thus, wells of any geometry - whether vertical, slanted, or horizontal — can be defined.

The second approach is only applicable for vertical wells. It eliminates the need for the user to convert field data on depths or elevations of open intervals to corresponding layers of the grid. With this approach, the user needs to specify a single spatial location for the well in terms of its row and column location in the grid and the elevations of the tops and bottoms of the open intervals (or well screens). If this option is used, then the model will compute the grid layers in which the open intervals occur, the lengths of the open intervals, and the relative vertical position of each open interval within a model layer. The top and bottom elevations (Ztop and Zbotm) are specified in dataset $2 \mathrm{~d}-2$. The elevations must be referenced to the same datum as the model grid.

If open intervals are defined by elevations, then the list of intervals must be ordered so that the first interval listed is the shallowest, the last interval listed is the deepest, and all intervals are listed in sequential order from the top to the bottom of the well. If an interval defined by elevations partially or fully intersects a model layer, then a node will be defined in that cell. If more than one open interval intersects a particular layer, then a length-weighted average of the cell-to-well conductances will be used to define the well-node characteristics; the cumulative length of well screens will be assumed to be centered vertically within the thickness of the cell. Additional details related to such complex situations are discussed below in the section on "Well Screen Variability." If the open interval is located in an unconfined (or convertible) layer, then its position in space remains fixed although its position relative to the changing water table will be adjusted over time, as discussed later in the section on "Partial Penetration." Finally, if the well is a single-node well, as defined by setting LOSSTYPE = NONE, and the specified open interval straddles more than one model layer, then the well will be associated with the one cell where the vertical center of the open interval is located. 


\section{Model Features and Processes}

This section describes the basis for and evaluation of the major features and processes of MNW2. Much of the testing and evaluation was done using representative test problems. Two basic test problems are described first.

\section{Description of Test Problems}

This section describes two sample problems with which some of the basic functions, and input variables, of the MNW2 Package are tested, evaluated, and demonstrated. Where possible, calculations made by the MNW2 Package are compared to known analytical solutions or previously published simulations.

\section{Fully Penetrating Pumped Well in Ideal Confined Aquifer (Lohman Problem)}

The first test case is based on the properties of a hypothetical aquifer system described by Lohman $(1972$, p. 19) as an example of a system with transient radial flow without vertical movement and amenable to solution by the Theis (1935) equation. That is, the test problem represents an ideal nonleaky confined aquifer of infinite areal extent and homogeneous and isotropic properties and analytical solutions are available for both fully penetrating and partially penetrating wells. The basic properties of this system are listed in table 1 .

A MODFLOW-2000 model was constructed to represent and simulate this relatively simple, hypothetical, confined aquifer system. The size of the domain was set at $300,000 \mathrm{ft}$ long by $300,000 \mathrm{ft}$ wide so that the boundaries would not influence drawdowns near the well during the expected simulation times. The well was located at the center of the model domain. The outer boundaries of the grid represent no-flow conditions, and zero recharge is assumed. The areal grid includes 438 rows and 420 columns of cells and has variable spacing, with the finest part of the mesh having a horizontal spacing of $5 \mathrm{ft}$ and located in the central part of the grid, near the pumping well. At a distance $200 \mathrm{ft}$ or more from the well, the 5-ft grid spacing increases gradually by a factor of about 1.2 to a maximum spacing of $5,000 \mathrm{ft}$ at the outer edges of the domain. Vertically, the domain was subdivided into one or more model layers, depending on the scenario being evaluated.

The first test was conducted to assure that the grid was sufficiently large so that the peripheral no-flow boundaries of the model domain did not appreciably affect the calculated heads and drawdowns at or near the pumping well at the center of the grid, and that the numerical solution adequately matched an appropriate analytical solution. The analytical solution for the base case of a fully penetrating pumping well is derived from the classic Theis (1935) solution and generated using the WTAQ Program (Barlow and Moench, 1999).
Table 1. Properties of the confined aquifer system analyzed in the Lohman test problem.

[Abbreviations used: feet, $\mathrm{ft}$; feet per day, ft/day; square feet, $\mathrm{ft}^{2}$; cubic feet per day, $\mathrm{ft}^{3} /$ day; per foot, $\mathrm{ft}^{-1}$ ]

\begin{tabular}{lcl}
\hline \multicolumn{1}{c}{ Parameter } & Symbol & \multicolumn{1}{c}{ Value } \\
\hline Horizontal hydraulic conductivity & $K_{h}$ & $140 \mathrm{ft} /$ day \\
Vertical hydraulic conductivity & $K_{z}$ & $140 \mathrm{ft} /$ day \\
Saturated thickness & $b$ & $100 \mathrm{ft}$ \\
Transmissivity & $T$ & $14,000 \mathrm{ft}^{2} /$ day \\
Specific storage & $S_{S}$ & $2 \times 10^{-6} \mathrm{ft}^{-1}$ \\
Storage coefficient & $S$ & $2 \times 10^{-4}(\mathrm{dimensionless})_{\text {Well radius }}$ \\
Well discharge & $r_{w}$ & $0.99 \mathrm{ft}^{3}$ \\
& $Q$ & $96,000 \mathrm{ft}^{3} /$ day \\
\hline
\end{tabular}

The WTAQ Program (Barlow and Moench, 1999) includes analytical solutions for drawdown at a pumped well (or an observation well) for a variety of cases, including that of a partially penetrating pumped well. The WTAQ Program implements the Laplace-transform solution of Moench (1997) for flow in a water-table aquifer, a modified solution of Dougherty and Babu (1984) for flow to a partially penetrating well in a confined aquifer, and the Theis solution for flow to a fully penetrating well in a confined aquifer. The Laplace-transform solutions are numerically inverted to the time domain by means of the Stehfest (1970) algorithm (Barlow and Moench, 1999).

The numerical solution for the first test was generated using one model layer to represent the 100 -ft thick aquifer and an initial time step of $2.41 \times 10^{-7}$ days, which was increased by a factor of 1.2 in each successive time step (requiring a total of 100 time steps to simulate a representative 100-day stress period). Because the cell where the pumping well is located has a grid spacing of $5 \mathrm{ft}$ by $5 \mathrm{ft}$, the equivalent well radius (computed using eq. 6 of Halford and Hanson, 2002, p. 9) is $r_{o}=0.99 \mathrm{ft}$. Thus, the analytical solution for the drawdown in the pumping well is based on a specified well radius of $0.99 \mathrm{ft}$ to maximize comparability and eliminate the need to correct for any difference between the well radius and the effective radius of the cell (that is, LOSSTYPE = NONE). The MODFLOW numerical results show excellent agreement with equivalent analytical solutions (fig. 3) for the pumping well and for observation wells at various distances $(r)$ from the pumping well. These results indicate that the numerical model of the hypothetical confined aquifer system is adequate to evaluate methods (described later in the report) to compute additional drawdown caused by partial penetration and other sources of well loss.

\section{Long, Unpumped Observation Well (Reilly Problem)}

Reilly and others (1989) used numerical experiments in a hypothetical ground-water system to demonstrate that appreciable wellbore flow can occur in observation wells screened through multiple layers, even in homogeneous aquifers having small vertical head differences (less than $0.01 \mathrm{ft}$ between 
the top and bottom of the screen). Konikow and Hornberger $(2006 a, b)$ slightly modified this test problem to evaluate solute transport through a multi-node well. This same test problem (herein called the "Reilly" test problem) is used in this study to help evaluate the MNW2 Package.

As described by Konikow and Hornberger (2006b), the hypothetical unconfined ground-water system represents regional flow that is predominantly lateral but includes some vertical components because of diffuse areal recharge [at a rate of $4.566 \times 10^{-3}$ feet per day (ft/d)] and a constant-head boundary condition at the surface of the right side of the regional groundwater system that controls discharge (fig. 4). No-flow boundaries are on all other external boundaries. The system is substantially longer $(10,000 \mathrm{ft})$ than it is thick (205 ft) or wide (200 ft); the width was selected to eliminate any important effect of the position of the lateral no-flow boundary on the solution in the area of the well. A nonpumping borehole with a $60-\mathrm{ft}$ screen is located close to the no-flow boundary on left side of the system ( $252 \mathrm{ft}$ from that boundary) (fig. 4). Other properties of the system and the model are listed in table 2. Reilly and others (1989) simulated the regional system with a two-dimensional crosssectional model, arguing that the width of the cross section was irrelevant for their analysis, and applied a local (approximately a 100 -ft-by-100-ft area) three-dimensional flow model in the vicinity of the wellbore. Their local model was discretized vertically into 5 -ft layers and used a variably spaced areal grid with a minimum spacing of about $0.33 \mathrm{ft}$ by $0.33 \mathrm{ft}$ around the borehole. They represented the borehole using a relatively high vertical hydraulic conductivity, the value of which was based on equivalence of Darcy's law to the equation for laminar pipe flow (Reilly and others, 1989, p. 272).

Konikow and Hornberger (2006a,b) simulated the regional flow system with a three-dimensional model with a domain width sufficient to minimize any effects of that dimension on the flow field close to the borehole; they represented the borehole using the MNW Package (Halford and Hanson, 2002). Because a vertical plane of symmetry is present and passes through the well, they only simulated one-half of the domain outlined by Reilly and others (1989). The grid has a variable spacing (fig. 5). In the local area around the well, however, a relatively fine and uniform areal cell spacing of $2.5 \mathrm{ft}$ by $2.5 \mathrm{ft}$ was used. This finest part of the grid included 20 rows, 40 columns, and 41 layers of cells. Outside the uniformly spaced part of the grid, the lateral grid spacing was increased geometrically to a maximum spacing of $50.25 \mathrm{ft}$ in the row $(x)$ direction and $9.55 \mathrm{ft}$ in the column (y) direction (fig. 5). The vertical discretization $(\Delta z)$ was $5 \mathrm{ft}$ everywhere in the model domain, and the top layer was assumed to be unconfined (convertible).

The well was assumed to have a 60 -ft screen that was open to layers 2 through 13 (that is, connected to 12 vertically aligned nodes of the grid) in the bounding row of cells. Reilly and others (1989) reported that their well was represented by

Table 2. Selected physical parameters used in MODFLOW simulation of ground-water flow in a three-dimensional, steadystate flow system containing a multi-node well.

[Abbreviations used: feet, $\mathrm{ft}$; feet per day, $\mathrm{ft} / \mathrm{d}$ ]

\begin{tabular}{ll}
\hline \multicolumn{1}{c}{ Parameter } & \multicolumn{1}{c}{ Value } \\
\hline Horizontal hydraulic conductivity & $250 \mathrm{ft} / \mathrm{d}$ \\
Vertical hydraulic conductivity & $50 \mathrm{ft} / \mathrm{d}$ \\
Well radius & $0.133 \mathrm{ft}$ \\
Well skin hydraulic conductivity & $125 \mathrm{ft} / \mathrm{d}$ \\
Well skin radius & $1.795 \mathrm{ft}$ \\
Recharge rate & $0.004566 \mathrm{ft} / \mathrm{d}$ \\
\hline
\end{tabular}

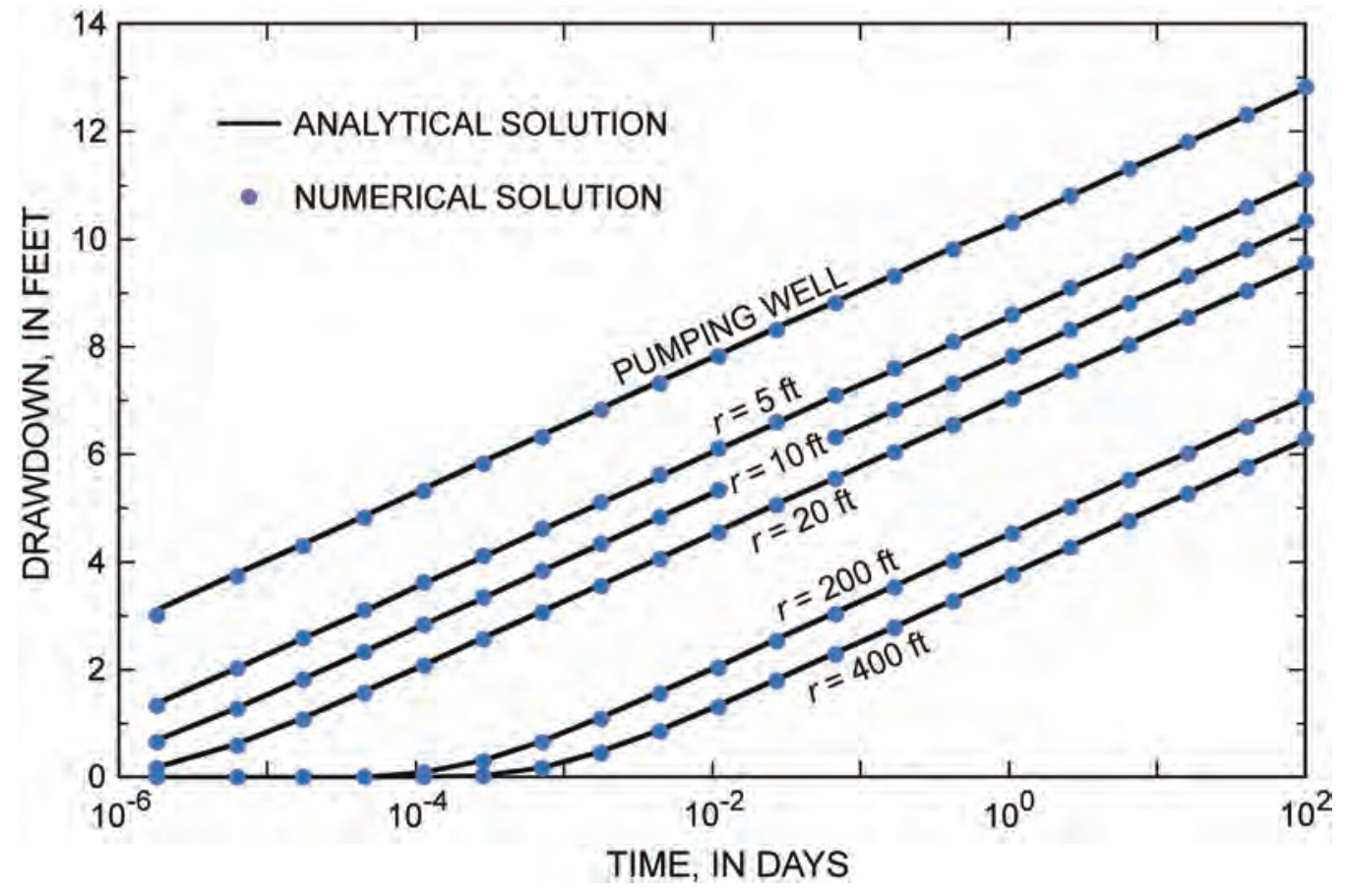

Figure 3. Semilog plot showing comparisons between drawdowns computed numerically using MODFLOW and drawdowns computed using the Theis (1935) analytical solution for selected distances $(r)$ from a well pumping at a rate of 96,000 cubic feet per day. Every fifth data point shown for numerical solutions. 


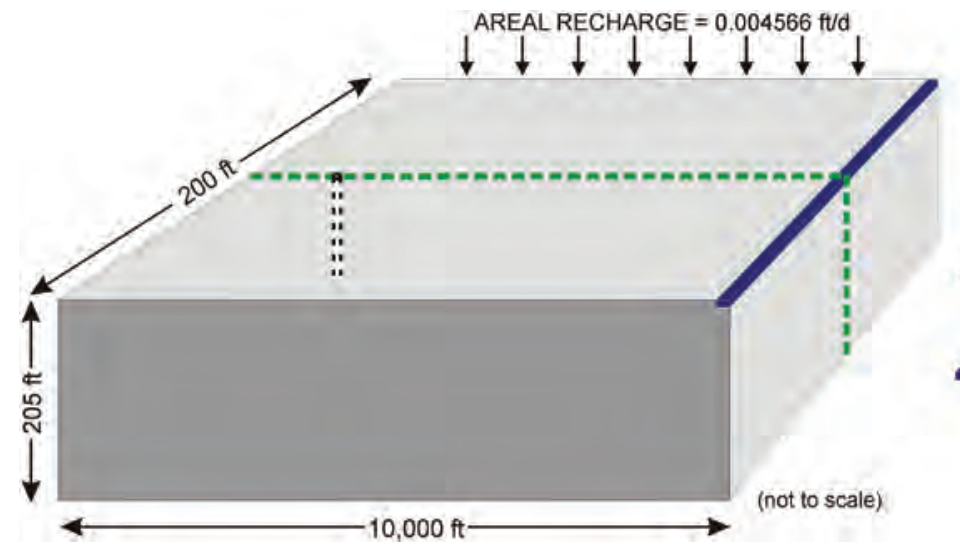

a cell having areal dimensions of $0.333 \mathrm{ft}$ by $0.333 \mathrm{ft}$, which yields a cross-sectional area of 0.111 square feet $\left(\mathrm{ft}^{2}\right)$. Because the well lies on the plane of symmetry in the grid, a well radius is assigned in the model that yields an equivalent crosssectional area to one-half of the cross-sectional area of the well in the simulation of Reilly and others $\left(0.0555 \mathrm{ft}^{2}\right)$. For a well with a circular casing, this equivalent cross-sectional area would require a well radius of $0.133 \mathrm{ft}$. It is also assumed that there would be a linear well-loss coefficient consistent with a lower permeability well skin. The values of the skin properties were adjusted during model calibration to achieve a vertical profile of flows between the aquifer and the well that closely matched that of Reilly and others (1989) (fig. 2).

Heads were calculated using the Preconditioned Conjugate Gradient (PCG2) solver in MODFLOW-2000, and the flow model iteratively converged to a steady-state head distribution with a 0.00 percent discrepancy. Konikow and Hornberger (2006a,b) obtained almost exactly the same heads and flows as did Reilly and others (1989). The calculated head in the well was $4.9322 \mathrm{ft}$. The head distribution in the aquifer near the nonpumping multi-node well indicated that water should flow from the aquifer into the upper part of the borehole and discharge back into the aquifer through the lower part of the well (fig. 6), which is consistent with the results of Reilly and others (1989). Inflow to the well is greatest near the
EXPLANATION

A. MULTI-NODE WELL

PLANE OF SYMMETRY

CONSTANT-HEAD OUTFLOW BOUNDARY $(\mathrm{h}=0.0 \mathrm{ft})$

top of the well screen, and outflow is greatest near the bottom of the well screen. The calculated total flow into the borehole was $9.79 \mathrm{ft}^{3} / \mathrm{d}$, which compares closely with $9.63 \mathrm{ft}^{3} / \mathrm{d}$ reported by Reilly and others (1989).

\section{Partial Penetration}

If a well only partially penetrates an aquifer or is only open to a fraction of the full thickness of the aquifer, then it is widely recognized that consequent vertical flow components will cause an additional drawdown in the well beyond that computed on the basis of assuming horizontal flow (for example, see Walton, 1962; Driscoll, 1986; Kruseman and de Ridder, 1990). Thus, if the three wells shown in figure 7 are all pumping at the same rate, then the drawdown in well $A$, which is fully penetrating, would be less than expected in wells $B, C$, or $D$, which are only partially penetrating. Driscoll (1986, p. 249) notes that: "For a given yield, ... the drawdown in a pumping well is greater if the aquifer thickness is only partially screened. For a given drawdown, the yield from a well partially penetrating the aquifer is less than the yield from one completely penetrating the aquifer." Similarly, if a well represented in the model is open to a vertical interval less than the thickness of the model cell, then the drawdown in the well

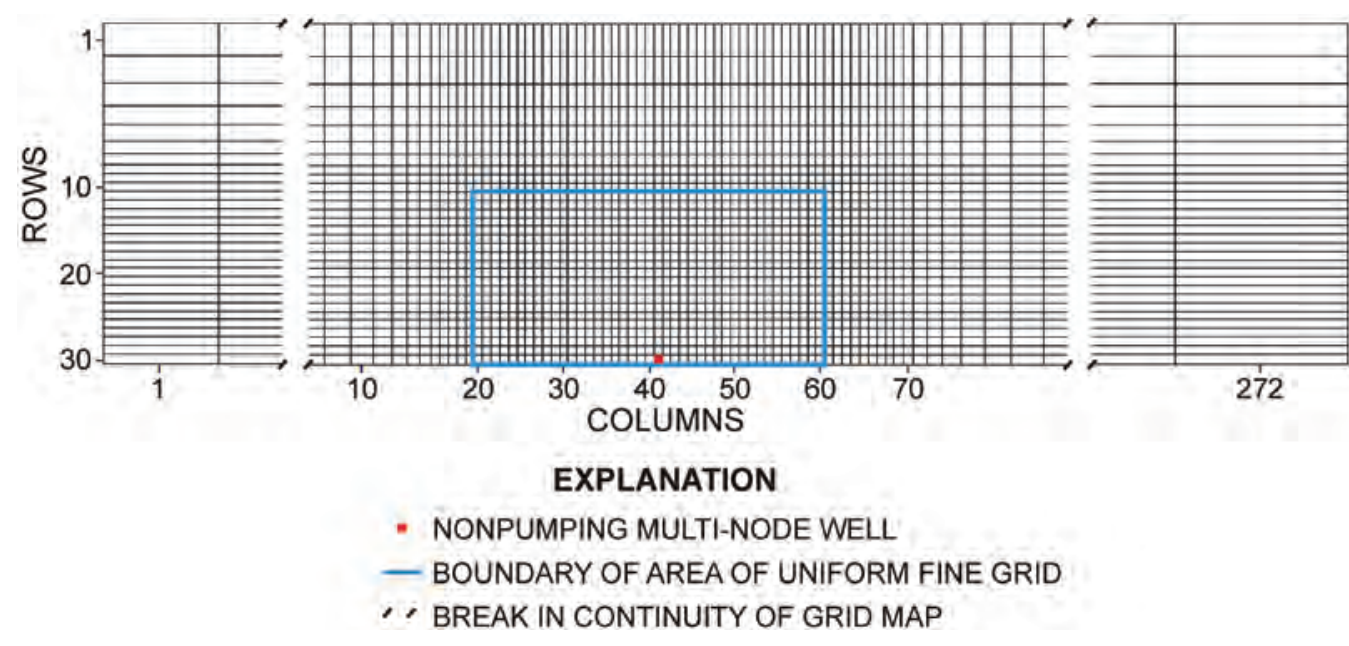

Figure 5. Map view of MODFLOW finite-difference grid showing location of fine grid area and of the nonpumping multi-node well in the Reilly test problem (modified from Konikow and Hornberger, 2006a). 


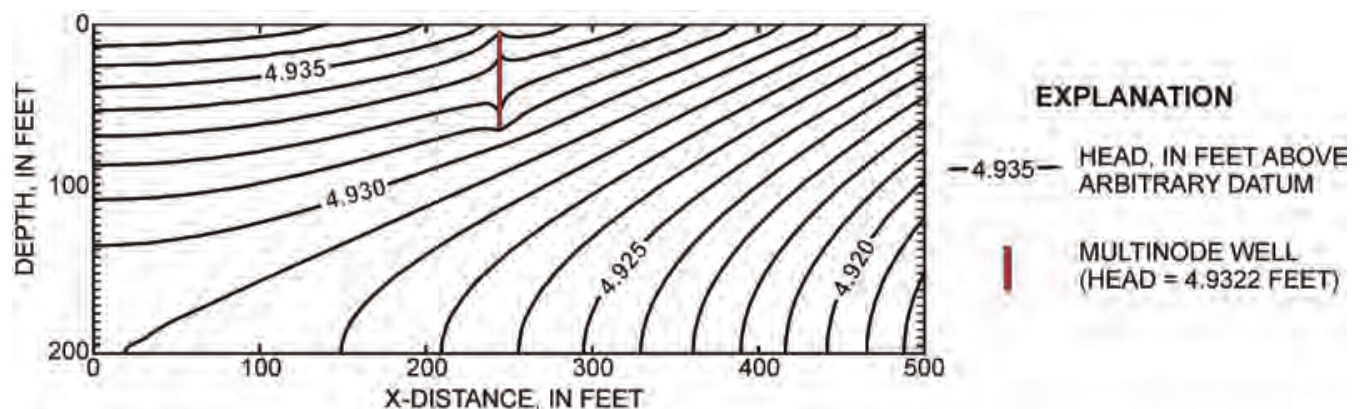

Figure 6. Calculated head distribution in vertical section near well on plane of symmetry. For clarity, only upgradient 5 percent of domain is shown (flow model domain extends to 10,000 feet in $x$-direction). From Konikow and Hornberger, 2006a. should be greater than that computed by the model for the associated cell and for a well that fully penetrates the cell.

Driscoll (1986) also demonstrates that the position and (or) distribution of well screens within an aquifer can influence the effects of partial penetration. Referring to figure 7, Wells $B$, $C$, and $D$ are all open to 33 percent of the saturated thickness of the aquifer $(\alpha=0.33$, where $\alpha$ is the fraction of the aquifer thickness to which the well is open - the partial penetration fraction). Wells $B$ and $C$ both have identical screen lengths, but because the screen in Well $B$ is adjacent to a no-flow boundary, there can be no contribution from vertical flow above the screen and it will experience greater drawdown for the same pumping rate compared with Well $C$. Well $D$ has three separate screens, which improves well efficiency by spreading the intake across a longer effective section of the aquifer, so it would experience less drawdown than either Well $B$ or Well $C$, even though the total lengths of screen are identical in all three cases.

In developing numerical models, one often has to evaluate tradeoffs among accuracy, generality, and simplicity. In developing the code for partial penetration effects in the MNW2 Package, a single well screen (or open interval) can

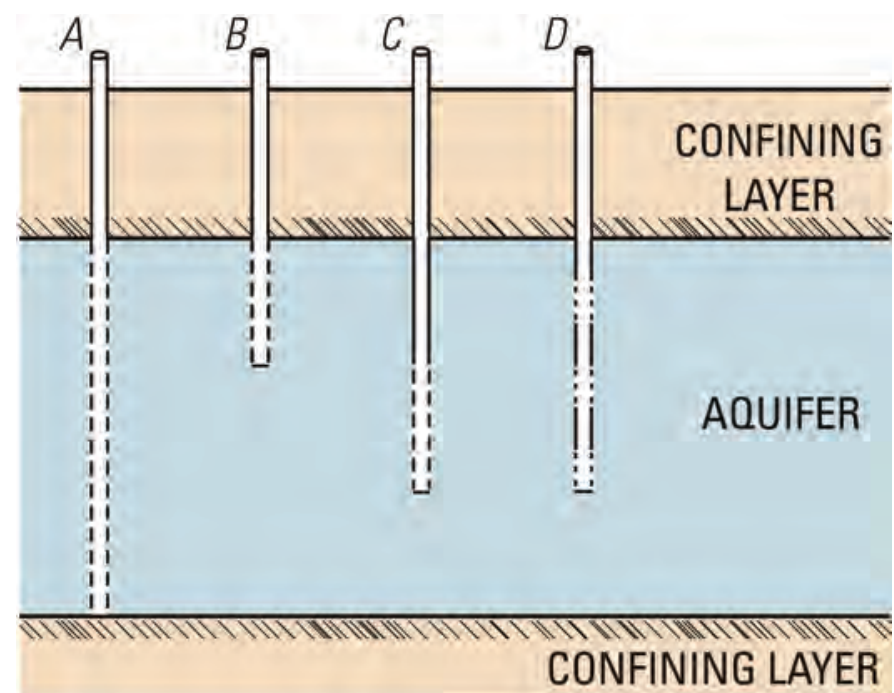

Figure 7. Schematic cross-sectional diagram showing $A$, fully penetrating, and $B-D$, partially penetrating wells in a nonleaky confined aquifer. Well $B$ is open to the uppermost third of the aquifer thickness, Well $C$ is screened in the middle third of the aquifer thickness, and Well $D$ has three separate screens with a cumulative length of screen (open interval) the same as Wells $B$ and $C$. occur at any position within a model layer if the user specifies the elevation of the top and bottom of the well screen (as illustrated by Wells $B$ and $C$ in fig. 7). Alternatively, if a multinode well is defined by nodes and partial penetration fractions (see appendix 1), then the model will assume that the center of the well screen is located at the vertical center of the cell (that is, the center of the screen would be assumed to be located halfway between the top and bottom elevations of the cell). The only exception is for a well node located in the uppermost active layer for its row and column location. In this case, if the layer is unconfined, then the bottom of the well screen will be assumed to be aligned with the bottom elevation of the cell.

MNW2 will not compute drawdowns due to partial penetration for the case of multiple well screens within a single model layer - that is, the situation represented by Well $D$ in figure 7 . If the user specifies multiple well screens in a single multi-node well and their elevations indicate multiple screens within a single cell of the grid, then the model will sum the individual screen lengths to compute a total composite length and a partial penetration fraction for that cumulative length. It is further assumed that the individual sections of screen within a cell are contiguous and that the equivalent composite well screen is vertically located in the middle of the cell. As above, an exception to this rule is made for a well node located in the uppermost active layer of the grid. In this case, if the layer is unconfined, then the bottom of the composite well screen is assumed to be aligned with the bottom elevation of the lowermost section of well screen located within the cell. Furthermore, partial penetration corrections are only implemented for vertical wells or vertical sections of wells, and are not enabled for horizontal or slanted sections of wells. A well screen (or open interval) is considered to be vertical if all nodes within a contiguous open interval and the immediately adjacent well nodes above and (or) below that interval are all located in the same row and column location of the MODFLOW grid.

The nature of the partial penetration effect is illustrated by the analytical solutions obtained using the WTAQ Program (Barlow and Moench, 1999) for a range of penetration fractions in the Lohman test problem (fig. 8); system properties are listed in table 1 . The solutions are generalized by presenting them in terms of dimensionless time $\left(t_{D}\right)$ and dimensionless drawdown $\left(\Delta h_{D}\right)$. Moench (1993) defines these terms as $t_{D}=T t / r^{2} S$ and $\Delta h_{D}=4 \pi T \Delta h / Q$, where $T$ is transmissivity $\left(\mathrm{L}^{2} / \mathrm{T}\right), t$ is time $(\mathrm{T}), r$ is radial distance $(\mathrm{L})$, and $S$ is storage coefficient (dimensionless). One important inference can 
be drawn from the results shown in figure 8-namely, that the additional drawdown due to partial penetration $\left(\Delta h_{p}\right)$ approaches a constant value after a relatively short time has elapsed. For example, for $\alpha=0.33$, an additional dimensionless drawdown of about 10 units greater than the fully penetrating case $(\alpha=1.0)$ is reached for dimensionless times greater than about $10^{4}$. That is, for all cases for $t_{D}$ greater than about $10^{4}$, the drawdown increases linearly with the log of time (that is, the family of solutions represent straight parallel lines after the early-time transient change has passed). Therefore, for $t_{D}>10^{4}$, the additional drawdown due to partial penetration effects is a constant value for a given set of conditions. Because most applications of MODFLOW are oriented toward regional analyses over time scales of months to years to decades, the early time transient changes are ignored and the constant value of $\Delta h_{p}$ calculated for the given set of conditions are assumed to apply over all times during a given stress period. This conceptual simplification results in substantial computational savings for many cases. Furthermore, for a broad range of realistic parameter values, $t_{D}=10^{4}$ is equivalent to an actual elapsed time of just a few minutes, which is rarely of concern in a ground-water model analysis.

Another relation that can be seen in figure 8 is the sensitivity of $\Delta h_{p}$ to the fraction of the aquifer penetrated by the well. If a well is open to more than 90 percent of the aquifer thickness, then the additional drawdown due to partial penetration effects is very small. As the partial penetration fraction decreases, the effect increases at an increasing rate (fig. 9). Figure 9 also illustrates the effect of the position of the open interval on the drawdown caused by partial penetration effects. All else being the same, the well with an open interval adjacent to a bounding impermeable confining layer (such as Well $B$ in fig. 7) will have greater drawdown than a well with an open interval that is vertically centered (such as Well $C$ in fig. 7), although the difference is negligible for penetration fractions greater than 0.5 . For penetration fractions less than 0.05 , the error caused by assuming that the position of the open interval is centered vertically when in fact it is at the edge of the aquifer may exceed 50 percent.

The effect of the relative vertical position of a fixed length of well screen within the aquifer is also illustrated in figure 10 for the case of a well screen that penetrates 33 percent of the saturated thickness of a confined aquifer. At extremely early times, there is only a negligible effect, followed by a relatively short transition period when the curves diverge. At late times, the curves are parallel and the differences among them remain constant over time. The maximum drawdown due to partial penetration occurs when the well screen is adjacent to the aquifer boundary, and the difference from the case of a vertically centered well screen is almost 10 percent. Because the effect of well screen position can substantially affect the additional drawdown, especially when the penetration fraction is small, the MNW2 Package is coded to automatically account for this effect (using either the top and bottom elevations of the well screens as specified by the user or the model assumed well screen positions, as described above).

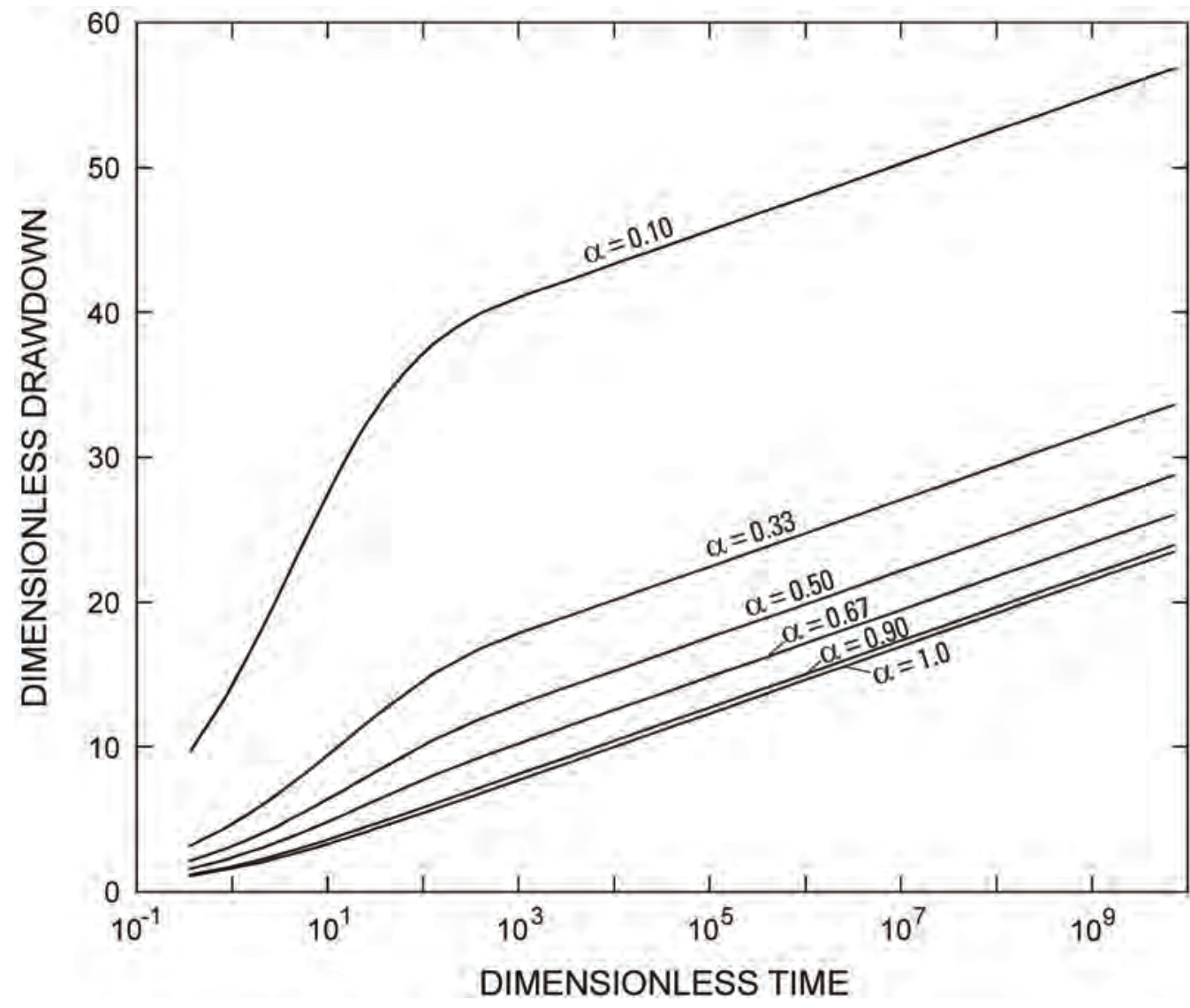

Figure 8. Semilog plots of dimensionless drawdown in a vertical pumping well with an open interval centered vertically in a nonleaky, homogeneous, isotropic, confined aquifer (the Lohman problem), showing the sensitivity of the analytical solution to the partial penetration fraction $(\alpha)$. Drawdown for a fully penetrating well $(\alpha=1.0)$, representing the Theis solution, shown for comparison. Drawdowns are calculated using the WTAO Program (Barlow and Moench, 1999). 


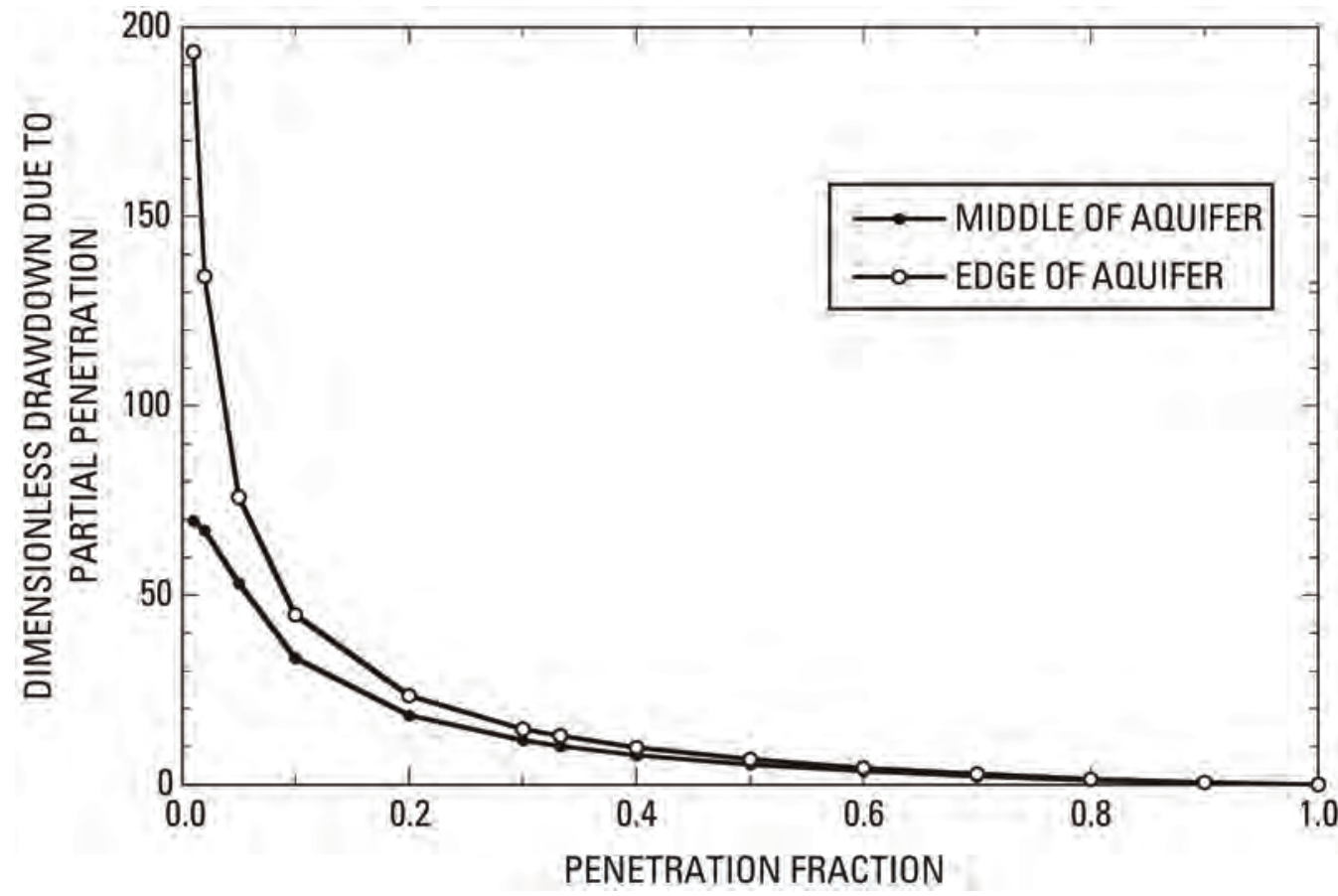

Figure 9. Plots showing the relation of dimensionless drawdown to penetration fraction $(\alpha)$ for a vertical pumping well in a nonleaky, homogeneous, isotropic, confined aquifer, for wells located vertically in the middle of the aquifer and at the edge of the aquifer (adjacent to a no-flow boundary formed by the overlying or underlying impermeable confining layer). Drawdowns calculated using the WTAQ Program (Barlow and Moench, 1999).
If the aquifer has vertical anisotropy (that is, $K_{h}>K_{z}$ ), then the effects of partial penetration on drawdown in the well would be greater than for an isotropic aquifer. Jacob (1963, p. 274) notes that for a partially penetrating well in an anisotropic aquifer, flow "becomes radial at a distance from the well equal to twice the aquifer thickness multiplied by the square root of the ratio of the horizontal to the vertical permeability" (that is, $2 b \sqrt{K_{h} / K_{z}}$ ). The algorithm incorporated in the new MNW2 Package accounts for the effect of vertical anisotropy on drawdown in a partially penetrating well. If the cell properties include horizontal anisotropy (that is, $K_{x} \neq K_{y}$ ), then $K_{h}$ is determined internally by MNW2 from

$$
K_{h}=\sqrt{K_{x} K_{y}}
$$

Prickett (1967) corrected for partial penetration effects in electric analog models by adding another resistor in series to a well node to represent additional head loss due to partial penetration - meaning that it is additive to the other wellloss contributions. Prickett's correction is based on Kozeny's

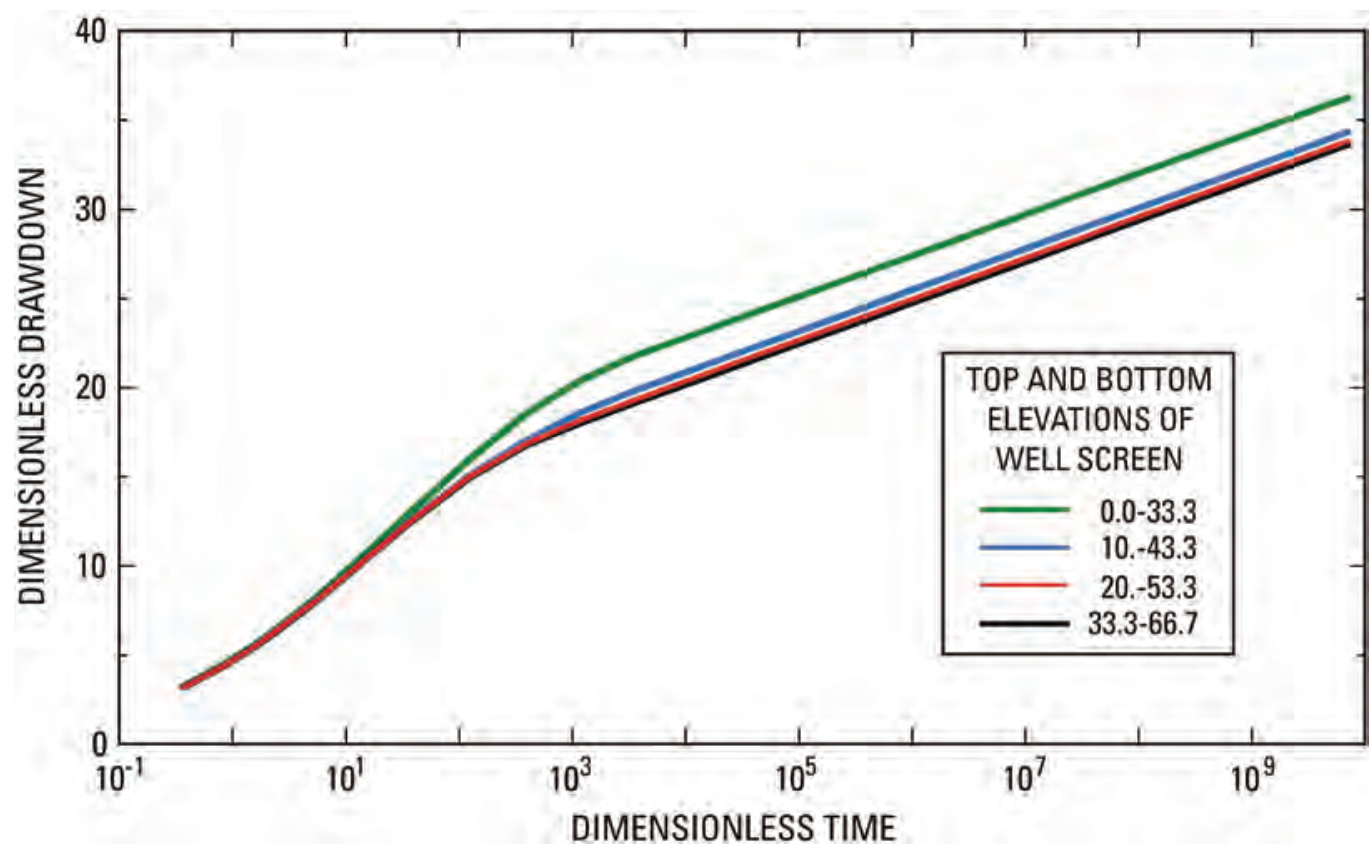

Figure 10. Drawdown due to partial penetration effects in a vertical pumping well that is open to 33 percent of the saturated thickness of the aquifer, showing sensitivity to the vertical position of the well screen within the aquifer. Elevation of the model layer ranges from 0.0 to 100.0 feet. Drawdowns calculated using the WTA0 Program (Barlow and Moench, 1999). 
(1933) empirical expression. Jacob (1963, p. 272) states that Kozeny's empirical expression "is a sufficient approximation for many purposes." However, Driscoll (1986) offers some words of caution about the use of Kozeny's equation, noting that the equation may not be valid for certain conditions, such as when aquifer thickness is small or the well radius is large.

Prickett (1967) calculates a partial penetration constant, $D$, which represents the normalized drawdown resulting from partial penetration effects as

$$
\frac{\Delta h_{p}}{\Delta h_{f}}=D=\frac{1}{\alpha\left[1+7 \sqrt{\frac{r_{w}}{2 b a}} \cos \left(\frac{\pi \alpha}{2}\right)\right]}-1,
$$

in which $\Delta h_{f}$ is the drawdown due to laminar flow of water through an areally extensive, homogeneous, isotropic aquifer to the pumped well under fully penetrating conditions, $\Delta h_{p}$ is the additional drawdown in the well due to the effects of partial penetration, $\alpha$ is the fraction of partial penetration (ratio of open interval to thickness), $r_{w}$ is the radius of the well, and $b$ is the saturated thickness of the aquifer.

However, estimating $\Delta h_{f}$ is problematic for use in a simple numerical approximation. Prickett (1967) states that a good approximation for the drawdown due to laminar flow under fully penetrating conditions can be made using the Thiem (1906) equation for steady-state flow in an areally extensive, homogeneous, isotropic aquifer, which can be expressed as

$$
\Delta h_{f}=\frac{Q}{2 \pi b K} \ln \frac{r_{e}}{r_{w}}=\frac{2.30 Q}{2 \pi b K} \log \frac{r_{e}}{r_{w}},
$$

where $r_{e}$ is the radial distance to a point where drawdown is negligible.

Prickett (1967) indicates that a value of $r_{e}=2,000 \mathrm{ft}$ would be adequate for most regional simulation models of confined aquifers. Walton $(1962$, p. 8) assumes that the partial penetration correction can be based on values of $r_{e}=10,000 \mathrm{ft}$ for a confined aquifer and $r_{e}=1,000 \mathrm{ft}$ for an unconfined aquifer. The approach of assuming a universal value of $r_{e}$ and not adjusting it for variations in aquifer dimensions or properties, however, is overly simplistic and arbitrary. A difficulty arises from the assumptions about the aquifer that are consistent with the applicability of the Thiem (1906) equation. Kruseman and De Ridder (1970, p. 51) note that a true steady state (where drawdown is zero) is impossible in a nonleaky confined aquifer, so that an exact value for $r_{e}$ is indeterminate. Nevertheless, the method of Prickett (1967) was implemented and evaluated for a range of assumptions about the value of $r_{e}$ in a series of numerical experiments. The results indicated that it worked acceptably well in some tested cases, but yielded unacceptably erroneous values in too many other cases that included plausible combinations of parameter values and boundary conditions.

To yield greater accuracy in estimating the drawdown due to partial penetration effects for a broader range of conditions, an analytical solution within the MNW2 Package was implemented to calculate the additional drawdown in a well that does not fully penetrate the saturated thickness of an aquifer. Following Moench (1993), the solution for drawdown $(\Delta h)$ in a well pumping from a nonleaky confined aquifer can be expressed as the sum of two components

$$
\Delta h=\Delta h_{T}+\Delta h_{p}
$$

where $\Delta h_{T}$ represents the drawdown computed with the Theis (1935) solution for flow to a well in a nonleaky confined aquifer. The WTAQ source code for the confined aquifer solutions (for both fully and partially penetrating conditions) has been extracted and incorporated as a subroutine internally within the MNW2 Package to calculate $\Delta h_{p}$; this coding implementation is invisible to the user of MODFLOW and MNW2.

Note that figures 8 and 9 indicate that, if the partial penetration fraction $(\alpha)$ is large, say greater than 0.90 , then there is only a very small partial penetration effect on drawdown, and if $\alpha \geq 0.99$, then the effect is negligible. Therefore, to avoid potential numerical problems when $\alpha \geq 0.99$, it is automatically assumed that the well is effectively fully penetrating whenever $\alpha \geq 0.99$ for a node in a multi-node well and that computation of drawdown due to partial penetration is not necessary under these conditions.

When the partial penetration fraction is very low, the drawdown correction may be very large (fig. 9) and very sensitive to small changes in the penetration fraction. Under these conditions, it is possible that the analytically based WTAQ solution for partial penetration effects will fail to converge. If that happens for a node of a multi-node well with a relatively low partial penetration fraction $(\alpha<0.20)$, then the cell-towell conductance will be set equal to zero, shutting off flow between the aquifer and that node of the well, and an appropriate informational message will be written to the output file; if it fails to converge for a relatively large partial penetration fraction $(\alpha \geq 0.20)$, then no partial penetration correction will be made (equivalent to assuming $\alpha=1.0$ ), and an appropriate informational message will be written to the output file.

It is assumed that the same relations used to estimate partial penetration effects in an aquifer are applicable to a well that is only open to a fraction of the saturated thickness of a model layer (or cell). The general well-loss equation introduced in equation 2 can be expanded to account for additional drawdown due to partial penetration effects in a vertical well as

$$
h_{W E L L}-h_{n}=A Q_{n}+B Q_{n}+C Q_{n}^{P}+\Delta h_{p},
$$

where $\Delta h_{p}$ is the additional drawdown in the well due to partial penetration.

Following the development of Halford and Hanson (2002, p. 8), the flow between the cell and the well can be expressed in terms of the head difference (equation 23) and a cell-to-well conductance, $C W C\left(\mathrm{~L}^{2} / \mathrm{T}\right)$, as

$$
Q_{n}=\left(h_{W E L L}-h_{n}\right) C W C_{n}
$$


Assuming that the additional drawdown due to partial penetration is additive with the other head loss terms, substituting the right side of equation 23 into equation 24, and solving for $C W C$ results in

$$
C W C_{n}=\left[A+B+C Q_{n}^{(P-1)}+\Delta h_{p} Q_{n}^{-1}\right]^{-1}
$$

The accuracy of the partial penetration correction in MNW2 was tested for the range of conditions depicted in figures 8-10. The results (fig. 11) show excellent agreement after early time (in these examples, after a dimensionless time of $10^{3}$ has passed, which is equivalent to less than 2 seconds of real time in this example problem). The disagreement at early times reflects the reliance of computing the head in the well partly on the basis of the steady-state Thiem (1906) equation, as discussed previously. The resulting error is limited to such a small initial transient time period that it should not have any effect on the reliability of results for regional ground-water simulations over typical time periods.

The analytical solutions for calculating drawdown in a partially penetrating well assume that the aquifer constitutes a single layer bounded above and below by confining layers. In a three-dimensional ground-water model, however, the vertical dimension may be discretized at a scale finer than the thickness of an aquifer. A range of vertical discretization possibilities are illustrated in figure 12. A well that is open to the middle third of an aquifer is depicted in figure $12 \mathrm{~A}$. If this aquifer were numerically simulated using a single model layer, then the thickness of the model layer $(\Delta z)$ would be the same as the aquifer thickness. The head computed for the finite-difference cell containing this well would be consistent with that for a fully penetrating well withdrawing water from the full volume of the cell. If observations of water levels in that well are to be compared to model-calculated values, then the head calculated for the well would have to be corrected for partial penetration effects, as well as for other possible well-loss terms.

In figure $12 B$ the aquifer is subdivided into three equally thick model layers. In this case, the partial penetration effects are explicitly modeled in MODFLOW because the well is open to the full thickness of model layer 2 and the finer vertical discretization allows the vertical components of flow above and below the well to be calculated directly; therefore, it is not necessary to simulate an additional drawdown term to account for the effects of partial penetration. One can question whether three model layers offers sufficient vertical discretization to accurately represent vertical components of flow near the well, but this can always be tested by trying an even finer vertical discretization, for example, as shown in figure $12 C$, where the aquifer is subdivided into six model layers, so the well could be simulated as an MNW open to (and fully penetrating) the middle two model layers.

The vertical head gradients above and below the open interval can be computed at two nodes in this case versus one node for the case in figure $12 B$. In figure $12 D$, the well screen (or open interval) is slightly longer than one-third of the thickness of the aquifer, and in a six-layer model of the aquifer, the well would fully penetrate model layers 3 and 4, but only penetrate about one-third of model layer 2 . If this well were represented by a MNW, then the correction for partial penetration would only affect the cell-to-well conductance in model layer 2, so the net effect on the head in the well would be substantially less than for a case in which a single-node well has a penetration fraction of 0.33 .

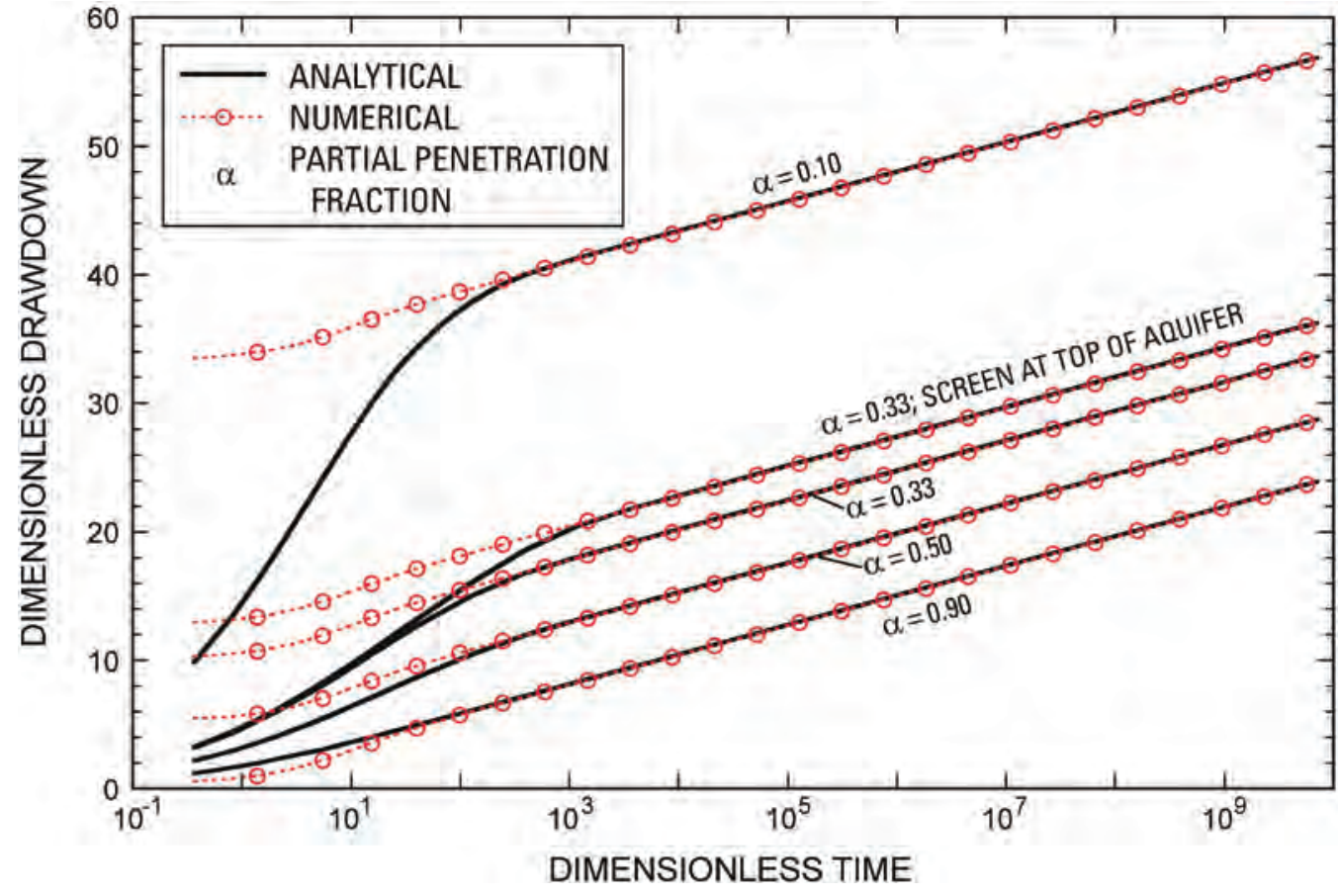

Figure 11. Plot showing comparisons of analytical and numerical solutions for dimensionless drawdown for selected cases shown in figures 8-10 for the Lohman problem. The well screen is located in the middle of the aquifer, except for one indicated case. Analytical solutions were calculated using the WTAO Program (Barlow and Moench, 1999). Numerical solutions (showing every fourth data point) were calculated using MNW2 in MODFLOW-2000 (Harbaugh and others, 2000). 


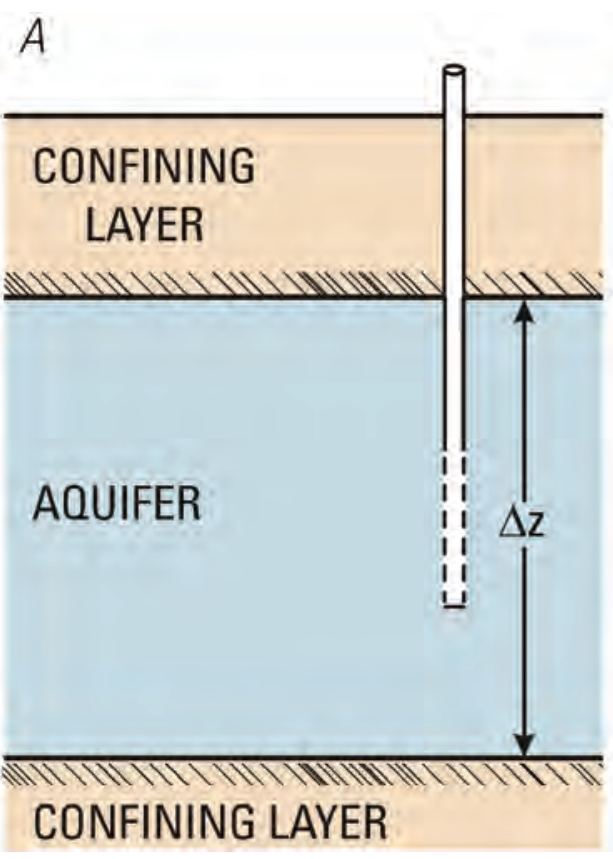

The alternative discretizations represented in figure $12 A-C$ were evaluated with MODFLOW for the Lohman problem using a single model layer. Figure 11 shows the results of applying MNW2 to the problem for the case of $\alpha=$ 0.33 ; the numerical MNW2 results were essentially identical to the analytical solution at dimensionless times greater than $10^{4}$. These results can then be compared with a simulation representing the three-layer conceptualization, as shown in figure $12 B$. In this case, the well fully penetrates layer 2 of the model, though it still penetrates only one-third of the aquifer. When the pumping is represented using the standard WEL Package of MODFLOW, the simulated results show a noticeable error (fig. 13). This is primarily caused by a discretization that is too coarse to allow vertical head gradients near the well to be calculated accurately. Therefore, as the discretization is made finer, and the number of layers increases, the results improve.

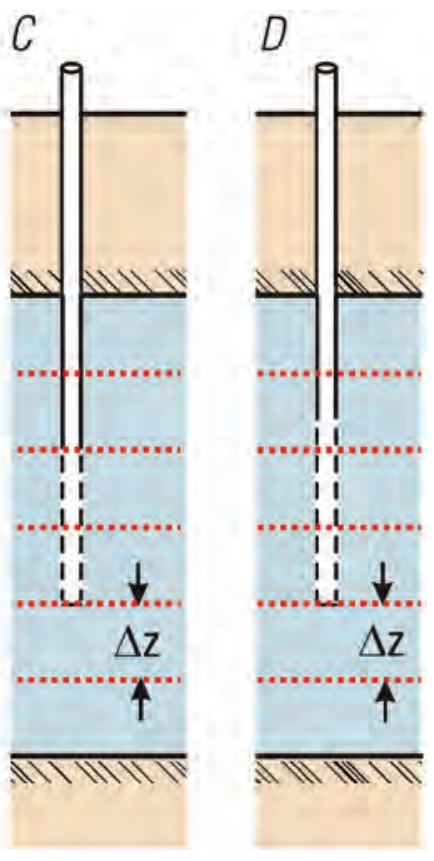

Figure 12. Schematic crosssectional diagram showing alternate vertical discretization possibilities for simulating a confined aquifer containing a partially penetrating well. In $A$, the aquifer is represented by a single model layer, and the vertical discretization in the model $(\Delta z)$ equals the aquifer thickness. In cases $B-D$, the red horizontal dotted lines represent the boundaries of the model layers used to simulate the aquifer, and $\Delta z$ is less than the aquifer thickness.

When the aquifer is further subdivided into six layers and the well assigned to the middle two layers, there is still a small error. However, when the aquifer is divided into 15 model layers and the well is represented with one-fifth of the total discharge in each of the middle five layers, the average head in the well computed numerically agrees almost exactly with both the analytical and MNW2 results after a dimensionless time of about $10^{3}$. This also illustrates the efficiency advantage of the MNW2 Package relative to the standard WEL Package; to obtain a match to the analytical solution with only a single model layer, the MNW2 results required 178 seconds of computational time, whereas the 15-layer model with the WEL Package used 3,396 seconds of computational time to produce an equivalent match.

For a water-table (unconfined) aquifer or a model layer that is allowed to convert from confined to unconfined, special care is required because the saturated thickness may change over time. An unconfined aquifer represented as a single

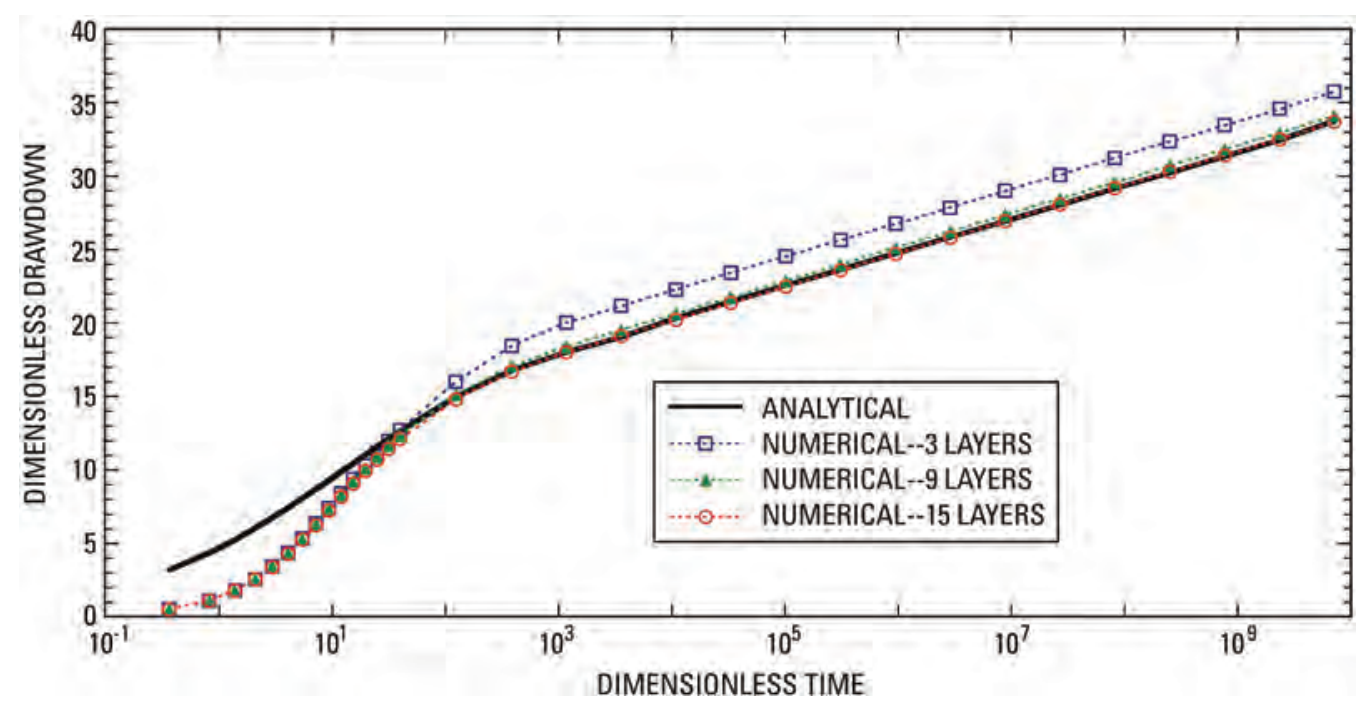

Figure 13. Plot showing comparisons of analytical and numerical solutions for dimensionless drawdown for the Lohman problem with a partial penetration fraction of 0.33 and the well screen located in the middle of the aquifer. Numerical solutions (showing the first 15 data points and then every fourth data point afterwards) calculated using the standard WEL Package in MODFLOW-2000 (Harbaugh and others, 2000). 
model layer is illustrated in figure 14 , in which the water table declines with time, represented sequentially from $A$ to $D$.

Because the position of the well screen is fixed, but the water table position changes with time, the relative position of the screen within the cell also changes with time. Therefore, the MNW2 Package will check to see if the saturated thickness (b) of a cell has changed, and if so, then the model will automatically update the values of the depths below the water table to the top and bottom of the well screen $\left(z_{p d}\right.$ and $z_{p l}$, respectively), the saturated length of the well screen $\left(l=z_{p l}-z_{p d}\right)$, and the penetration fraction $(\alpha=l / b)$, as appropriate. If the water-table elevation drops below the bottom of the screen within a cell, as in figure $14 D$, then all flow between the cell and that node of the multi-node well is cut off (equivalent to resetting the cell-to-well conductance for that node to zero). Note that if the water table subsequently rises, then the screen will be assumed to rewet and become active again, with its length and partial penetration fraction updated on the basis of the new water table elevation and the screen characteristics.

An unconfined aquifer is often discretized vertically into multiple model layers to obtain improved resolution of the results, as depicted in figure 15 , which shows a case where an unconfined aquifer is subdivided into three model layers. In this example, the well screen fully penetrates model layer 2 , both at the initial conditions (fig. 15A) and after a small decline of the water table within model layer 1 (fig. 15B). However, after the water table declines further so that it becomes located in model layer 2 (fig. 15C), model layer 1 at that location becomes inactive and both the saturated thickness of the cell and the saturated length of the well screen in layer 2 are reduced accordingly. If, however, the well screen were originally shorter and only partially penetrated model layer 2 (fig. 15D), then after the water table declined into model layer 2 , the depths below the water table to the top and bottom of the well screen ( $z_{p d}$ and $z_{p l}$, respectively), the saturated length of the well screen $\left(l=z_{p l}-z_{p d}\right)$, and the penetration fraction $(\alpha=l / b)$ would have to be adjusted (and so they are automatically updated in MNW2 after each time step).

The overriding assumption made in implementing the partial penetration correction in the MNW2 Package is that it can be applied on a model layer basis rather than on an aquifer basis. The likely disparity here is that the analytical solution assumes that the aquifer is bounded above and below by an impermeable confining layer, whereas in a complex three-dimensional model of a heterogeneous ground-water system, hydraulic conductivity values can vary by any amount between vertically adjacent cells. Furthermore, the analytical solution assumes that the aquifer is laterally homogeneous. Because in reality, hydraulic conductivity can vary by any amount between vertically and horizontally adjacent cells, the accuracy of the computed corrections for partial penetration effects may be compromised to some degree by these departures from the idealized assumptions.

The previous tests of the correction for the effects of partial penetration used the MNW2 Package to represent single-node wells because they can approximate the geometry and boundary conditions for which analytical solutions are available, thus allowing the accuracy of the numerical solution to be evaluated. If one or more nodes of a true multi-node well only partially penetrate the model layers to which they are connected, then the flow between the cell and the well at that node would also be reduced relative to a comparable well that fully penetrates all cells. In other words, the correction for partial penetration effects should be applied to any node of a vertical multi-node well that penetrates less than the full thickness of a cell. However, no analytical solutions are known to apply to this situation. Therefore, the length of the well screen of the multi-node well in the Reilly problem was adjusted so that one node (the uppermost one) will penetrate less than the full thickness of the cell to which it is connected and the
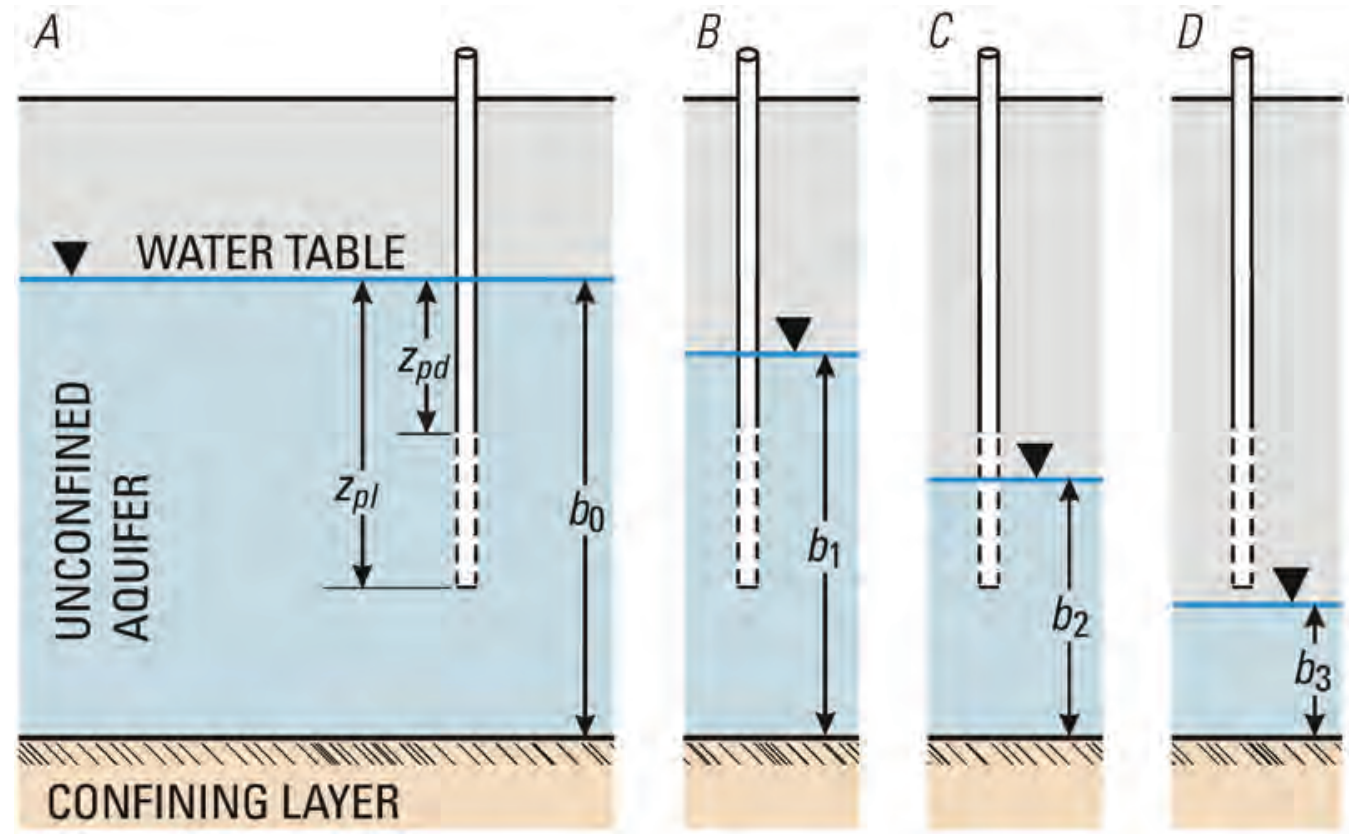

Figure 14. Schematic cross section of an unconfined aquifer simulated as a single "convertible" model layer showing the relation of the position of a partially penetrating well screen to the water table as the water table declines sequentially over time from $A$ to $D$. As the saturated thickness $(b)$ is reduced with time, the depths below the water table to the top and bottom of the well screen $\left(z_{p d}\right.$ and $z_{p l}$, respectively), the saturated length of the well screen $\left(I=z_{p l}-z_{p d}\right)$, and the penetration fraction $(\alpha=I / b)$ are automatically updated. 


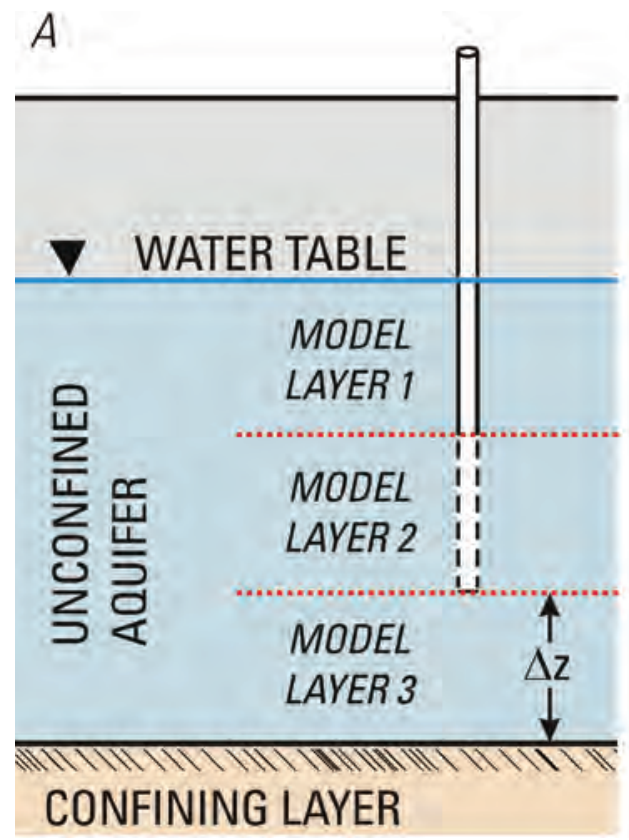

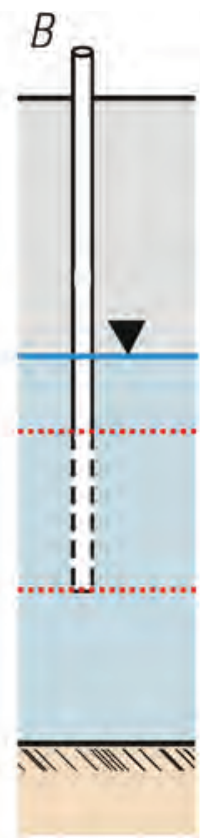

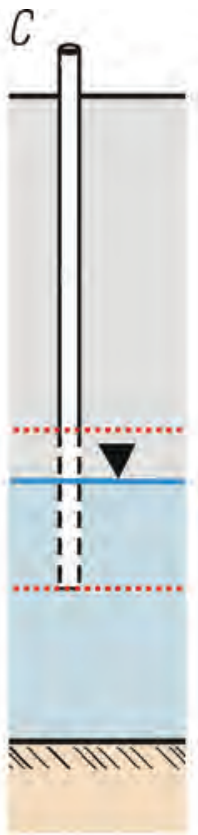

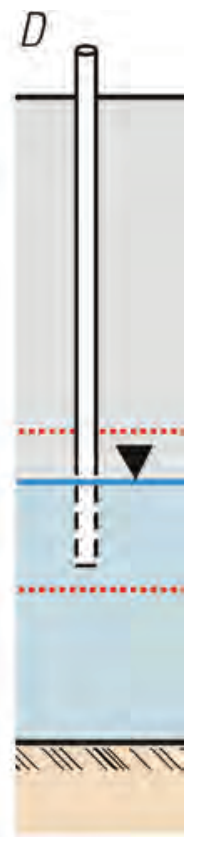

Figure 15. Schematic cross section of an unconfined aquifer represented by three model layers, showing the relation of a well screened in model layer 2 to the water table as the water table declines over time (sequentially from $A$ to $C$ ). The well screen fully penetrates model layer 2 in $A-C$, but is only partially penetrating in $D$. The red horizontal dotted lines represent the boundaries of the model layers used to simulate the aquifer, and $\Delta z$ is the layer thickness. results can be compared to the fully penetrating case. The evaluation is therefore limited to examining the relative effects on head and flow in the well and assuring that the results are logical and consistent.

To provide the basis of this test, the elevation of the top of the screen was lowered in increments from the elevation of the top of model layer 2 to the elevation of the bottom of model layer 2. This corresponded to reducing the total screen length from $60 \mathrm{ft}$ to $55 \mathrm{ft}$ (a reduction in length by 8.3 percent). Overall, one would expect that reducing the total length of the well screen would reduce the total flow through the well. This also corresponds with changing the partial penetration fraction $(\alpha)$ for the uppermost node of the multi-node well from a value of $\alpha=1.0$ to $\alpha=0.0$ as the elevation of the top of the screen is reduced.

The results show that the adjustments of the penetration fraction in just one of the 12 nodes comprising the well have a very small effect on the head (or water level) in the well (fig. 16A) and that the change in head over the total range of adjustment is only $-0.00018 \mathrm{ft}$ (fig. 16B). That is, the head in the well goes down slightly as the penetration fraction decreases. The low sensitivity of head in the well to these adjustments can be contrasted with the relatively high sensitivity of the total flow through the borehole to the same changes (fig. 17). The total intraborehole flow decreases from about $9.79 \mathrm{ft}^{3} / \mathrm{d}$ to about $8.28 \mathrm{ft}^{3} / \mathrm{d}$ (15.4 percent) as the uppermost node changes from 100 percent penetration to 0 percent penetration. This change is about twice the percentage reduction in total length of the well screen.

The change in flow shown in figure 17 can be attributed primarily to reduced inflow in node 1 (the uppermost node of the 12 nodes constituting this multi-node well) as the length of the screen in node 1 is sequentially reduced from the full thickness of the cell to zero (fig. 18). The results show a large change in flow in the uppermost node, where the penetration is adjusted; nodal changes are propagated downward to other nodes with diminishing effects with distance.

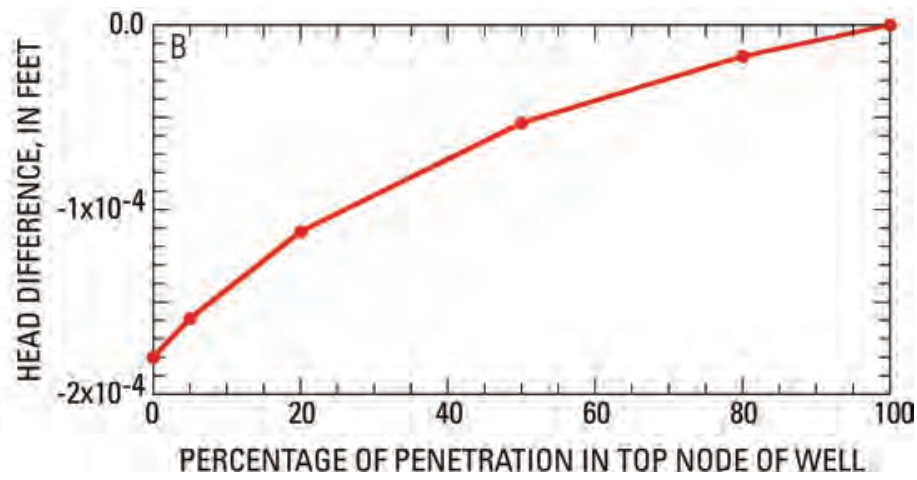

Figure 16. Plot showing the effect of variations in the penetration fraction for the uppermost node of the multi-node well in the Reilly problem on the computed water level (head) in $A$, the well; and $B$, on the corresponding change in water level relative to fully penetrating well. 
Overall, all of the observed effects in the numerical experiments of partial penetration of one node out of 12 appear to be logical and consistent with hydrologic principles. These results indicate that the partial penetration correction, as applied to individual nodes of a multi-node well, is working correctly.

Because the correction for effects of partial penetration, as implemented in the MNW2 Package, is clearly an approximation, the application of the correction is optional, and the user must specify whether or not the heads or water levels in a multi-node well should be corrected according to the algorithm described in equation 25. (The effects of partial penetration are included in MNW2 calculations if the user specifies a value of input variable PPFLAG greater than 0 in input item $2 b$.) If the user indicates that partial penetration corrections should be made, and the open intervals of a vertical well are specified in terms of the elevations of the tops and bottoms of one or more open (or screened) intervals in a long well, then MNW2 will calculate the length of open interval associated with each node of the multi-node well and automatically

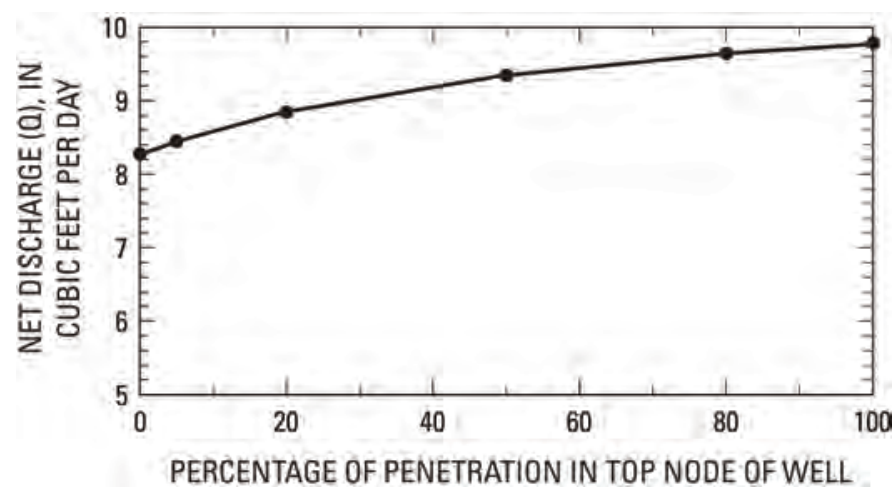

Figure 17. Plot showing sensitivity of total intraborehole flow $(0)$ to variations in the penetration fraction for the uppermost node of the multi-node well in the Reilly problem. calculate the penetration fraction at all nodes of the well. If the user indicates that partial penetration corrections should be made, but nodes are specified in terms of model layers, then the user must also explicitly define the penetration fraction associated with every node of that multi-node well (using input variable $\mathrm{PP}$ in item $2 \mathrm{~d}-2$ of the MNW2 input).

\section{Seepage Face}

In the MNW2 Package, it is normally assumed that flow between the well and each cell associated with the well is driven by the head difference between the well and the respective cell. In an unconfined aquifer, however, it is possible that the water level in the well can be computed to lie some distance below the water table. Chenaf and Chapuis (2007) note that when a well is pumping from an unconfined aquifer, "...the water table usually does not join the water level in the well. There is a seepage face inside the well, which is a key element in evaluating the well performance." Thus, in a numerical model, if the computed water level in a well in an unconfined aquifer drops in elevation over time, then its position may fall into the model layer underlying the cell containing the water table (fig. 19). This creates a seepage face and a disconnect in the hydraulic continuity between the saturated zone in the cell and the water in the well.

When the computed water level in the well falls below the bottom elevation of a cell, the normal assumption in the model that the flow is driven by the hydraulic gradient - defined by the difference between the water-table elevation and the water level in the well - would be an overestimation of the driving force because of the loss of continuous saturation between the water in the upper cell and the water in the well. Under such conditions, a seepage face can be surmised to occur in the upper part of the well screen - at least in the cell containing the water table. When such a seepage face is detected by the model, flow in that cell from the saturated zone into the multi-node well is simulated as a general-head boundary, and the flow is

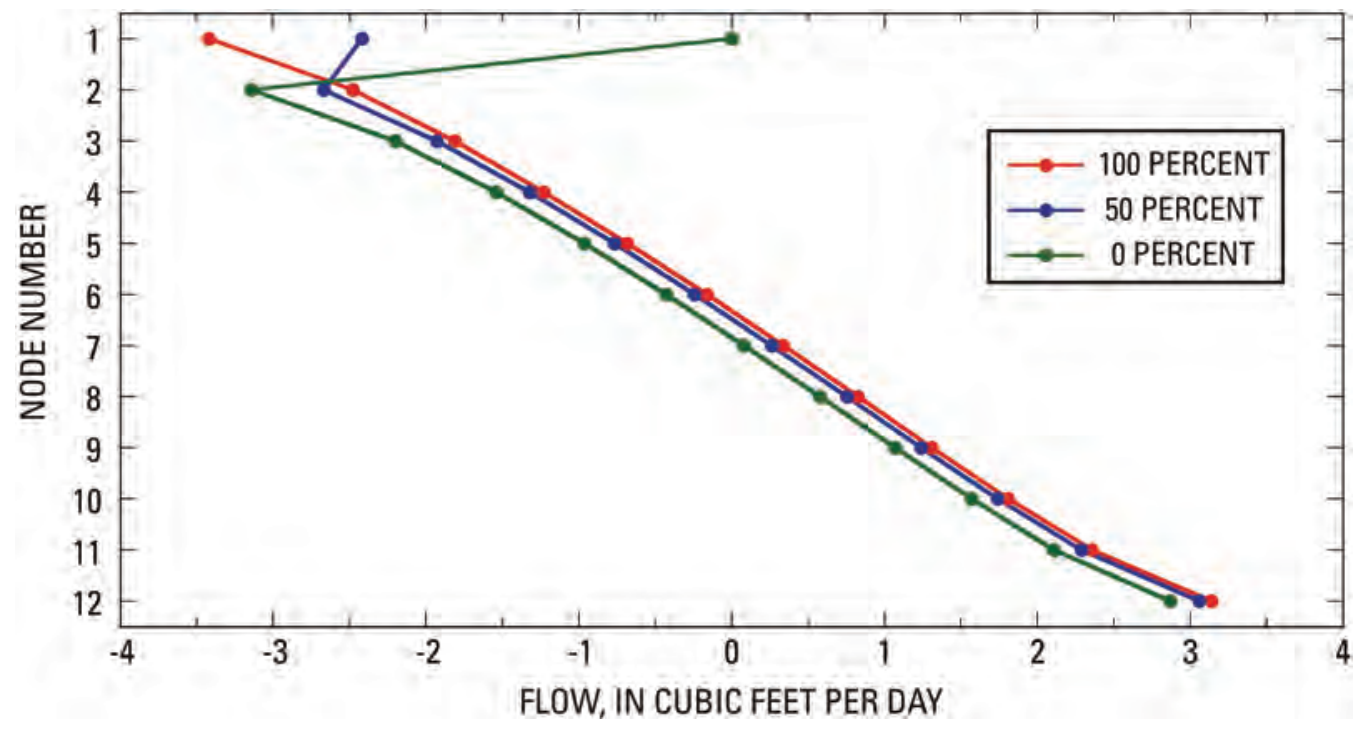

Figure 18. Plot showing flux into or out of each node of the borehole for penetration fractions of the top node of the well of $0.0,0.5$, and 1.0 in the Reilly test problem. Negative values represent flow from the aquifer into the borehole and positive values represent flow out of the borehole and into the aquifer. 
computed on the basis of the cell-to-well conductance (based on the saturated thickness of the cell containing the water table) and the hydraulic gradient as defined by the difference between water-table elevation in that grid cell and the elevation of the bottom of the cell. Figure 19 also shows that a small seepage face develops in model layer 2 in that hypothetical example. However, the model does not treat this seepage face any differently than normal because the cell is fully saturated and the water level in the well is above the bottom elevation of the cell, so the governing hydraulic gradient would be the same over the entire thickness of the cell.

If both the water level in the well and the head in the grid cell fall below the bottom elevation of the cell, then the model will assume that hydraulic continuity is lost. Therefore, no flow is allowed between the aquifer and that particular node of the multi-node well under those conditions.

The effect of computing the presence of a seepage face is illustrated with an example based on the Reilly test problem. To generate a seepage face condition, the Reilly problem as described above was modified to convert it to a transient flow problem with a pumping rate $\left(Q=-10,000 \mathrm{ft}^{3} /\right.$ day) sufficient to generate drawdown in the multi-node well so that the water level in the well would decline to a level below the bottom elevation of the first cell connected to the multi-node well. Additionally, the hydraulic conductivity of the skin was set equal to one-tenth of that in the base case $\left(K_{S K I N}=12.5 \mathrm{ft} / \mathrm{day}\right)$. The modified parameters for this test are listed in table 3 . All other parameters are identical to the base case for the Reilly problem. The transient simulation was run for a stress period of 150 days, using 12 time steps and a time-step multiplier of 1.3. The initial heads were defined by the solution generated in a preliminary steady-state stress period in which the multi-node well was assigned a net discharge of zero.

This test case was simulated using the described correction for the presence of a seepage face and without the correction (assuming that driving force for flow between the aquifer and the well is always the head difference between the $h_{n}$ and
Table 3. Modified parameters in Reilly problem for evaluating seepage face calculation in multi-node pumping well.

[ft/d, feet per day; ft, feet; $\mathrm{ft}^{3} / \mathrm{d}$, cubic feet per day]

\begin{tabular}{ll}
\hline \multicolumn{1}{c}{ Parameter } & \multicolumn{1}{c}{ Value } \\
\hline Specific storage (all layers) & $3 \times 10^{-4} \mathrm{ft}^{-1}$ \\
Specific yield (layer 1) & 0.30 \\
$K_{S K I N}$ & $12.5 \mathrm{ft} / \mathrm{d}$ \\
$Q$ & $-10,000 \mathrm{ft}^{3} / \mathrm{d}$ \\
\hline
\end{tabular}

$\left.h_{W E L L}\right)$. As seen in figure 20, $h_{W E L L}$ did not drop below the bottom elevation of the cell associated with the top node of the well (-10.0 ft) until the ninth time step (at about 65 days). (Note that this figure shows changes during the transient stress period, and not for the preliminary steady-state stress period.) From then on, there was a small difference in the computed value of $h_{W E L L}$ between the uncorrected and corrected cases, with the head in the well being somewhat lower when the correction is made. During this time, the head in the top cell connected to the well (located in model layer 2) remained above the bottom elevation of the cell through the $11^{\text {th }}$ time step (at about 114 days) while the computed water level in the well was below the bottom elevation of that cell - creating the conditions for a seepage face to develop. During the $12^{\text {th }}$ and final time step, the head in this cell dropped below the bottom elevation of the cell $(-10.0 \mathrm{ft})$, thereby disconnecting it from the well. Also during the final time step, $h_{\text {WELL }}$ dropped below the bottom elevation of the cell in layer $3(-15.0 \mathrm{ft})$, thereby creating a seepage face condition in that cell, which contains the second node of the multi-node well. If $h_{W E L L}$ drops below several layers of active nodes, then the model will allow the development of multiple seepage faces and compute adjusted inflows accordingly.

The flow into the top node of the well was more substantially affected by the implementation of the correction (fig. 21) than were the heads. The inflow from the aquifer into node 1 of the well (located in model layer 2) decreased slightly over time

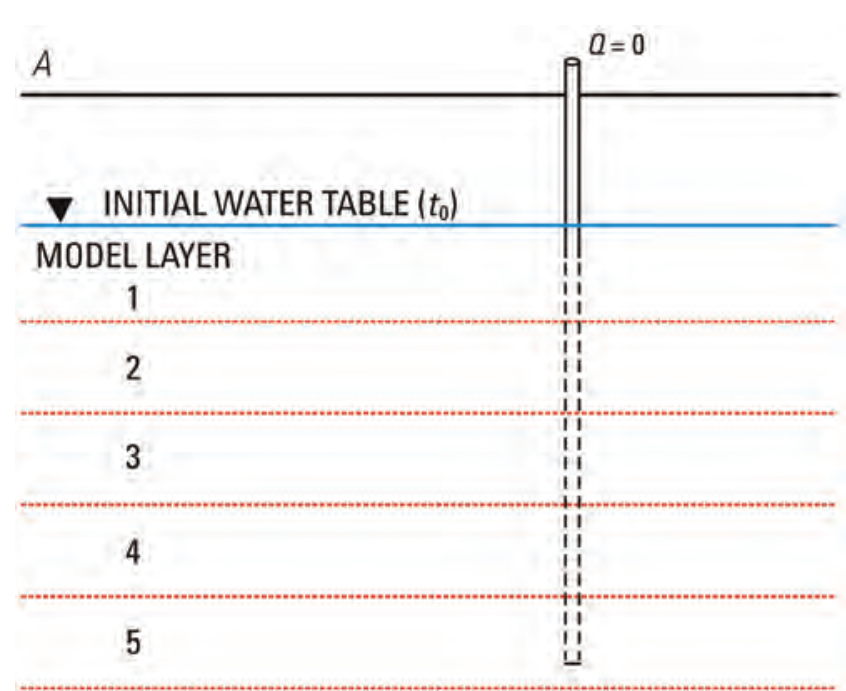

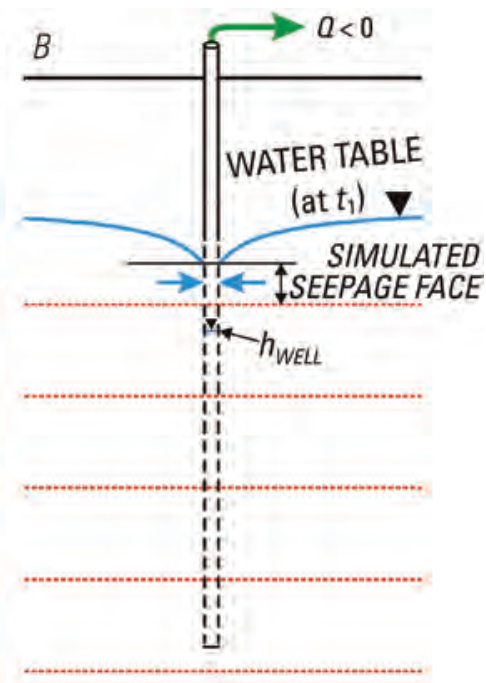

Figure 19. Schematic cross section of $A$, an unconfined aquifer showing a multi-node well open to parts of the uppermost five model layers, and $B$, the relation of the screens (open intervals) to lower water levels at a later time $\left(t_{1}\right)$, when the water level in the well has fallen below the bottom elevation of model layer 1. 


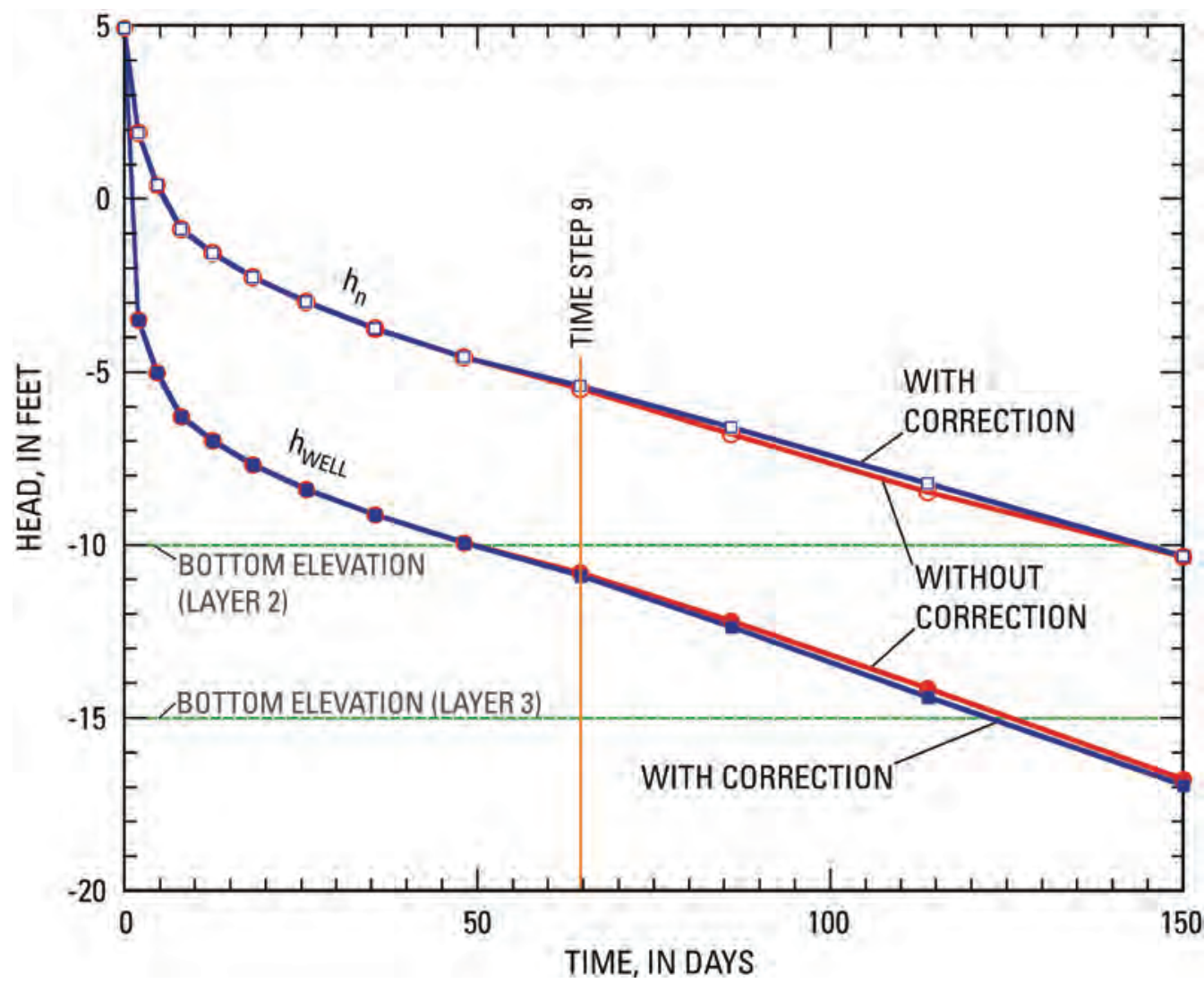

Figure 20. Computed changes in head in the multi-node pumping well ( $\left.h_{\text {WELL }}\right)$ and in the aquifer cell connected to the uppermost node of the multinode well $\left(h_{n}\right)$ for the modified Reilly problem, both with and without a correction for the development of a seepage face in the uppermost cell. Top node of well located in model layer 2. Results of preliminary steadystate stress period represent initial conditions for the 150day transient stress period shown in this figure. through the eighth time step as the head in the aquifer and the water level in the well both declined. However, once the water level in the well dropped below the bottom elevation of the cell, the rate of decrease in the inflow was much greater with the correction on, which resulted in a lower flow rate to the well compared with the simulation without the correction. Because the net discharge from the well is specified, as the inflow decreases in node 1 there are compensating increases in inflow at the other nodes of the multi-node well (fig. 22). Once the cell in model layer 2 goes dry (or when the head in the aquifer falls below the bottom elevation of the cell if the cell is not convertible, as in this example), the inflow to the well from that cell ceases. In this example, this occurs during the last time step (at 150 days, as seen in fig. 21). Overall, the correction for the development of a seepage face, as described above, yields changes that are logically consistent with expectations based on well hydraulics. Although this example problem shows only small effects of the seepage face, in other situations, the effects can be much greater.

The calculations related to a seepage face are performed automatically by MNW2 whenever it detects the presence of conditions for which a seepage face is expected to occur, as described above. The model user does not have an option to control this feature.

\section{Constraints on Pumping Rate}

The range over which the water level in a well can potentially change may not be unbounded. For example, in discharging wells, pumping cannot continue if the water level drops below the depth of the pump settings and screen intakes. In recharging wells, the water level might be constrained by the land surface or the maximum injection head. Halford and Hanson (2002) recognized that a drawdown (or water level) constraint on pumping or injection rates is especially useful for predictive scenarios and ground-water management analyses where the future stresses and hydraulic interference among wells are not known, and they built this capability into MNW1. This same capability is incorporated into MNW2 with minor modifications; the capability is activated by setting input variable $\mathrm{Q}$ limit $>0$ in the MNW2 input file.

As stated by Halford and Hanson (2002), the maximum discharge rate for an individual well may be limited by the drawdown (change in head or water level) within that well, which is a function of the hydraulic conductivity of the surrounding aquifer, frictional energy loss owing to formation damage from drilling, and energy losses due to flow through the well screen. Nearby wells also can contribute to the drawdown in a pumped well and thereby additionally limit the discharge from a well. For example, well BM1 (fig. 23) is screened deeper and discharges more water than do the neighboring wells PA1 and PA2. Because of the water-table decline caused by discharge from well BM1, the maximum discharge rate for well PA1 might be reduced, and well PA2 would be rendered inoperative.

MNW2 computes a drawdown-dependent decrease in net discharge (or in net recharge rate for an injection well) 

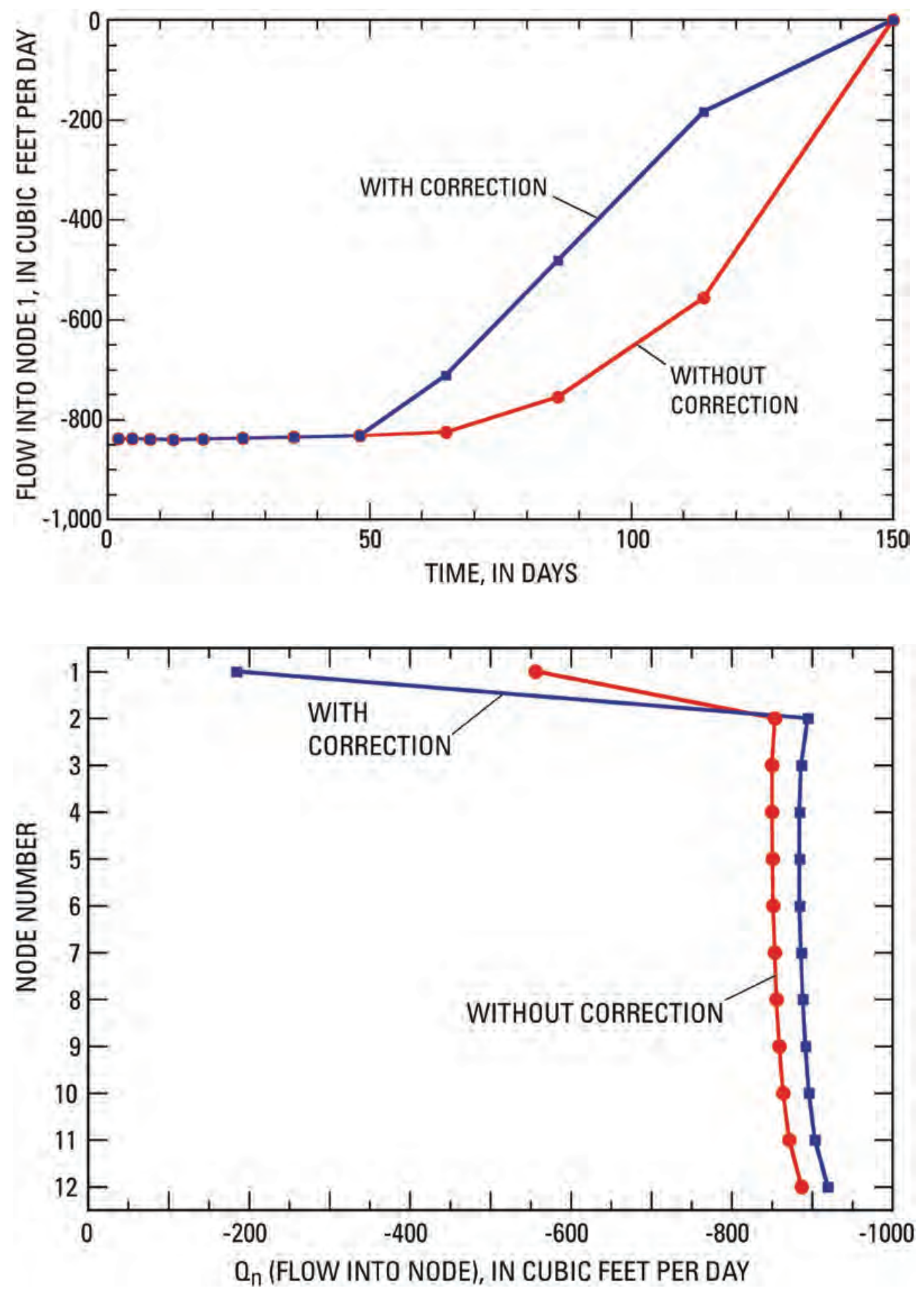

Figure 21. Computed flow from the aquifer into the uppermost node of the multinode well for the modified Reilly problem, both with and without a correction for the development of a seepage face.
Figure 22. Computed distribution of flows from the aquifer into all nodes of the multi-node well during the $11^{\text {th }}$ time-step (at about 114 days) for the modified Reilly problem, with and without a correction for the development of a seepage face. Negative values of $Q_{n}$ indicate that flow represents a discharge from the aquifer. Node numbers increase with depth and nodes are located 5 feet apart. if constraints are imposed and if a limiting head in the well is reached or exceeded. Furthermore, if the option to apply constraints is activated, then the user can specify a minimum pumping rate ( $\mathrm{fr} \mathrm{cmn}$ ) that represents the lower limit of the fixed range of pump capacity for each well (the upper limit is the desired flow, Qdes). Discharge is reduced to zero if the computed net discharge falls below the specified minimum pumping rate. In MNW1 this condition was checked with lagged heads; that is, the potential net discharge for a time step was computed at the beginning of that time step using heads at aquifer nodes computed at the end of the previous time step. Thus, it was possible that the computed net discharge could have been less than the specified minimum for one time step before the pump shuts off in the model. In MNW2, the condition is checked using the most recent estimates for heads within a time step. Recharging (injection) wells are limited in the same manner but the signs are reversed (and Qf r cmn represents a minimum injection rate). 


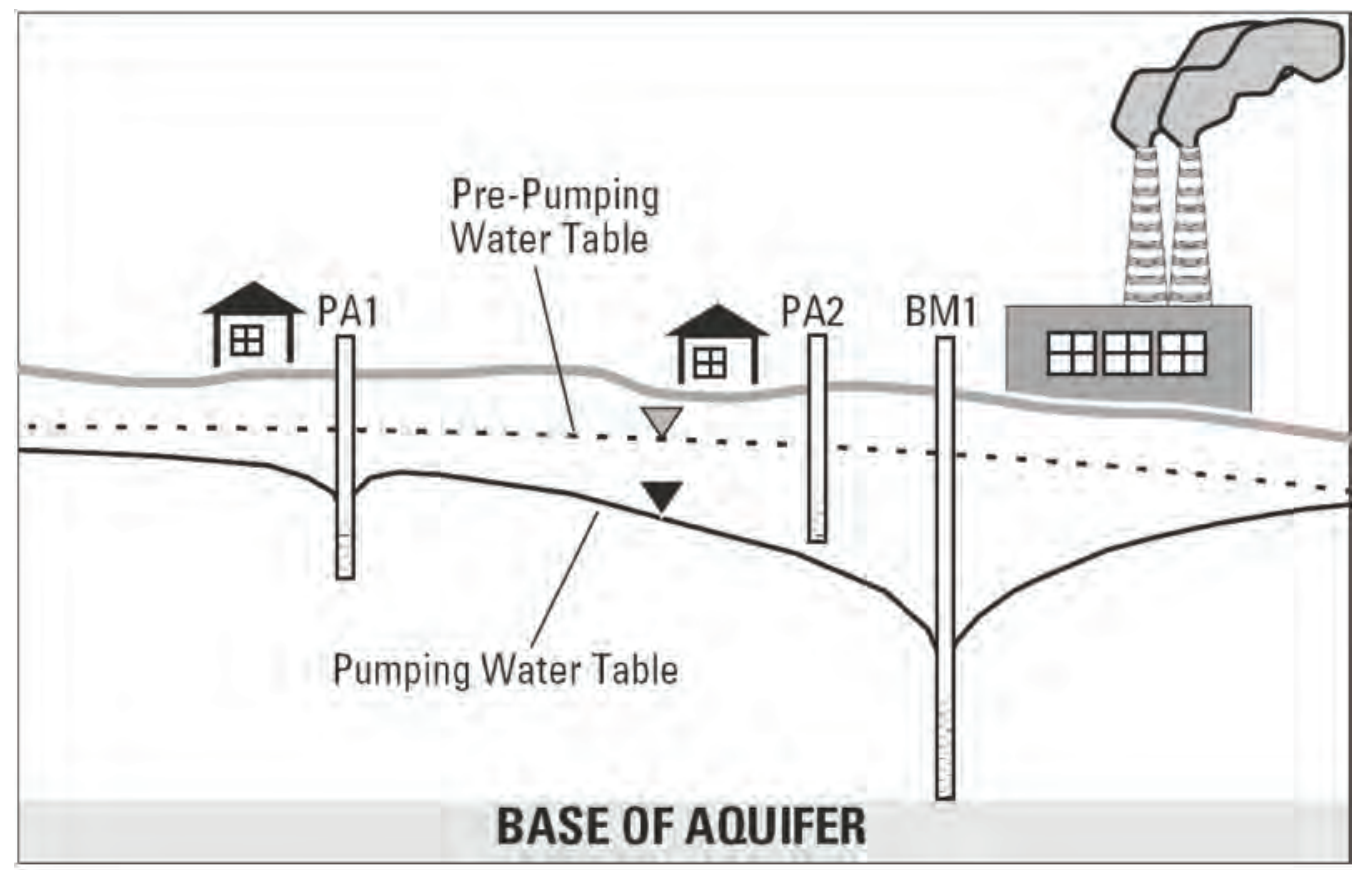

Figure 23. Hypothetical cross-section illustrating limitations on well discharge rates owing to aquifer characteristics, well construction, and influence of other wells (from Halford and Hanson, 2002).
In transient flow systems, it is possible for heads at a particular location in an aquifer to cycle between rising and falling stages. This means that a well for which constraints caused pumping to cease as water levels fell can have pumping and discharge restart if water levels subsequently rise sufficiently. In the model, pumpage from a constrained well is restored if the potential pumping rate exceeds a user-specified threshold ( $\mathrm{f}$ r cmx ). The absolute value of the threshold $\mathrm{Qfr} \mathrm{cm} x$ must be different from and greater than the absolute value of the minimum pumping rate $Q$ f r $\mathrm{cmn}$ to help avoid oscillating numerical solutions, which could produce instability and lack of convergence in solving the ground-water flow equation. Unlike MNW1, MNW2 also uses the most recent calculated head values to check this condition (instead of head values lagged from the previous time step). Qf r cmn and Qf r cmx can be specified by the user either as explicit volumetric rates or as percentages of the specified net discharge for the well (Qdes).

If the option to impose constraints is activated (that is, Qlimit $>0$ ), then the net discharge from a withdrawal well becomes limited when the water level in the well, $h_{W E L L}$, reaches or falls below a user-defined lower limit, $h_{\text {lim }}$ (Hlim in input dataset $2 \mathrm{f}$ or $4 \mathrm{~b}$ ). (Note that MNW1 allowed a user to set a constraint either in terms of a critical water level or in terms of a drawdown and a reference elevation. For simplicity, MNW2 only enables the former approach.) If $h_{W E L L}$ remains above or equal to $h_{\text {lim }}$, then the flow rate will be estimated as normal with equation 12 . Subsequently, if $h_{W E L L}$ drops below the level of $h_{\text {lim }}$, then the maximum potential discharge $\left(Q_{p o t}\right)$ is computed using the same equation but with $h_{\text {lim }}$ substituted for $h_{W E L L}$. If the potential discharge exceeds the user-specified discharge $\left(\left|Q_{\text {pot }}\right|>\left|Q_{\text {des }}\right|\right)$, then the latter is used in solving the ground-water flow equation (that is, the well discharge is not constrained). If the potential discharge is less than the user-specified discharge $\left(\left|Q_{\text {pot }}\right|<\left|Q_{\text {des }}\right|\right)$, then the former is used in solving the ground-water flow equation (and the well discharge is thereby constrained). In this manner, the applicable boundary condition represented by the multi-node well transitions from a specified-flux type of boundary condition to a general-head type of boundary condition (with $h_{\text {lim }}$ as the controlling head). If $h_{n}$ at all aquifer nodes linked to a multinode well fall below $h_{\text {lim }}$, then there will be no net discharge from the well. Note that zero discharge is a limit to prevent the net well discharge from artificially reversing signs and change from discharging to recharging conditions during a given stress period. If the net discharge from a multi-node well falls to 0 , however, then cross-flow between model layers (via intraborehole flow in the multi-node well) will still be simulated. Recharge (injection) wells are limited in the same manner, but the signs are reversed, and $h_{\text {lim }}$ represents a maximum water level.

These relations are best illustrated by an example-one also based on the Reilly test problem. To illustrate the use and effects of constraints on a discharging well, the Reilly problem, as modified for the seepage face example (see tables 2 and 3), was used with a specified limiting head $\left(h_{\text {lim }}=-7.5 \mathrm{ft}\right)$ and no minimum pumping rate specified (Qcut $=0$, where Qcut is defined in input dataset $2 \mathrm{f}$ or $4 \mathrm{~b}$ ). All other parameters, stress periods, and time steps are identical to those described for the seepage face example. The results (fig. 24) show that once the head in the well reached the limiting head (in the fifth time step, at about 19 days), it was prevented from declining any further, and the computed discharge decreased as the heads in adjacent nodes continued to decline with time. Note that the discharge remained constant at the specified rate $\left(-10,000 \mathrm{ft}^{3} /\right.$ day $)$ prior to the time when the head in the well reached the limiting head.

The stabilization of $h_{W E L L}$ at the value of $h_{\text {lim }}$ is reasonable as long as the heads at linked nodes in the aquifer 
are higher than $h_{W E L L}$, thereby allowing a net inflow to the multi-node well, which will balance the net discharge from the well. However, if the computed heads at the aquifer nodes connected to the multi-node well decline below the value of $h_{\text {lim }}$, then the net discharge would be reduced to zero, and the head in the well would decline to deeper levels than specified by $h_{\text {lim }}$. This was tested and demonstrated by rerunning the previous example, but with specified withdrawals in three single-node wells added at nearby nodes (in layers 2,7 , and 13 of row 28 , column 43 ) at rates of $-4,000 \mathrm{ft}^{3} /$ day each. (Note that because the single-node pumping wells are not located on the plane of symmetry, their effects on drawdown in the aquifer would be equivalent to each one having a matching well on the other side of the plane of symmetry.) The additional drawdown in the multi-node well caused by interference from the three additional pumping wells causes the head in the multinode well to decline faster than before (fig. 25). In this case, the head in the well reached the limiting head in the second time step (at about 4.6 days), and the net discharge decreased to $-9,190 \mathrm{ft}^{3} /$ day from the $-10,000 \mathrm{ft}^{3} /$ day rate during the first time step. However, because of the additional drawdown relative to the previous case, the net discharge continued to decrease to zero in the ninth time step. After the discharge ceased, the computed water level in the well again began to decline further - to depths below the specified value of $h_{\text {lim }}$.

For comparison, the average of the heads in the 12 aquifer nodes connected to the multi-node well are also shown in figure 25. During the eighth time step, the heads at several nodes (those closest to the three single-node pumping wells) are below the value of $h_{\text {lim }}$, causing outflow from the multinode well (recharge to the aquifer) in these nodes, although there is sufficient inflow to the multi-node well (discharge from the aquifer) at the remaining nodes so that the net discharge, though greatly reduced by this time, is still nonzero at about $-100 \mathrm{ft}^{3} /$ day. In the ninth step the average head has dropped to about $-8.9 \mathrm{ft}$ and is below the value of $h_{\text {lim }}$ at every one of the 12 aquifer nodes connected to the multi-node well. Therefore, the net discharge is zero, and the water level in the well drops below $h_{\text {lim }}$ as it equilibrates to the new lower aquifer heads. As expected, while there is a net discharge from the multi-node well, the head in the well is noticeably lower than the average head in the aquifer adjacent to the well, but when the net discharge is zero, $h_{W E L L}$ is almost exactly equal to the average of the adjacent nodal heads. Note that even with this net discharge of zero, there exists a complex intraborehole flow pattern in which water flows out of the well in layers containing one of the three discharging single-node wells and water flows into the well in other layers - though inflows from the aquifer will exactly balance outflows to the aquifer (fig. 26).

To demonstrate the ability of the MNW2 Package to shut off a pumping well when the constraints cause the discharge rate to fall below a specified minimum rate, the same problem was resimulated with the minimum pumping rate ( $Q$ fr $\mathrm{rmn}$ ) set to 20 percent of the specified desired rate (that is, $Q$ frcmn $=0.20$, which is equivalent to $Q f r c m n=-2,000 \mathrm{ft}^{3} /$ day). The results (fig. 27) can be compared with those shown in figure 25 for the case without a minimum rate imposed. During the seventh time step, the net discharge would have been calculated to equal about $-1,460 \mathrm{ft}^{3} /$ day, which is less than the minimum pumping rate. Because the calculated net discharge fell below the value of $Q$ frcmn during the iterations to solve the flow equation during the seventh time step, the pump was shut off and the net discharge was set to equal zero during this time step. Thus, because $Q_{n e t}$ is reduced to 0.0 during the

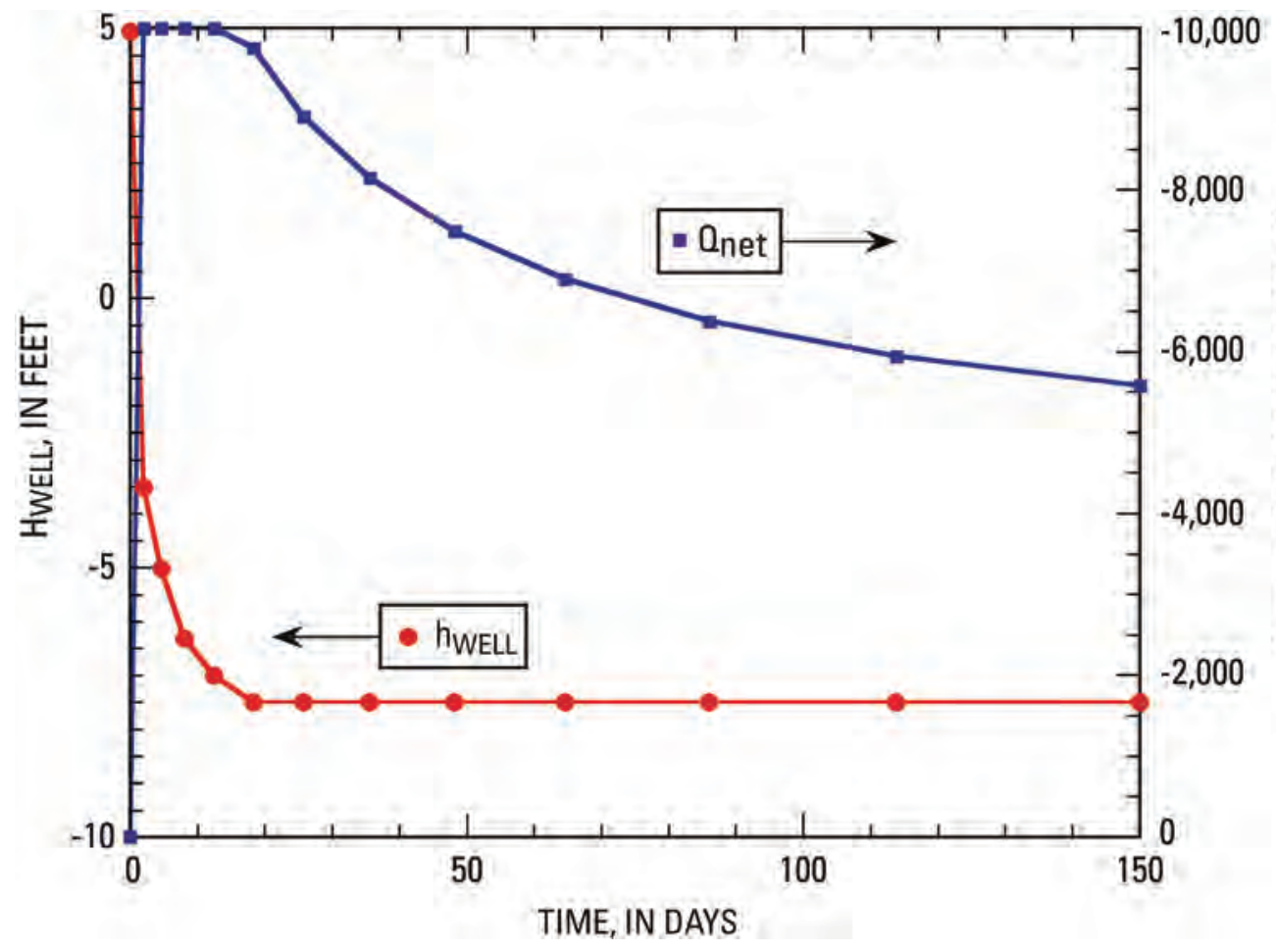

Figure 24. Plot showing relation between computed net discharge $\left(Q_{n e t}\right)$ from a multinode well and computed head in the well ( $\left.h_{\text {WELL }}\right)$ for case in which well is subject to a constraint in which the limiting head $\left(h_{\text {lim }}\right)$ is set at -7.5 feet. Arrows indicate proper axis labels for each variable plotted. 


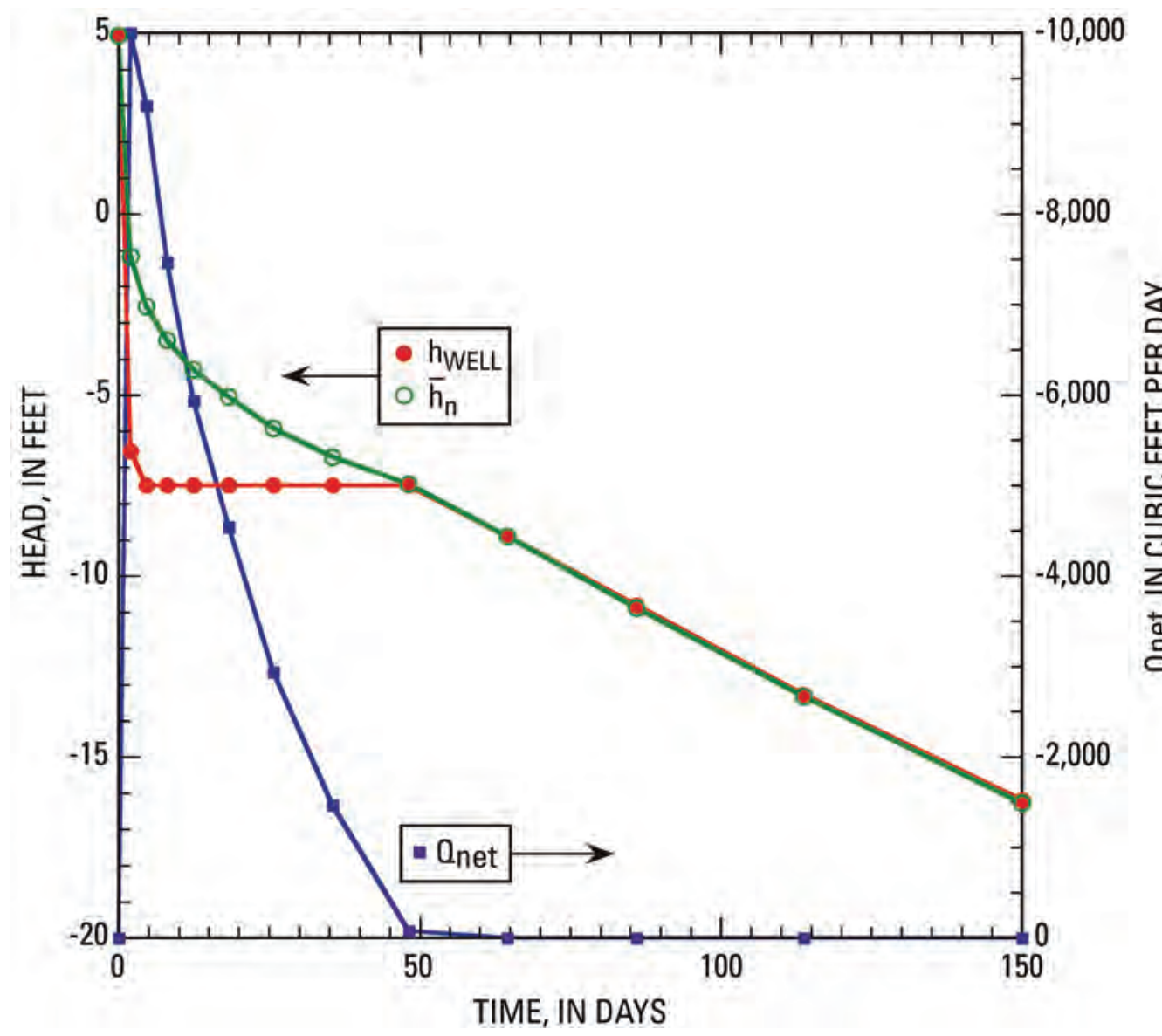

Figure 25. Plot showing relation between computed net discharge $\left(Q_{\text {net }}\right)$ from a multi-node well and computed head in the well ( $\left.h_{\text {WELL }}\right)$ for case in which well is subject to a constraint in which the limiting head $\left(h_{\text {lim }}\right)$ is set at -7.5 feet and additional nearby pumping wells cause additional drawdown in the multi-node well. Average of heads in 12 aquifer nodes $\left(\bar{h}_{n}\right)$ linked to the multi-node well are shown for comparison. seventh time step, the water level in the well and the heads in the aquifer all show a small recovery relative to the situation when pumping continues through the seventh time step. Once the net discharge equals zero, the head in the well becomes almost equal to the average of the heads in the 12 aquifer nodes connected to this multi-node well, and calculations of intraborehole flow continue.

Once the pumpage is shut off by constraints during a time step, the pump is not allowed to turn back on during the same time step in order to facilitate stability and convergence of the numerical solution. Also note that the constraints are implemented slightly differently in MNW2 than in MNW1, in which the well would have been shut off for the next time step rather than the present time step in which the constraining condition for the minimum pumping rate is met. One consequence of the lag implemented in MNW1 is that the net discharge computed for the last time step before the pump is shut off can actually be less than the allowable minimum, if one is specified.

To demonstrate the capability to restart a pumping well when water levels rise again after earlier declines that cause the well to shut off, the previous problem was again modified-this time by adding another 150-day stress period during which the three nearby single-node wells are shut off, thereby leading to water-level recovery in the aquifer. The minimum allowable pumping rate to shut off the well was arbitrarily set at 10 percent of the desired rate (equivalent to $Q$ frcmn $=-1,000 \mathrm{ft}^{3} /$ day, one-half the rate specified for the case illustrated in figure 27), and the minimum rate that must be exceeded to reactivate the well was arbitrarily set at 15 percent of the desired rate (equivalent to Qfrcmx $=-1,500 \mathrm{ft}^{3} /$ day).

The effect of specifying a lower value of Qfrcmn can be seen during the first 150-day stress period (fig. 28), in that now the net discharge $\left(Q_{n e t}\right)$ does not go to zero until the eighth time step (at about 48 days), whereas previously $Q_{\text {net }}$ went to zero in the seventh time step (at about 35 days). During the recovery stress period, the water levels rise in response to shutting off the three nearby single-node pumping wells. In the seventh time step of the second stress period (at about 185 days), the water level in the well and heads in the aquifer have risen sufficiently such that the computed potential net discharge exceeds the value of Qfrcmx. Consequently, the pump is turned back on during the seventh time step of the second stress period, and the computed net discharge at that time is about $-1,922 \mathrm{ft}^{3} /$ day. The restarted discharge from the well causes the water level in the well to drop back down to the value of $h_{\text {lim }}$ and the rate of recovery of heads in the aquifer adjacent to the well to slow down. As with shutting off a pump, a small difference between MNW2 and MNW1 in restarting a pump is that in MNW2 the pump is restarted during the same time step in which the computed potential net discharge exceeds the value of $Q$ frcmx. In MNW1 restarting was lagged one time step. 

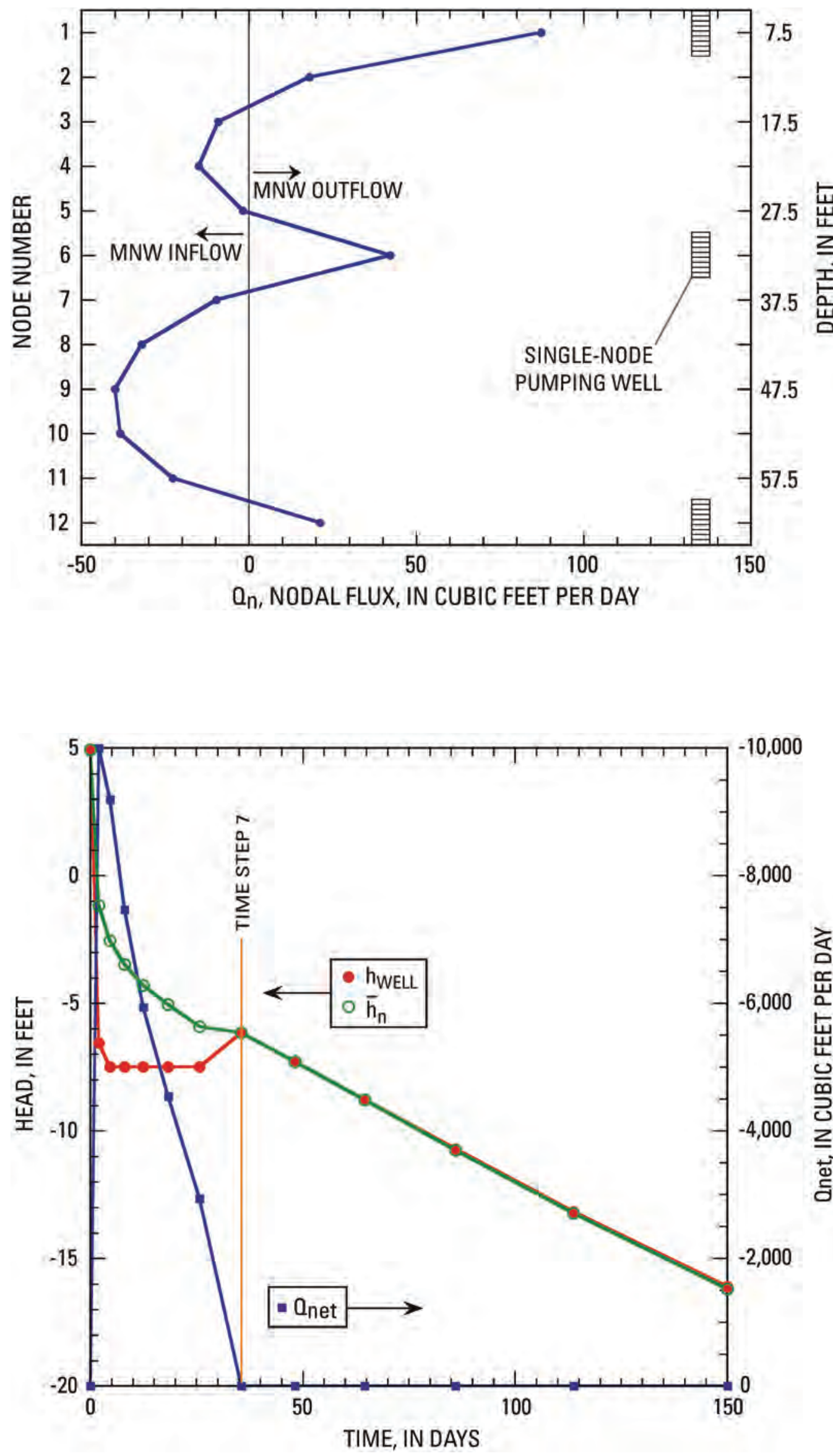

Figure 26. Variations in nodal flux at the ninth time step (at about 65 days, when $Q_{\text {net }}=0.0$ ) between the multi-node well and aquifer for modified Reilly problem with three additional single-node pumping wells nearby. Vertical positions of single-node wells shown for comparison. Positive values of flux indicate outflow from well and recharge to aquifer.
Figure 27. Plot showing relation between computed net discharge $\left(Q_{\text {net }}\right)$ from a multi-node well and computed head in the well ( $\left.h_{\text {WELL }}\right)$ for the case in which the well is subject to a constraint in which the limiting head $\left(h_{\text {lim }}\right)$ is set at -7.5 feet, additional nearby pumping wells cause additional drawdown in the multi-node well, and the minimum allowable pumping rate is set at $-2,000$ cubic feet per day. Average of heads in 12 aquifer nodes $\left(\bar{h}_{n}\right)$ linked to the multi-node well are shown for comparison. 


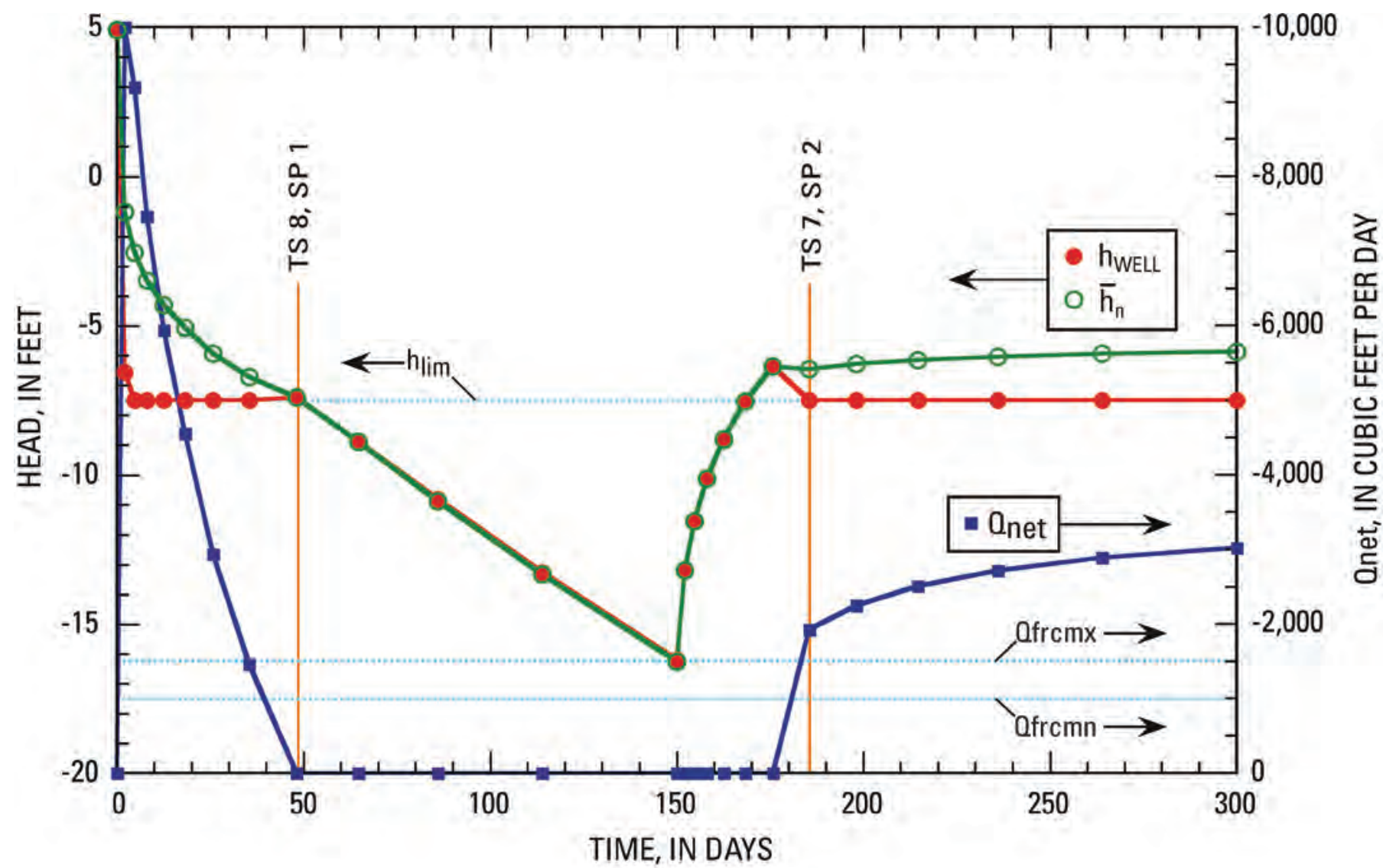

Figure 28. Plot showing relation between computed net discharge $\left(Q_{\text {net }}\right)$ from a multi-node well and computed head in the well $\left(h_{\text {WELL }}\right)$ for case in which a second 150-day stress period, during which the three additional single-node pumping wells are shut off to allow water-level recovery, is added to the case previously described for figure 27 . In this modified case, the minimum allowable pumping rate ( $\mathrm{E} \mathrm{fr} \mathrm{cmn}$ ) is set at $-1,000$ cubic feet per day $\left(\mathrm{ft}^{3} /\right.$ day), and the threshold to restart pumping ( $\mathrm{Q} \mathrm{frmx}$ ) is set at $-1,500 \mathrm{ft}^{3} / \mathrm{day}$. Average of heads in 12 aquifer nodes $\left(\bar{h}_{n}\right)$ linked to the multi-node well are shown for comparison. Selected time steps (TS) and stress periods (SP) discussed in the text are labeled.

\section{Flowing Wells: Special Application of Constraints on Pumping Rate}

The use of constraints can also be applied to simulate discharge from a free-flowing well (or a flowing artesian well). In nonpumped open boreholes, if the head in the well is above a limiting or controlling elevation (such as the elevation of the land surface or the top of the casing), then water should discharge from the aquifer and flow out of the borehole. The flow rate should be proportional to the head difference between the well and the control elevation. Thus, the discharge would decrease, and eventually cease, if the head in the aquifer at or near the well declines over time.

To simulate a flowing well with the MNW2 Package, the user should set $h_{\text {lim }}$ equal to the controlling elevation and specify the desired discharge rate $\left(Q_{d e s}\right)$ at an artificially very high value. With these constraints in place, the model will automatically compute the flow rate discharging from the well as a function of the head difference between $h_{W E L L}$ and $h_{\text {lim }}$, as long as the head in the well is above the controlling elevation. If $h_{W E L L}$ drops below the controlling elevation, then the net discharge from the well will drop to zero, although intraborehole flow will still be allowed. Furthermore, if at a later time the head in the well rises to a level above $h_{\text {lim }}$, then the well will begin to flow again at the land surface.

To illustrate this capability of the constraint option within the MNW2 Package, a problem based on another variant of the Reilly test problem was used. A single-node nonpumping well was placed in layer 35, row 30 , column 270 of the grid and a limiting head set at $h_{\text {lim }}=0.0 \mathrm{ft}$. The node of this cell is located on the plane of symmetry (see fig. 4) at a depth of $172.5 \mathrm{ft}$ below the top of the model, about $125 \mathrm{ft}$ from the impermeable downgradient boundary, and about 9,875 ft from the upgradient boundary. This well was assumed to have a well radius of $0.1333 \mathrm{ft}$, a skin radius of $1.795 \mathrm{ft}$, and a skin hydraulic conductivity of $12.5 \mathrm{ft} /$ day. After an initial equilibrium state is established, the same three single-node pumping wells as described above (for the problem with results described in figure 28) were active for a 150-day stress period and then all three were turned off for a subsequent 300-day stress period. The 150-day stress period was simulated using 15 time steps, and the 300-day stress used 25 time steps; a time-step multiplier of 1.1 was applied in both stress periods. 
The original upgradient multi-node well is not present in this simulation.

The results of this 450-day transient simulation show that initially the head in the aquifer at the depth of the nonpumping single-node well is about $0.62 \mathrm{ft}$ (fig. 29) and greater than the limiting head, which might represent the land surface elevation or the top of an open casing. Therefore, at this time, the well is free flowing at a rate of about $-94 \mathrm{ft}^{3} /$ day. The head in the well is computed to lie at the limiting head $\left(h_{W E L L}=h_{\text {lim }}=0.0 \mathrm{ft}\right)$. Because of the drawdown caused by the discharge from this free-flowing well plus that from the three upgradient single-node pumping wells, both the head and the discharge continue to decrease with time (fig. 29). In the $14^{\text {th }}$ time step of the first transient stress period, the head in the aquifer drops below the value of $h_{\text {lim }}$, so at this time the discharge ceases, and $h_{W E L L}$ equilibrates with the head in the aquifer. Water-level recovery begins at this location about 40 days into the second stress period (after pumping ceases in the three upgradient single-node wells). The head at the well node rises above the value of $h_{\text {lim }}$ at a total elapsed time of about 306 days, and at that time the well begins to flow again. The flow rate then increases with time as the head in the aquifer increases. The water level in the well, however, remains constrained at a value of $h_{\text {lim }}=0.0 \mathrm{ft}$.

\section{Pump Capacity}

The capacity of a pump installed in a well to deliver water depends on several factors, including the size of the pump and the power of the motor. It also depends on the lift, or vertical distance over which the water must be raised. That is, for a constant-speed pump with given characteristics, the yield (or discharge) will vary depending on the lift requirements and other factors. There are a number of reasons why well yields and pump performance might decrease over time (see, for example, Driscoll, 1986). Some involve damage or deterioration to the pump or well screens. Others simply are related to changing heads over time. Driscoll (1986, p. 583) gives an example for a deep-well turbine pump where "the total head would be as low as $60 \mathrm{ft}$ [18.3 meters $(\mathrm{m})$ ] during a season of high water level or minimum withdrawal of water; but during another season, the total head might be $100 \mathrm{ft}$ $(30.5 \mathrm{~m})$ because the water level in the aquifer has decreased or interference from adjacent wells has increased. Under these

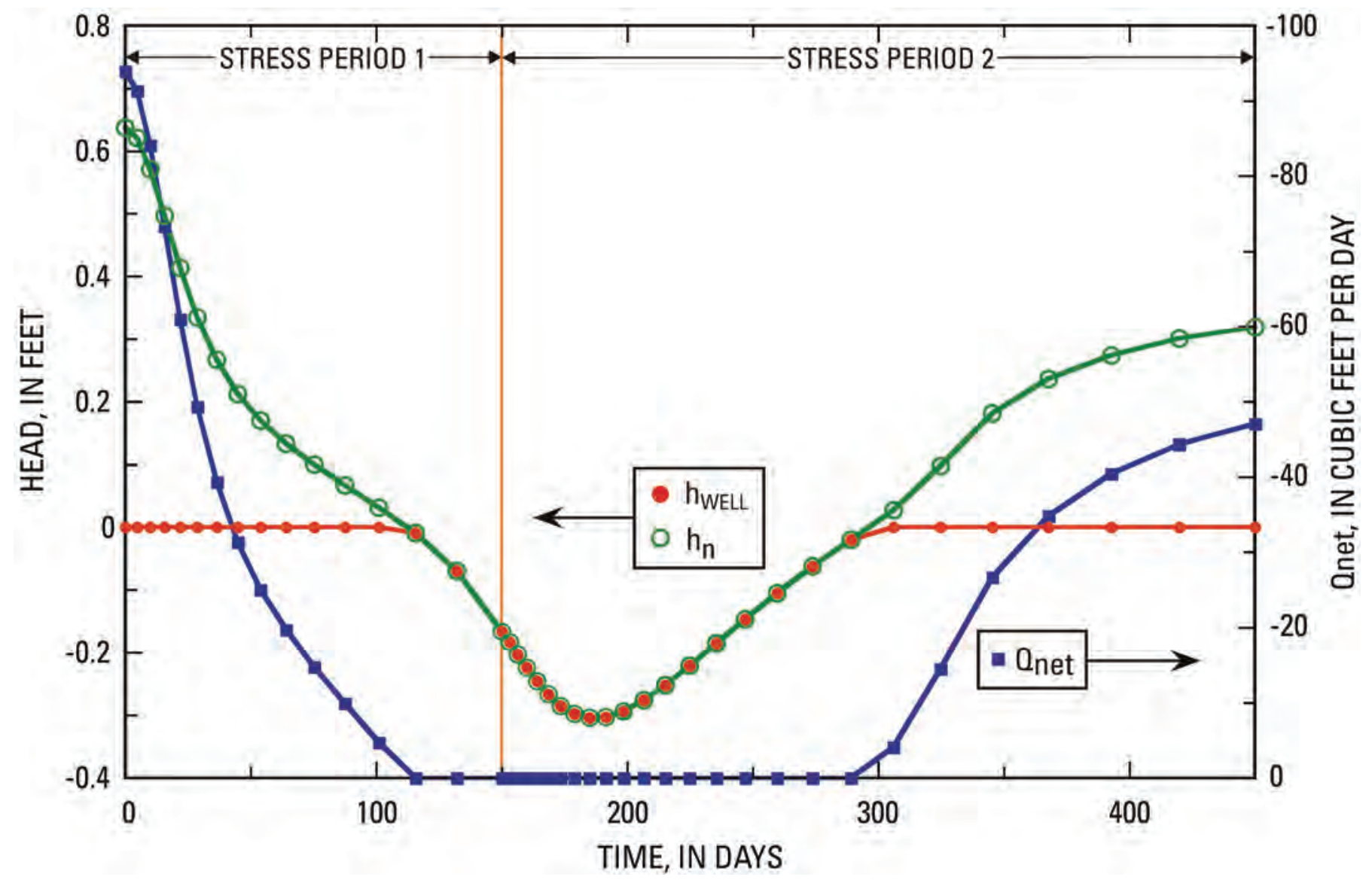

Figure 29. Plot showing relation between computed net discharge $\left(Q_{n e t}\right)$ from a nonpumping, free-flowing, single-node well located close to the downgradient boundary in a variation of the Reilly problem. Shown for comparison are the computed head in the aquifer at the well location $\left(h_{n}\right)$ and the computed water level in the well ( $\left.h_{\text {WELL }}\right)$ for a case in which three upgradient single-node pumping wells are active during the first 150-day transient stress period and inactive during a second 300-day transient stress period. 
conditions, the rate of pumping would range from nearly 1,340 gallons per minute (gpm) $\left[7,300\right.$ cubic meters per day $\left(\mathrm{m}^{3} /\right.$ day)] down to about $620 \mathrm{gpm}\left(3,380 \mathrm{~m}^{3} /\right.$ day)." Driscoll (1986, p. 585) also shows that there is a "shut-off head" at which no flow will occur, which is consistent with Halford and Hanson's (2002, p. 11) statement that it is unrealistic for pump discharge to vary smoothly from the specified rate down to zero.

Boonstra and Soppe (2007) relate pump efficiency and pump performance to the total dynamic head, which they state "is made up of (1) the water-level depth inside the pumped well ...; (2) the above ground lift; and (3) head losses due to friction and turbulence in the discharge pipelines." Conceptually, after pumping starts, the water level in the well will decline over time, and the lift (and total dynamic head) required to discharge at a fixed point and elevation above the land surface will increase. As the total dynamic head increases, more work is required to lift and discharge a unit volume of water and so the discharge from a standard constant-speed pump will tend to decrease. The methods described in this report are not applicable to a variable-speed pump designed to maintain a constant discharge under conditions of changing lift.

Most pump manufacturers provide performance curves for their products that typically include a head-capacity curve relating the total dynamic head to the discharge rate (Boonstra and Soppe, 2007). A hypothetical example set of performance curves having representative shapes is shown in figure 30 . Near the design capacity of the pumps, the curves are steeper and there is a relatively small change in discharge for a unit change in total dynamic head. However, as the lift increases, the curves tend to flatten out and there may be a relatively large change in discharge for a unit change in total dynamic head - until a point is reached where the pump can no longer provide water, and the discharge decreases to zero.

In developing, calibrating, and using a ground-water flow model, there may be cases where it is deemed valuable to incorporate the reduction in well yield with increases in drawdown. Where historical data on discharge from wells are based on metering or other estimates of the total volume produced over a given time period, incorporating these relations may provide little or no added value for model calibration. However, if the model is used to make predictions of future behavior, evaluation of management scenarios, or for small-scale studies near a pumping center, the use of these head-capacity curves may add more realism and defensibility to predictions of future conditions.

The new MNW2 Package allows the user to specify a performance curve (head-capacity curve) for each well. This capability is offered as an option, and the user need not implement it if it is not appropriate to the simulation. The capability is activated by setting input variable PUMPCAP $>0$ in the MNW2 input file. The pump capacity option has a similarity to the option for imposing a constraint on pumpage based on a limiting water level in a well in that both can lead to the well discharge being set to zero in response to water-level declines. However, the reduction in pumpage arising from constraints will be relatively abrupt with no change in discharge over a

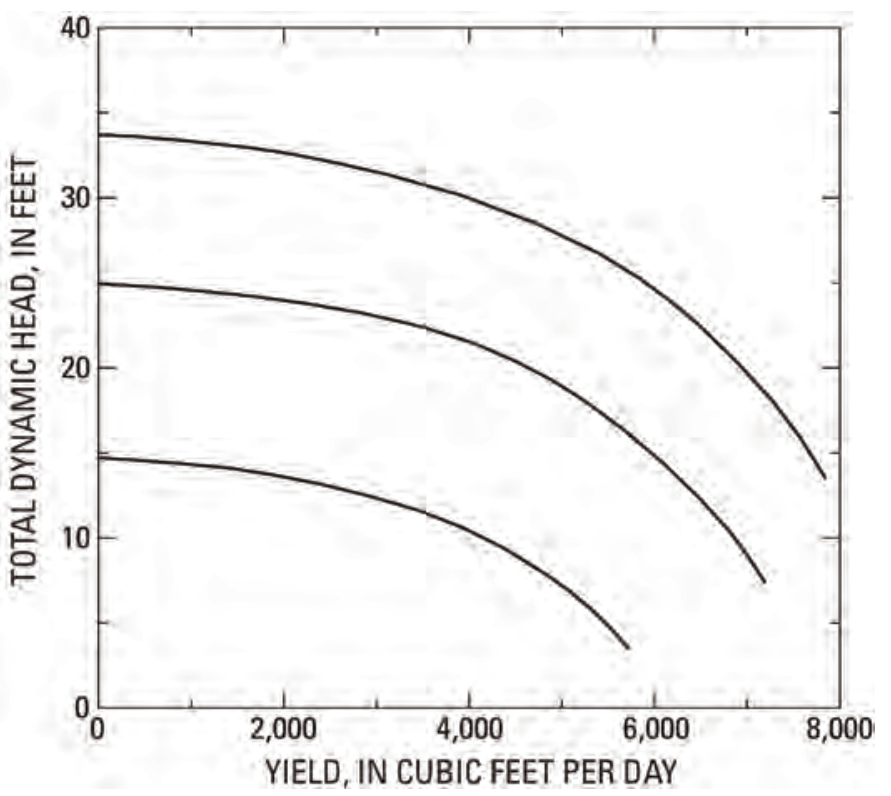

Figure 30. Hypothetical but representative performance (headcapacity) curves for three models (and sizes) of vertical turbine pump, with the top curve representing the largest and most powerful pump.

relatively large range in water levels. Conversely, the reduction in pumpage arising from the pump capacity option will lead to a much more gradual adjustment of the pumping rate over a large range in water levels. Because the constraint based on a limiting water level in the well is linked to the intake location in the borehole, whereas the pump capacity relations are based on the elevation of the outflow (discharge) location, it is possible that a user may want to impose both types of conditions for a single well. In this case, both conditions are evaluated separately, and whichever condition is more constraining (that is, leads to a lesser pumping rate) will take precedence. The pump capacity condition is only allowed for a withdrawal well and is not available for an injection well or a nonpumping well.

If this option is activated, then the user must specify a reference elevation corresponding to the elevation of the discharge point (input variable Hlift). The model will then automatically compute the lift (or total dynamic head) based on the difference between the reference elevation and the most recent calculated water level in the well. If the user wants to account for head loss due to friction and turbulence in the pipes, the reference elevation can be increased proportionately. During successive iterations in solving the flow equation, the MNW2 routines alternate between specifying the MNW2 boundary condition as a fixed head in the well and as a fixed flux. If the pump capacity option is activated, at the beginning of each iteration cycle the MNW2 routines will update the net discharge from the well on the basis of the most recent value of the water level in the well.

The user must input data to approximate the head-capacity curve for the pump. The end points of the applicable curve, representing values of total dynamic head corresponding with both zero discharge and the maximum design discharge, must be specified by use of input variables LIFTq0 and LIETqmax, 
respectively. In addition, a minimum of one additional intermediate point on the curve must be specified. The model will apply linear interpolation to estimate the yield (discharge rate) for any value of total dynamic head between defined points. As seen in figure 31, the more intermediate points that are used, the more accurately the model can follow the curve and estimate the reduction in discharge. For the representative curves shown, even the use of only one intermediate point leads to an error of a few percentage points at most and is probably adequate for many problems. The use of three or four intermediate points leads to a very accurate approximation over the entire range of head.

If the pump-capacity option is active, then after the first iteration in a given time step is completed, the model will determine the lift (total dynamic head) based on the value of the head in the well calculated during the previous iteration. The lift is next used to estimate the net discharge for the next iteration. Because the pump-capacity curves may be nonlinear and, where gently sloping, small changes in lift may induce large changes in discharge, the overall numerical solution may become unstable, fail to converge, or oscillate. To minimize such numerical problems, several steps are taken in the code.

First, to help the numerical solution stabilize, at the beginning of a time step, the updated net discharge will not be applied during the first two iteration cycles. Subsequently, if the estimated discharge changes by less than 1.0 percent from the previous value, then it will be assumed that the net discharge has stabilized, and no further changes related to pump-capacity curves will be allowed during that time step. Because this may

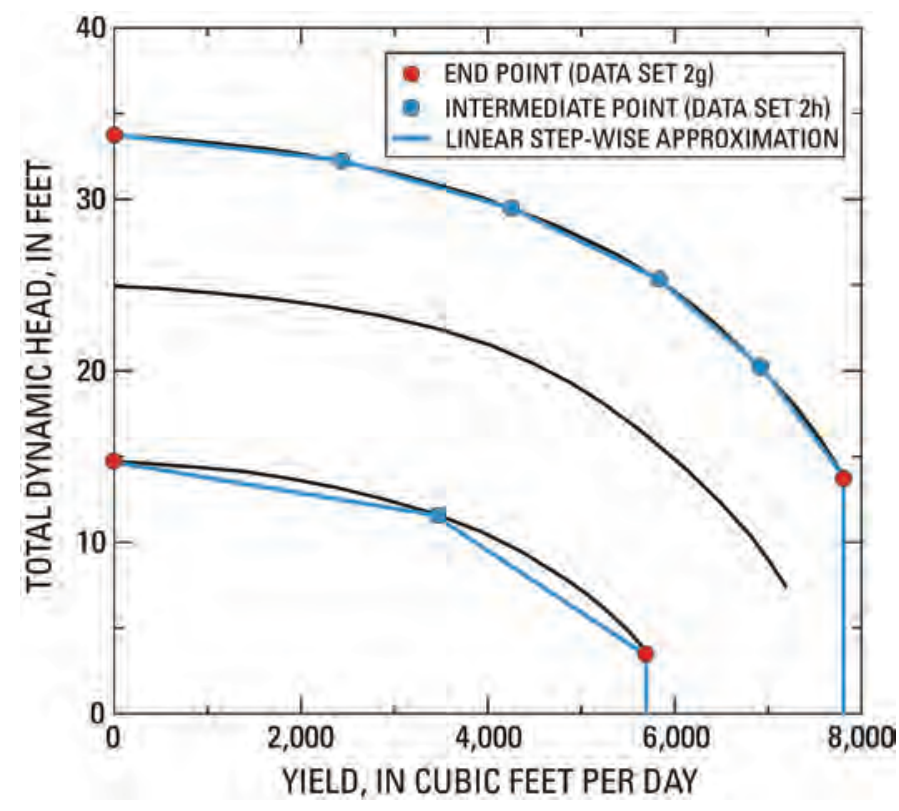

Figure 31. Hypothetical performance (head-capacity) curves for three models (and sizes) of vertical turbine pumps, showing points defined for approximation using linear interpolation for two of the performance curves. The user must always define end points and an optional number of intermediate points (one intermediate point used for the bottom curve and four intermediate points used for the top curve in this example). not occur if the range of head changes during a time step are on a part of the curve where yield is relatively insensitive to changes in head (for example, the steepest part of the top curve on the right side of figure 31), a convergence check is also applied to the changing value of head in the well. Specifically, if the value of $h_{W E L L}$ changes from one iteration to the next by less than a user-specified tolerance, $h_{W E L L}$ will be assumed to have stabilized, and the value of net discharge associated with that latest value of $h_{\text {WELL }}$ will be locked in for the remainder of that time step. (The tolerance, HWto $\mathrm{l}$ in dataset $2 \mathrm{~g}$, is specified as an absolute value and is analogous to the closure criteria HCLOSE in the flow equation solver; the value of HWtol should typically be about 10 to 100 times the value of HCLOSE.) If the pumpcapacity curves indicate a relatively large change in net discharge from one iteration to the next, then the code will limit the change in discharge to a maximum of 25 percent during a single iteration. This constraint, however, precludes the net discharge from reaching the limit of 0.0 if the lift is increasing. Therefore, at the beginning of a new time step, the model also checks the lift to see if the net discharge should equal zero, in which case it is set equal to 0.0. If the net discharge at the start of a time step is zero and the updated lift indicates that it should be increased, then when discharge is first updated, the initial increase will be limited to 50 percent of the calculated value. In spite of these preprogrammed measures to facilitate convergence, numerical problems may still be evident. In such cases, the user may have to change numerical solution tolerances, reduce the time-step size by adjusting the number of time steps or decreasing the time-step multiplier, increase the allowable number of iterations, or adjust the pump-capacity relations.

The model will assume that, for any total dynamic head equal to or less than the minimum-head end point (on the right side of figure 31), the discharge will equal the maximum operating discharge (defined by Qdes in dataset $4 \mathrm{a}$ for a particular well). For any total dynamic head equal to or greater than the maximum-head end point (input variable LIFTq0), the model will assume that the discharge equals zero. If at a later time or subsequent iteration the water level in the well rises sufficiently that the lift does not exceed the maximum total dynamic head, then pumping will resume. The discharge may be turned on again at the beginning of the next time step if the water level is within the operating range of the pump.

To provide the user with flexibility, the option to apply the pump capacity curves can be turned on or off for any particular stress period in MODFLOW. Furthermore, in any given stress period in which the use of pump capacity curves are active, fractional adjustments to the calculated yield are allowed through the use of a multiplication factor. For example, this might be used to represent increased inefficiency of a pump over time due to wear and tear by setting the multiplier to 0.8 for a later stress period. Then all computed yields would be equal to 80 percent of that calculated from the original head-capacity curves. (These options are implemented by use of input variable CapMult in dataset $4 \mathrm{a}$ of the input dataset.)

To test and illustrate the use of head-capacity curves, the Reilly problem was modified so that the long borehole had a 
pump with a characteristic performance curve that followed the upper curve in figures 30 and 31 . The desired pumping rate was set at $-7,800 \mathrm{ft}^{3} / \mathrm{d}$. This pumping rate is artificially high so that the drawdown will be large enough to illustrate clearly the effects of using pump-capacity curves to limit discharge. The option to constrain pumping on the basis of a limiting water level in the well was turned off (that is, Qlimit $=0$ in the input data). The three adjacent pumping wells were also turned off.

In the first test, a 300-day transient stress period followed the initial steady-state stress period. The 300 days were divided into 20 time steps using a time-step multiplier of 1.2. The reference elevation for calculating lift ( $\mathrm{Hlift}$ ) was set equal to $10.0 \mathrm{ft}$, LIFTq0 and LIFTgmax were set equal to $33.75 \mathrm{ft}$ and $13.65 \mathrm{ft}$, respectively, and the pump-capacity curve was defined using the four intermediate points shown for the upper curve in figure 31. The results (fig. 32) show that the net discharge remained unchanged at the desired rate until the fourth time step. During the first three time steps, the calculated lift was sufficiently small that the maximum discharge of the pump was allowed. In the fourth time step, the head in the well fell below $-3.65 \mathrm{ft}$ (yielding a lift exceeding $13.65 \mathrm{ft}$, which is the specified value of LIFTqmax), and the discharge was reduced (see top curve in figure 31). From the fourth time step on, the net discharge from the well was reduced gradually as the head in the well declined (and the pumping lift increased) continually during the remainder of the stress period. By the end of the simulation, the discharge had been reduced by about 15 percent.

A second test was evaluated to assure that the pumpcapacity curves can shut a pump off if the lift increases substantially, as well as allow the pump to be turned back on if the head in the well subsequently rises sufficiently. In this variation of the previous test, heads were simulated for two one-year (365-day) transient stress periods. During the first transient stress period, the three nearby wells were set at discharge rates equal to $-4,000 \mathrm{ft}^{3} / \mathrm{d}$ each, and during the second transient stress period, these three wells were shut off so that heads would recover. During both transient stress periods, the desired discharge from the multi-node well was set equal to $-7,800 \mathrm{ft}^{3} / \mathrm{d}$. Both transient stress periods were simulated using 15 time steps and a time-step multiplier of 1.2. The results (fig. 33) show that the simulated net discharge from the multi-node well was reduced relative to the desired discharge during every time step, until it was reduced to zero during the $12^{\text {th }}$ time step when the head in the well dropped below the value yielding a lift greater than the maximum lift for this pump (in this case, a head in the well of $-23.75 \mathrm{ft}$ for a lift of $33.75 \mathrm{ft}$ ). During the first time step of the second transient stress period, when the three additional nearby wells were shut off, the heads recovered sufficiently quickly such that the pump in the multi-node well was reactivated. The computed net discharge continued to increase as the water levels rose in response to shutting off the three nearby wells.

These two tests indicate that the pump-capacity relations work as expected. Additional tests indicated that, under some circumstances, oscillatory behavior or nonconvergence occurred, but these problems could be eliminated or minimized by adjusting numerical parameters or time-step size. Again, the use of pump-capacity relations is optional, and the user can deactivate it during any one or all stress periods.

\section{Horizontal and Slanted Wells}

Most of the methods and literature about computing water levels in wells represented in numerical models assume that the wells are vertical. Although this is usually the case, the construction and use of horizontal wells is becoming more common, and horizontal wells at depth require slanted (directional) drilling at shallower depths. Halford and Hanson

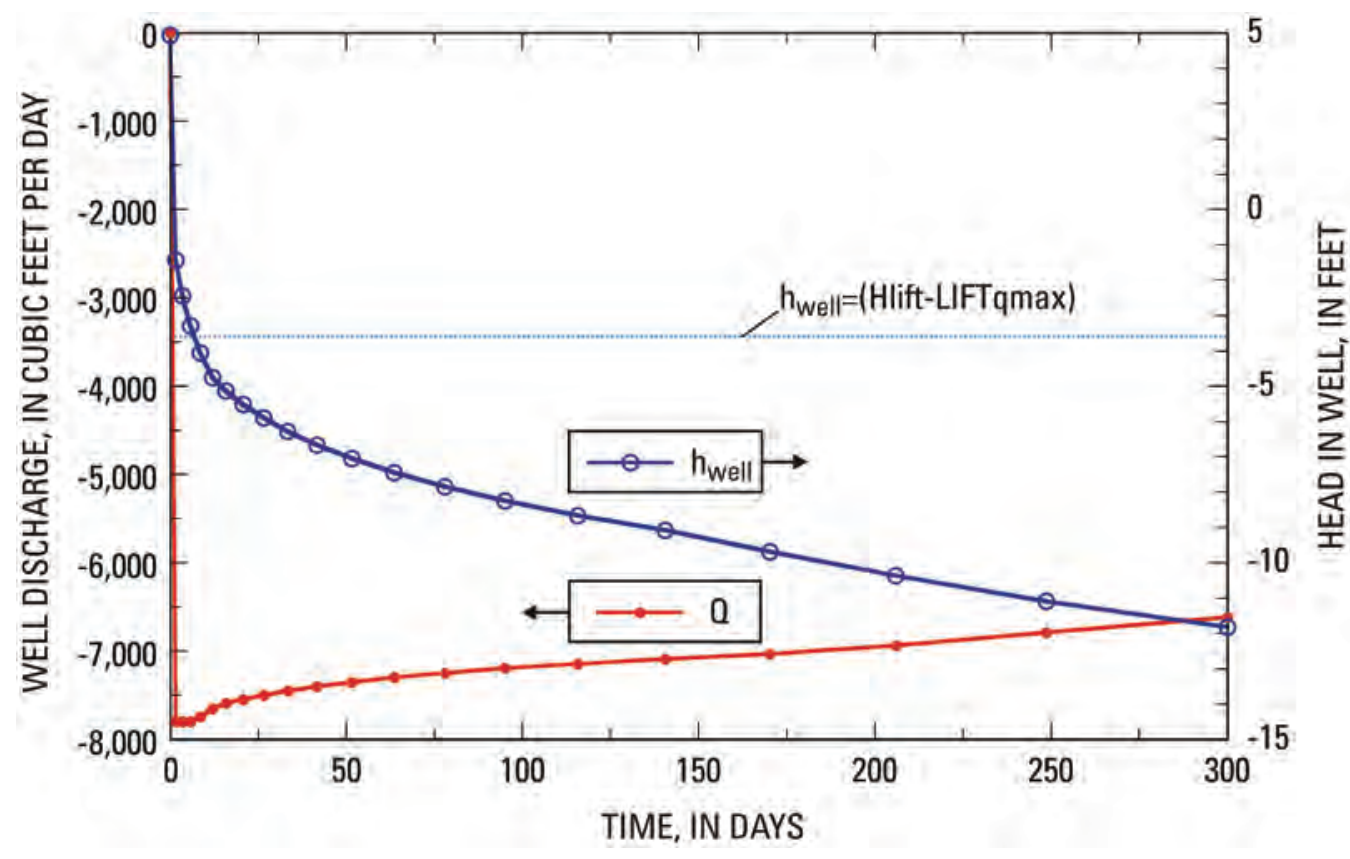

Figure 32. Plot showing results of applying the pumpcapacity relations to the modified Reilly problem in which the desired discharge equals $-7,800$ cubic feet per day for a 300-day transient stress period. When the head in the well equals or exceeds -3.65 feet, the lift is equivalent to that for the maximum discharge of the pump. 
(2002, p. 9) state that for horizontal wells equation 15 "is not a good estimator of cell-to-well conductance $(C W C)$. Suitable equations for estimating $C W C$ of horizontal wells are not well defined." This is also true for slanted wells or slanted sections of wells. Thus, Halford and Hanson (2002, p. 9) recommend that the user "experiment with defining $C W C$ external to MODFLOW and directly specifying appropriate $C W C$ values in the MNW Package input." This approach, though still valid, may create additional work for the user without a clear and objective path to completion. Therefore, MNW2 offers the user an alternate approach for a nonvertical well, in which the model will calculate the appropriate value of $C W C$ on the basis of user-defined well characteristics. These calculations are performed automatically by MNW2 whenever a nonvertical section of open interval is detected for which LOSSTYPE equals THIEM, SKIN, or GENERAL.

As background to our approach, several aspects of hydraulic properties used in a numerical model such as MODFLOW are noted. First, certain hydraulic properties, such as hydraulic conductivity and transmissivity, have effective values that are directionally dependent. Mathematically, these parameters can be characterized as tensors. In three-dimensional space, a tensor is characterized by three orthogonal principal values. In MODFLOW, it is inherently assumed that the three principal directions of the hydraulic conductivity tensor are aligned with the three coordinate axes. The directional properties of a tensor quantity can be represented by an ellipsoid in which the lengths of the semiaxes are directly proportional to the square roots of the principal values of the tensor. Thus, the effective value of the parameter in any direction can be resolved in terms of the equation describing an ellipsoid. Voss and Provost (2002) provide a detailed example of these relations for the dispersion tensor.

The cell-to-well conductance term $(C W C)\left(\mathrm{L}^{2} / \mathrm{T}\right)$ is analogous to the conductance of a streambed, which is proportional to the length of the streambed within a finite-difference cell, as defined in the Streamflow Routing Package (Prudic, 1989).
Finite-difference discretization requires an assumption that a borehole is linear between sequential nodes in a multi-node well. The length of a borehole within a finite-difference cell is constrained by the dimensions of the cell, as determined by the local grid spacing, which can be represented as $\Delta x, \Delta y$, and $\Delta z$ for the grid spacing in the row, column, and layer directions, respectively; these also correspond with terms DELR, DELC, and THCK, as used by Harbaugh and others (2000) to represent the widths of the cell in the row and column directions, and the vertical thickness of the cell, respectively. In a finite-difference grid used for a regional ground-water simulation, the grid spacing in the vertical direction is usually much smaller than in the horizontal directions. Thus, the length within a cell of a vertical borehole is usually equal to the smallest possible dimension of the cell. The length within a cell of a horizontal borehole would typically be much larger than that of a vertical borehole. The longest possible length of a borehole within a cell would occur if it connects the opposite corners of the cell and passes diagonally through the node (fig. 34). Therefore, the borehole length in any direction through a finite-difference cell cannot be characterized by an ellipsoid that has principal directions aligned with the finite-difference grid coordinate axes. Also, if all else is the same, then the cell-to-well conductance increases proportionately with the length of a borehole within a given cell (analogous to the streambed conductance).

If it is assumed that the cell-to-well conductance per unit length in each principal direction is an "intrinsic property" for which the effective value for well alignments other than in the $x-, y$-, and $z$-directions can be estimated using ellipsoidal interpolation (analogous to the hydraulic conductivity tensor), then the effective value of $C W C$ in a cell for a nonvertical linear well or well segment can be estimated from the effective value of the cell-to-well conductance per unit length multiplied by the length of the borehole (as described below).

The linear aquifer-loss coefficient $(A)$, as described for a vertical well by equation 8 , is described first. For a horizontal

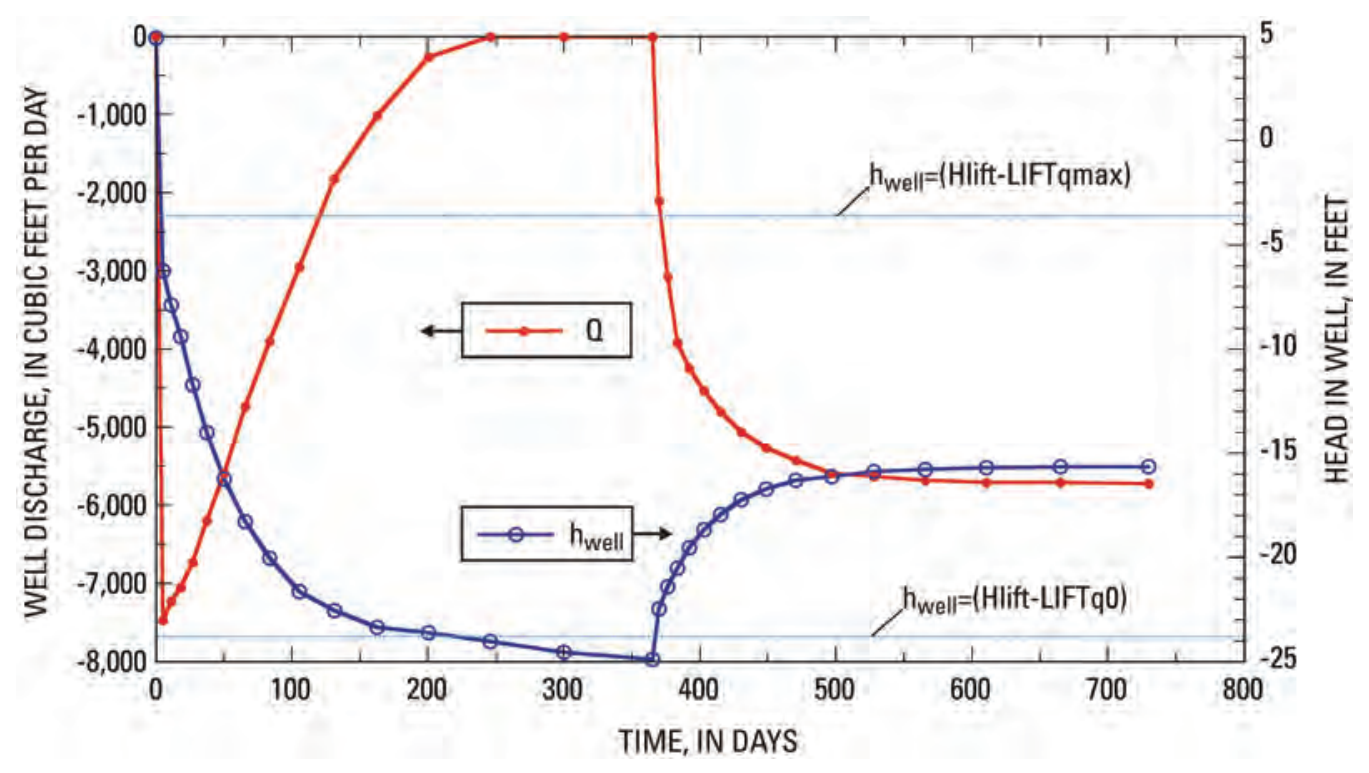

Figure 33. Plot showing results of applying the pump-capacity relations to the modified Reilly problem in which the desired discharge equals $-7,800$ cubic feet per day $\left(\mathrm{ft}^{3} / \mathrm{d}\right)$ for two 365 day transient stress periods with three nearby wells pumping at $-4,000 \mathrm{ft}^{3} / \mathrm{d}$ during the first transient stress period. When the head in the well equals or exceeds -3.65 feet, the lift is equivalent to that for the maximum discharge of the pump. When the head in the well drops below $-23.75 \mathrm{ft}$, the lift is greater than the maximum capacity of the pump and the net discharge becomes zero. 


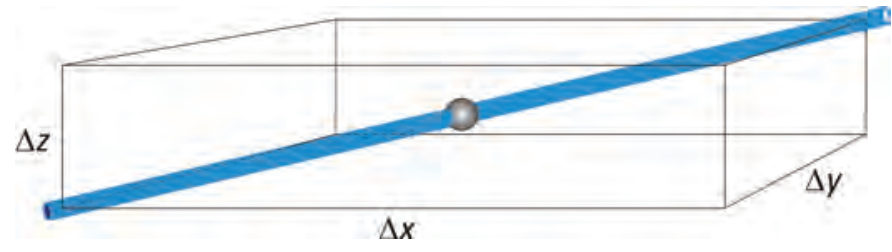

Figure 34. Schematic three-dimensional perspective drawing of a representative finite-difference cell connected to a nonvertical multinode well passing through the block-centered node, the lower-left corner on the front face, and the upper-right corner of the back face of the cell. For visual clarity, vertical spacing $(\Delta z)$ is exaggerated relative to horizontal dimensions compared to a typical grid used in a regional ground-water simulation.

well, the value of $r_{o}$ is recomputed by replacing values of $b$, $K_{x}$, and $K_{y}$ with the appropriate corresponding terms for the new orientation. For example, if a horizontal well extends the full length of the cell and is aligned with (parallel to) the columns of the grid ( $y$-direction) (fig. 35), then

$$
A_{y}=\frac{\ln \frac{r_{o y}}{r_{w}}}{2 \pi \Delta y \sqrt{K_{x} K_{z}}}
$$

where $A_{y}$ is the value of $A$ for a well oriented parallel to the $y$-direction, and $r_{o y}$ is the effective radius of the cell when a horizontal well is oriented parallel to the $y$-direction, also expressed as

$$
r_{o y}=0.28 \frac{\left[\Delta x^{2} \sqrt{\frac{K_{z}}{K_{x}}}+\Delta z^{2} \sqrt{\frac{K_{x}}{K_{z}}}\right]^{1 / 2}}{\left(\frac{K_{z}}{K_{x}}\right)^{1 / 4}+\left(\frac{K_{x}}{K_{z}}\right)^{1 / 4}} .
$$

Similarly, if a horizontal well is aligned with the rows of the grid ( $x$-direction), then

$$
A_{x}=\frac{\ln \left(\frac{r_{o x}}{r_{w}}\right)}{2 \pi \Delta x \sqrt{K_{y} K_{z}}} .
$$

and

$$
r_{o x}=0.28 \frac{\left[\Delta y^{2} \sqrt{\frac{K_{z}}{K_{y}}}+\Delta z^{2} \sqrt{\frac{K_{y}}{K_{z}}}\right]^{1 / 2}}{\left(\frac{K_{z}}{K_{y}}\right)^{1 / 4}+\left(\frac{K_{y}}{K_{z}}\right)^{1 / 4}} .
$$

As noted in figure 35 , it is common that $\Delta z$ will be much smaller than $\Delta x$ or $\Delta y$.

The linear well-loss coefficient $(B)$, as described for a vertical well by equation 10 , is examined next. Start by

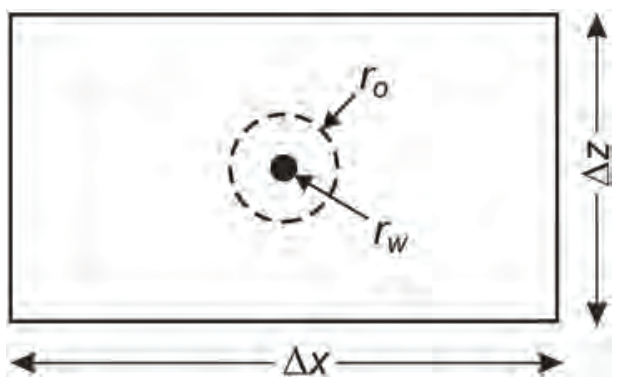

Figure 35. Schematic cross-sectional view of a finite-difference cell containing a horizontal well aligned with the $y$-direction of the grid, showing approximate relation between cell size and equivalent grid-cell radius $\left(r_{o}\right)$, although $\Delta z$ is usually much smaller than $\Delta x$ in regional ground-water models.

assuming that the basic relations represented in equation 10 for a vertical well would also be applicable for a horizontal well. If the properties of the well (including $r_{w}, b_{w}, r_{s k i n}$, and $\left.K_{S K I N}\right)$ are known (or estimated), then extending equation 10 to a horizontal well requires the determination of the proper components of hydraulic conductivity to substitute in the equation on the basis of the orientation of the wellbore in relation to the grid.

For well orientations aligned with the $x$-, $y$-, and $z$-directions, it is assumed that flow into or out of the well is locally in the plane perpendicular to the well and has radial symmetry. In equation 9, the average effective hydraulic conductivity $\left(K_{\text {eff }}=K_{h}\right)$ within the horizontal plane (which is perpendicular to the axis of a vertical well) is taken as the geometric mean of the principal values of the hydraulic conductivity tensor $\left(K_{x}\right.$ and $K_{y}$ ); that is, $K_{\text {eff }}=\sqrt{K_{x} K_{y}}$. Then by analogy, for a horizontal well oriented in the $y$-direction, the effective hydraulic conductivity would be a function of $K_{x}$ and $K_{z}$. Assuming that flow radially into or out of the well is parallel to this plane, the average effective hydraulic conductivity within the plane of radial flow can be computed as the geometric mean of $K_{x}$ and $K_{z}$, or $K_{\text {eff }}=\sqrt{K_{x} K_{z}}$. Substituting appropriate parameters for $b, b_{w}, K_{h}$, and $K_{y}$, yields

$$
B_{y}=\frac{\left(\frac{\Delta y \sqrt{K_{x} K_{z}}}{K_{\text {SKIN }} L_{w}}-1\right) \ln \left(\frac{r_{\text {SKIN }}}{r_{w}}\right)}{2 \pi \Delta y \sqrt{K_{x} K_{z}}},
$$

where $B_{y}$ is the linear well-loss coefficient for the case of a horizontal well oriented in the $y$-direction, and $L_{w}$ is the length of the horizontal well in the cell. Because $L_{w}=\Delta y$ if the horizontal well passes through the entire length of the cell, equation 30 can be further reduced to

$$
B_{y}=\frac{\left(\frac{\sqrt{K_{x} K_{z}}}{K_{S K I N}}-1\right) \ln \left(\frac{r_{S K I N}}{r_{w}}\right)}{2 \pi \Delta y \sqrt{K_{x} K_{z}}} .
$$


Similarly, the linear well-loss coefficient for the case of a horizontal well oriented in the $x$-direction can be computed from

$$
B_{x}=\frac{\left(\frac{\sqrt{K_{y} K_{z}}}{K_{S K I N}}-1\right) \ln \left(\frac{r_{S K I N}}{r_{w}}\right)}{2 \pi \Delta x \sqrt{K_{y} K_{z}}} .
$$

The nonlinear well-loss coefficient $(C)$ and related power term $(P)$ do not explicitly depend on well or aquifer parameters, but are typically derived from certain types of well tests. Thus, given the estimates derived from field tests, no additional adjustments are needed to account for the well being horizontal.

Equations 8, 10, 26, 28, 31, and 32 provide the means to compute $C W C$ for each of three coordinate directions (recalling that no partial penetration corrections are made for nonvertical wells). The cell-to-well conductance per unit length in each principal direction can be represented by $C L_{i}$, where $i$ is the index for the $x$-, $y$-, and $z$-directions. $C L_{i}$ values for wells oriented in the three principal directions can be calculated from a modified version of equation 15 :

$C L_{i}=\left[\frac{\ln \left(\frac{r_{o i}}{r_{w}}\right)}{2 \pi \sqrt{K_{j} K_{k}}}+\frac{\left(\frac{\Delta x_{i} \sqrt{K_{j} K_{k}}}{K_{\text {SKIN }}}-L_{w i}\right) \ln \left(\frac{r_{S K N N}}{r_{w}}\right)}{2 \pi \Delta x_{i} \sqrt{K_{j} K_{k}}}+L_{w i} C Q_{n}^{(P-1)}\right]^{-1}$,

where $i$ is the principal direction aligned with the well, $j$ and $k$ are the two orthogonal principal directions, $\Delta x_{i}$ represents $\Delta x$, $\Delta y$, or $\Delta z$ depending on the orientation of $i$, and $L_{w i}$ represents the length of a hypothetical fully-penetrating well aligned with the principal direction. The values of $\sqrt{C L_{x}}, \sqrt{C L_{y}}$, and $\sqrt{C L_{z}}$ constitute the semiaxes of the ellipsoid. Then, knowing the direction of the well's orientation, the ellipsoid can be used to compute the correct value of $C L$ in that direction. Finally, knowing the length of the well (or well segment) in that direction, multiply $C L_{i}$ by $L_{w}$ (the length of the well in the cell) to compute the value of $C W C$ for the well (or well segment) having that orientation and length.

It is possible that a multi-node well passing through a particular grid cell to which it is connected might change direction at the node (fig. 36) (in fact, direction changes can only occur at nodes). In this case, the value of $C W C$ is computed for each of the two segments in the cell separately because $C W C$ can vary as a function of the well orientation; the total $C W C$ for that cell is taken as the sum of the two components. The total length of the well within the cell is the sum of the lengths of the two segments.

It is assumed that the alignment and orientation of a nonvertical well are adequately described by the line connecting successive active nodes of the multi-node well. The slant (or tilt angle), orientation (direction or angle of well axis relative to the $x$-direction of the MODFLOW grid), and length of that section of the well are determined by MNW2 on the basis of geometric considerations. The orientation and alignment of a nonvertical well or well segment can be given in terms of two angles, $\theta$ and $\omega$, which respectively define the angle in the horizontal plane that the trace of the well makes with the $x$-direction of the model grid and the slant (or tilt angle) of the borehole alignment in the vertical plane containing the well, measured as a deviation from the vertically downward direction (fig. 37). By this convention, for example, a horizontal well oriented parallel to the $x$-direction would have values of $\theta=0^{\circ}$ and $\omega=90^{\circ}$. If a well changes orientation or dip along its length, these same conventions apply to each individual linear segment of a well between two nodes. Because multinode wells are always defined in terms of connected nodes of the MODFLOW grid, well segments are assumed to be linear between nodes (fig. 36). MNW2 will automatically calculate $\theta$ and $\omega$, when appropriate, and the user does not have to specify these values.

If a nonvertical well, as defined by associated grid nodes to which it is connected, passes through a cell not associated with the multi-node well, it is assumed that the part of the well casing that passes through the unconnected cell of the grid is a blank (unperforated) section of casing (fig. 38). Thus, this part of the well does not contribute to the calculated cell-to-well conductance, although it is considered part of the total length of the well. Note that information describing open and closed intervals of a multi-node well are included in certain output files.

By analogy to the development of Voss and Provost (2002), the effective value of cell-to-well conductance per unit length of well $(C L)$ for a well oriented at angles $\theta$ and $\omega$ is calculated from

$$
\frac{1}{C L}=\left(\frac{\cos ^{2} \theta}{C L_{x}}+\frac{\sin ^{2} \theta}{C L_{y}}\right) \sin ^{2} \omega+\left(\frac{1}{C L_{z}}\right) \cos ^{2} \omega
$$

(A.M. Provost, USGS, written commun., 2008). The value of $\mathrm{CL}$ is then defined by

$$
C L=\frac{C L_{x} C L_{y} C L_{z}}{C L_{z}\left(C L_{y} \cos ^{2} \theta+C L_{x} \sin ^{2} \theta\right) \sin ^{2} \omega+C L_{x} C L_{y} \cos ^{2} \omega}
$$

Given the lengths of the two well segments of a multinode well associated with a given node, the cell-to-well conductance for that node can be calculated as:

$$
C W C_{n}=C L_{1} L_{w 1}+C L_{2} L_{w 2}
$$

where the subscripts 1 and 2 refer to the segment number.

The method used to calculate the total length of a well and the length of the two well segments associated with each node of the multi-node well $\left(L_{w}\right)$ is derived from that developed by Konikow and Hornberger (2006b). The method can account for a well that has multiple discrete sections of well screen. The following working assumptions and rules are made for nonvertical wells: 


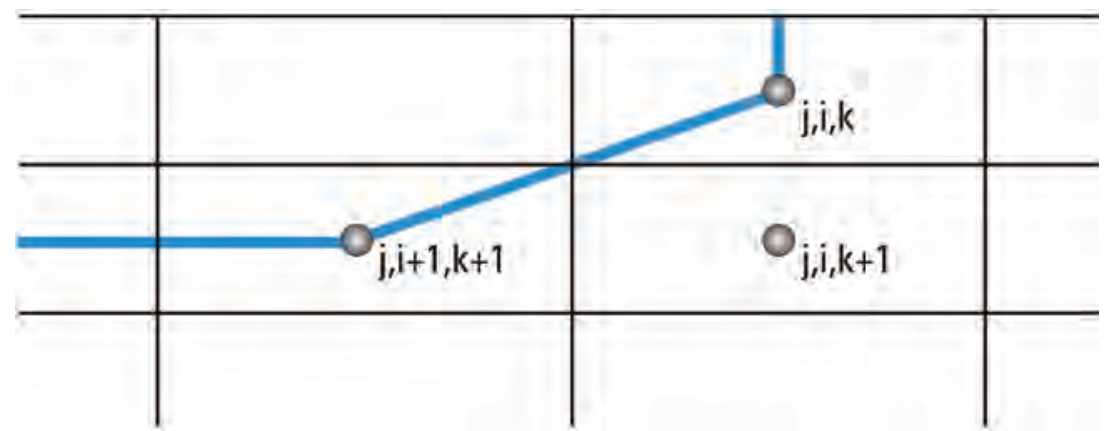

EXPLANATION

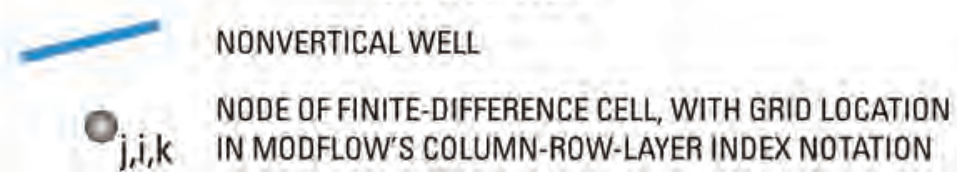

Figure 36. Schematic cross-sectional view to the west of part of a MODFLOW grid containing a multinode well that changes orientation from a vertical well at the surface to a horizontal well in model layer 2. Both cells " $j, i, k$ " and " $j, i+1, k+1$ " contain two well segments that are not aligned in the same direction.

\section{A. TOP VIEW}

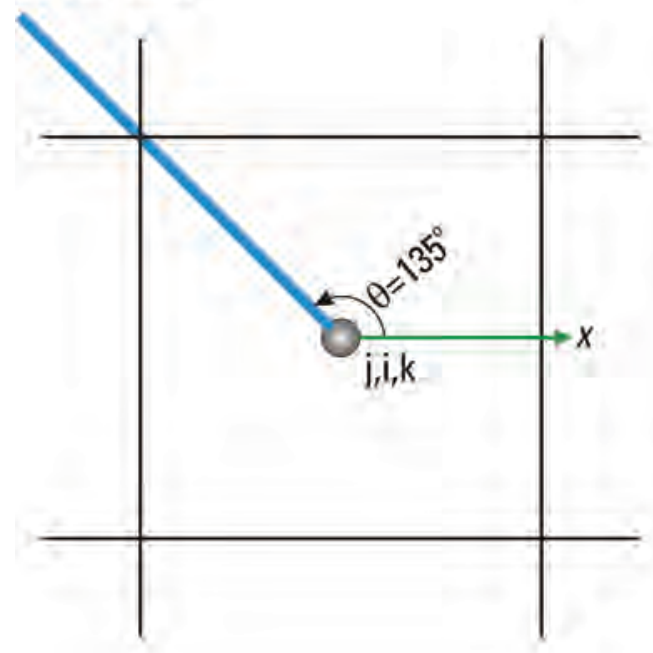

B. SIDE VIEW

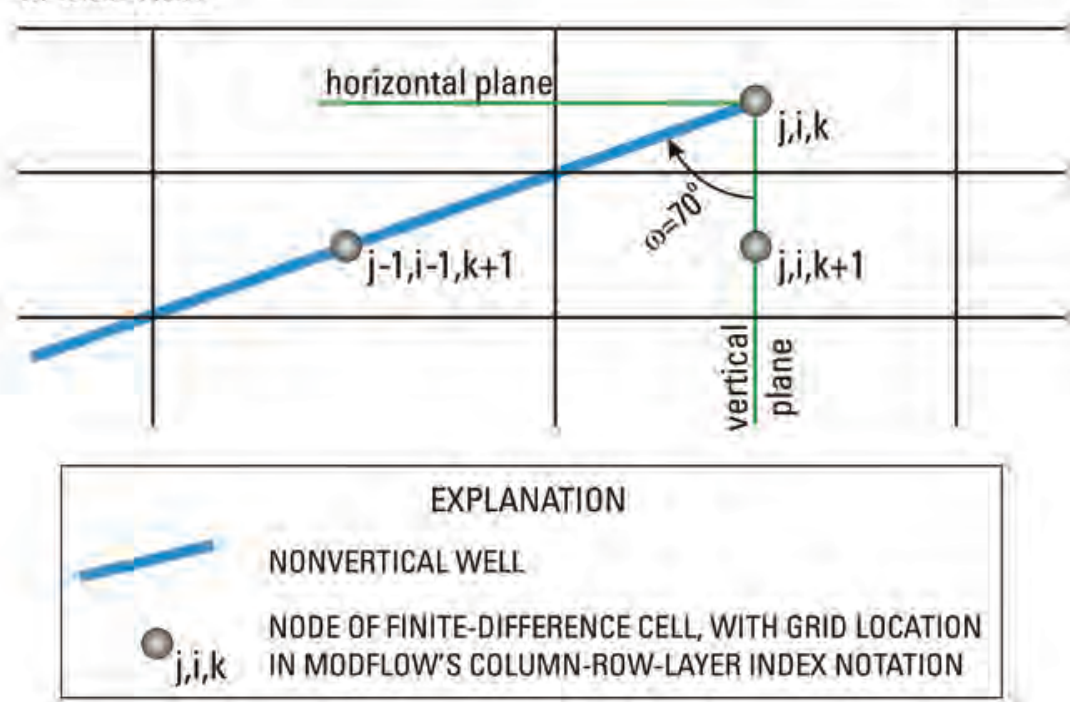

Figure 37. Depiction of orientation and alignment of a nonvertical well on the basis of two characteristic angles. $A$, top (plan) view showing example of well oriented at 135 -degree angle $(\theta)$ from the $x$-direction measured at the cell node " $j, i, k^{\prime}$ connected to the top of the well. $B$, side (cross-sectional) view in the vertical plane containing the well showing the tilt angle $(\omega)$ of approximately 70 degrees as measured from the vertical plane passing through the top node of a well (or of a well section).

- Where a multi-node well is open to the aquifer, the open interval of the well is assumed to pass through the block-centered node in the finite-difference cell; any change in direction or orientation of a well can only occur at the location of the node.

- A well is assumed to fully penetrate each fully saturated cell in which a well node is located (that is, it crosses or touches two cell faces in addition to passing through the node).

- Where a well node is located in an unconfined (convertible) cell, the upper limit of the open interval is defined by the elevation of the water table. If the open intervals are defined by specified elevations, these will further constrain the position and length of the open interval.
- The location, orientation, geometry, and elevations of the well and its open intervals are defined on the basis of (and consistency with) the initial conditions specified for the model. These will not change with time even though the saturated thickness and relative node location in unconfined cells may change with time.

- Each node of a multi-node well has two linear segments associated with it; each segment connects the block-centered node with a cell face through which the borehole enters or exits the cell.

- Nodes for each multi-node well must be listed in sequential order in the input data file, starting with the first node closest to the wellhead at the land surface and ending with the deepest node furthest from the wellhead. 
- The length of the well between two successive nodes of a multi-node well is defined as the distance between those two nodes. If two nodes are not adjacent to each other (such as well nodes " $j, i, k$ " and " $j, i+1, k+2$ " in figure 38), it is assumed that the well is not open to that part of the aquifer represented by the intervening cells.

- The first segment of the first node of a multi-node well is always assumed to be vertical and extend upwards to the land surface (as in figures 38 and 39). Thus, if the first node of the well is not in the uppermost active layer of the model at that location in the grid, where the well passes through higher layers, the casing is closed and the well is not connected to the aquifer (fig. 39).

- The second (last) segment of well screen (or open interval) associated with the final end node of a multinode well is assumed to have an identical length and orientation as the first segment of that well node, with symmetry about the cell node (figs. 39 and 40). For the relatively simple case illustrated in figure 39 , the cumulative length of the two segments of open interval in the fifth well node would be equal to the width of column 5.

- If a node of a multi-node well is unconfined and the water-table elevation is below the top elevation of the well screen, then the length of the open interval is based on its top coinciding with the water table. The length of the well above the water table is considered to be dry, noncontributing, and therefore a component of the closed interval of the well. In a transient simulation, both the open and closed lengths of the well within a cell can change every time step if the watertable elevation and saturated thickness change (fig. 40).

\section{Well Screen Variability}

It is possible for wells to have complex sets of multiple well screens (open intervals), or variable diameter boreholes, or skin properties that vary with depth. The revised MNW2 Package has added a limited capability to deal with such complexities in vertical wells, although the model is inherently limited to one set of composite well properties to be associated with each node of a multi-node well and its associated node of the finite-difference grid. For example, when drilling a well, it is not unusual that the driller will use a larger diameter drill bit and casing for the upper part of the hole and then reduce the bit size and borehole diameter at greater depths. Thus, depending on the relative elevations of the tops and bottoms of model layers, it is possible that the diameter (and radius) of the open interval of a well may change within the thickness interval represented by a particular model layer (fig. 41A). It is also possible that a well may have been constructed with multiple screens and that a well may have different skin properties for different intervals. If the lengths of the screens are short relative to the thickness of a model layer representing an aquifer, then it is possible that more than one screen of a long well may lie within a single model layer (fig. 41B).

Well $A$ (fig. 41) fully penetrates all three model layers into which the aquifer is discretized. However, in this example the larger diameter screen penetrates the upper 40 percent of model layer 2, and the smaller diameter screen penetrates the deeper 60 percent of this cell. In cases like this, the MNW2 Package will compute a cell-to-well conductance value for each section of screen (or open interval) that has unique properties and then compute a length-weighted average conductance value for that node as

$$
C W C_{n}=\frac{\sum_{i=1}^{k} L_{i} C W C_{i}}{\sum_{i=1}^{k} L_{i}}
$$

where $C W C_{n}$ is the effective cell-to-well conductance for the node, $C W C_{i}$ is the calculated cell-to-well conductance for the $i^{\text {th }}$ section of screen, $k$ is the number of sections of screen (open intervals) in the cell, and $L_{i}$ is the length of each section of screen. The average effective well radius would be calculated in the same manner.

If the specifications of top and bottom elevations of well screens indicate that there are multiple well screens within a single model layer (fig. $41 B$ ), then the model will compute the cell-to-well conductance for each interval and then compute a length-weighted average conductance value for that node using equation 37. Conductances are normally computed under an assumption that the screen is open to the full thickness of the model layer in which it is located. In the case where the sum of the lengths of the multiple well screens within the cell is less than the thickness of the cell (such as Well $B$ in figure 41), the effective conductance of the combined length of well screen must be adjusted for the reduced total length relative to the thickness of the cell, and the effects of partial penetration on heads should also be considered. That is, if the sum of the lengths of the well screens in Well $B$ for example, is $40 \mathrm{ft}$ and the thickness of the cell is $100 \mathrm{ft}$, then the cell-to-well conductance would only be 40 percent of that for a fully penetrating length of well screen. Therefore, in such cases, equation 37 above must be modified to account for the effect on cell-to-well conductance of having a shorter total length of screen than the thickness of the cell as

$$
C W C_{n}=\frac{\sum_{i=1}^{k} L_{i} C W C_{i}}{\sum_{i=1}^{k} L_{i}} \times \frac{\sum_{i=1}^{k} L_{i}}{b_{n}}
$$

where $b_{n}$ is the thickness of the cell. In the case where cell-towell conductance values for each screen interval are explicitly specified by the user (under the option in dataset $2 \mathrm{~b}$ of LOSSTYPE=SPECIFYCWC), it is assumed that the specified value of conductance is already appropriate for the actual 

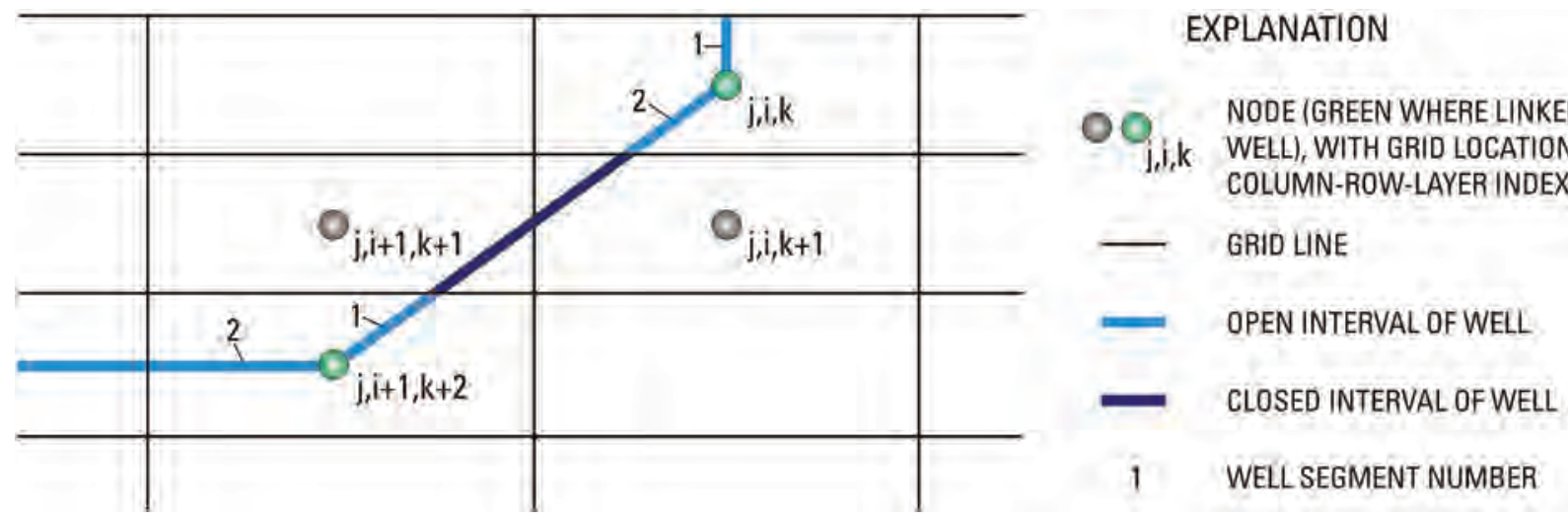

Figure 38. Schematic cross-sectional view (looking west) of part of a MODFLOW grid containing a multi-node well that changes direction and is connected in sequence from node " $j, i, k$ " to node " $j, i+1, k+2$." The casing is assumed to be closed off to both cells in model layer $k+1$ through which the well passes. Each node of the well consists of two segments. A borehole is always assumed to extend vertically from its first node to the top of the model grid.

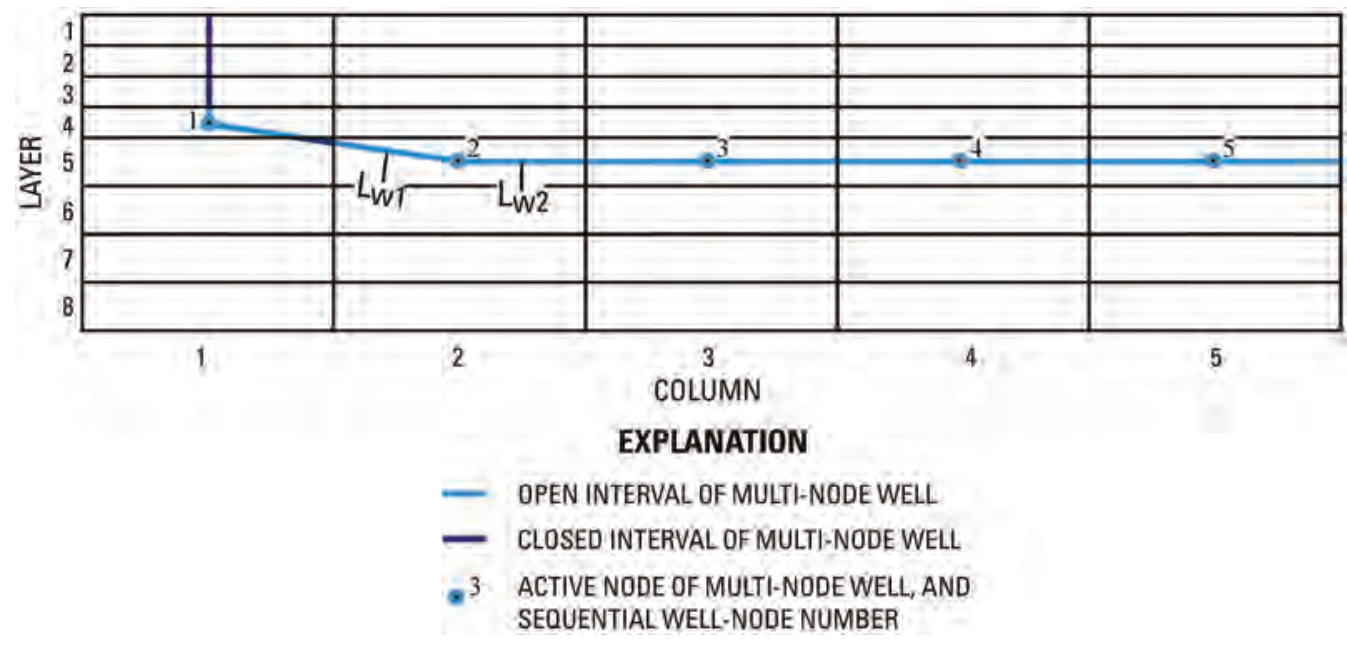

Figure 39. Schematic crosssectional view through a MODFLOW grid showing a mostly horizontal multi-node well open to columns 2 through 5 in layer 5 and column 1 in layer 4 and assumed to extend vertically from the first node to the top of the model to compute total borehole length. The well changes direction at nodes 1 and 2 , and the two segments associated with these two nodes are of unequal lengths; $L_{w 1}$ and $L_{w 2}$ are labeled for node 2. Modified from Konikow and Hornberger (2006b.)
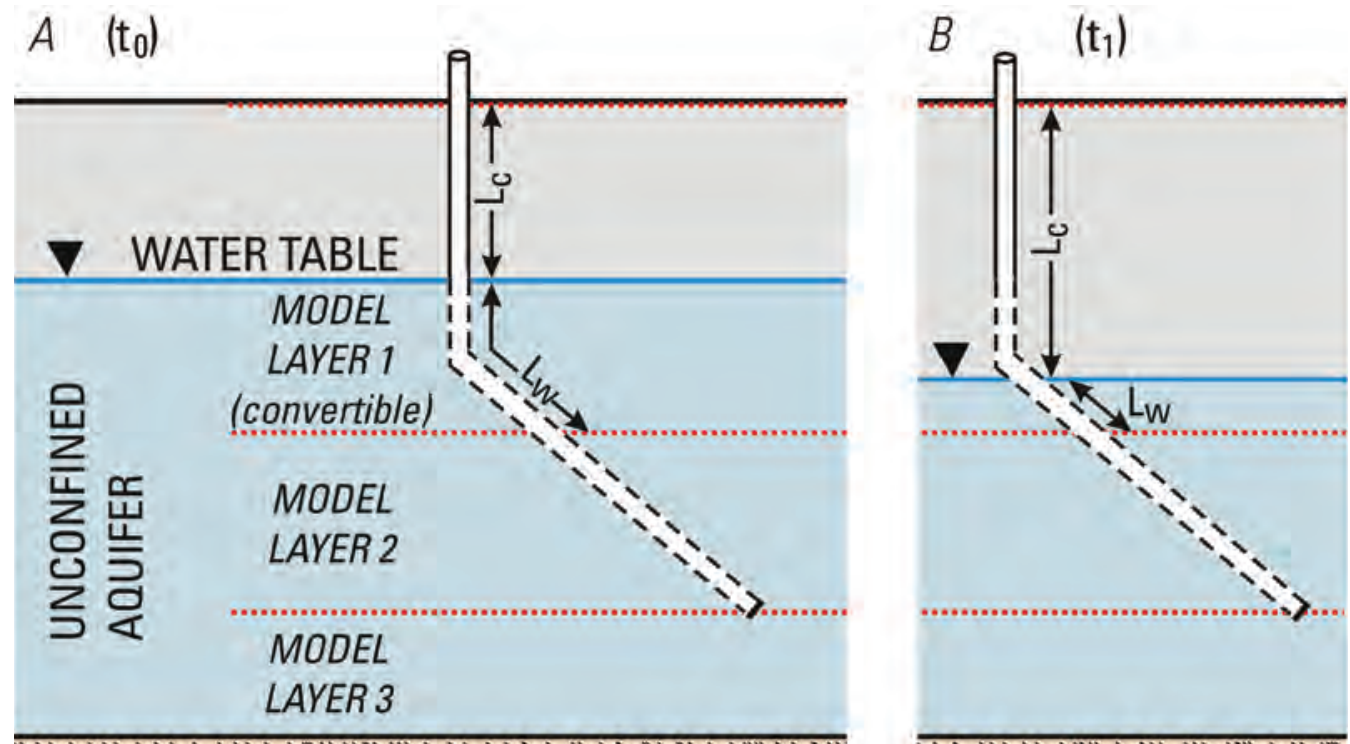

Figure 40. Schematic cross section of an unconfined aquifer represented by three model layers, showing the relation of the open and closed intervals ( $\mathrm{L}_{\mathrm{W}}$ and $\mathrm{L}_{\mathrm{C}}$, respectively) to the position of the water table within unconfined model layer 1. $A$, at the initial time $\left(\mathrm{t}_{0}\right)$, the water table coincides with the top of the vertical well screen segment and $L_{W}$ equals the sum of the lengths of the two segments; $B$, at a later time $\left(\mathrm{t}_{1}\right)$, the water table has declined and part of the well screen is dry, so $\mathrm{L}_{C}$ has increased and $\mathrm{L}_{W}$ has decreased compared to $t_{0}$. 
length of the screen, and no further adjustments are made for its length relative to the layer thickness.

To compute the additional drawdown due to partial penetration effects, the model assumes that the cell contains a single composite well screen (or open interval) having a length equal to the sum of the lengths of all sections of screen, an effective well radius equal to the length-weighted average radius, and an effective cell-to-well conductance as described above. The composite well screen is generally assumed to be centered vertically halfway between the top of the highest individual section of well screen and the bottom of the deepest individual section of well screen (fig. 41). However, if the uppermost active layer is unconfined (or convertible) and contains a partially penetrating composite well screen, it is positioned in the cell so that the bottom of the composite screen is aligned vertically with the bottom of the lowermost screened interval within the cell (fig. 42). This assures that the well will continue to be connected to the cell if the calculated water-table elevation is above the bottom of the deepest part of the actual screen. Similarly, if the uppermost active layer is unconfined (or convertible) and contains a partially penetrating well screen defined by a partial penetration fraction for a node of a multi-node well, then the composite screen is positioned in the cell so that the bottom of the screen is aligned vertically with the bottom of the cell. Note also that in these cases, the user-defined partial penetration fraction and the initial saturated thickness of the cell are used to calculate the length of the screen. This length remains constant with
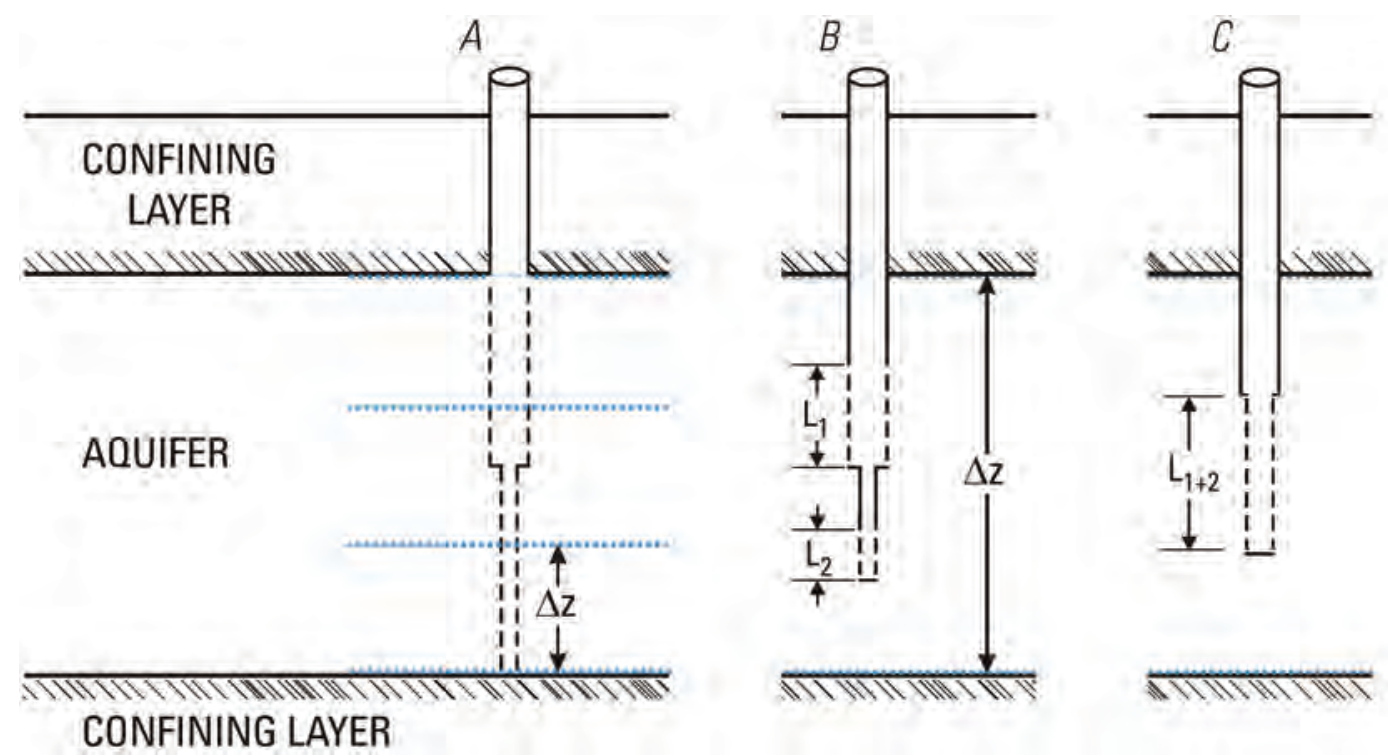

EXPLANATION

i) OPEN INTERVAL

i OFWELL

BOUNDARY OF MODEL LAYER

THICKNESS OF
MODEL LAYER

Figure 41. Diagrammatic cross section showing wells with complex (nonuniform) well screens or open intervals within a model layer. Well $A$ has uniform open intervals in model layers 1 and 3 , but sections with two different well radii in model layer 2 . Well $B$ has two short well screens with different characteristics within a single model layer, which in MNW2 would automatically be replaced by an equivalent composite well screen that is partially penetrating (Well $C$ ).

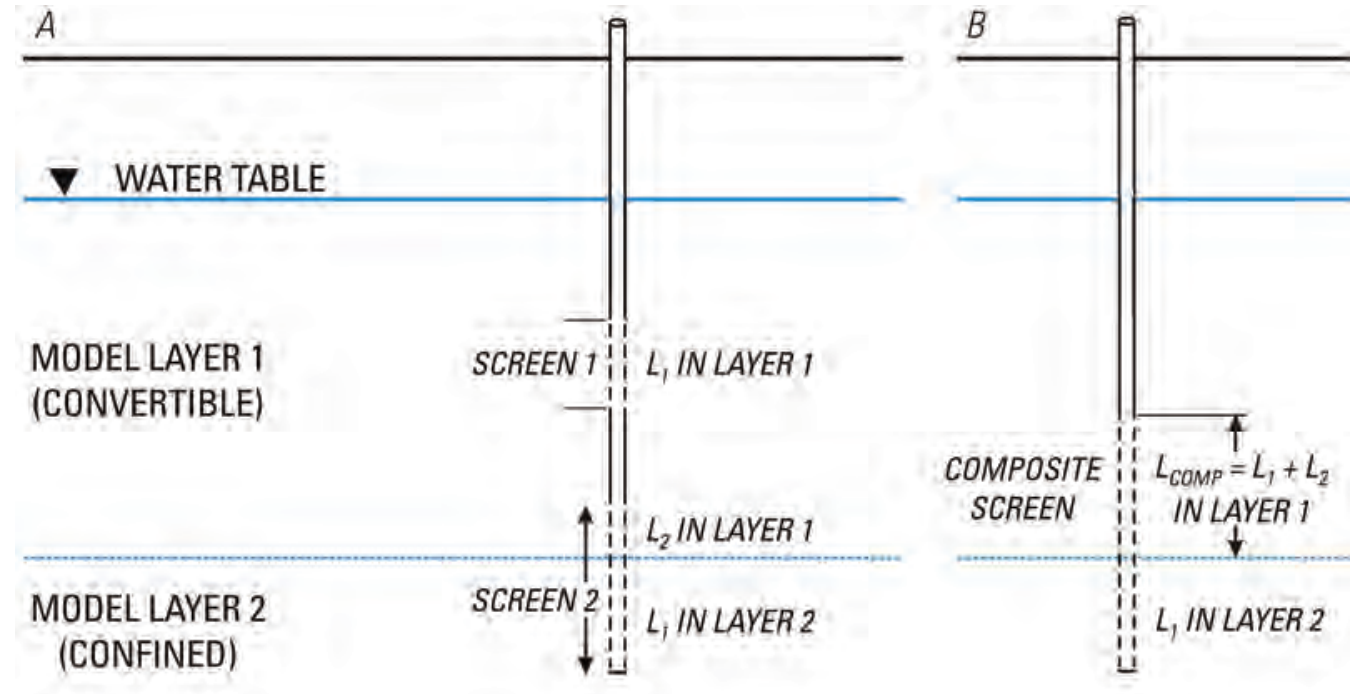

Figure 42. Schematic cross section of an unconfined aquifer showing a multi-node well and the relation of multiple screens in the uppermost model layer $A$, to the length and position of the reconstructed single composite screen in model layer $1 . B$, the position and length of the part of screen 2 in model layer 2 remain fixed. 
time and provides the basis for adjusting the partial penetration fraction if the water table changes position over time in a transient flow simulation.

Given the effective cell-to-well conductance, the effective value of the combined well-loss terms in equation 15 can be computed as

$$
A+B+C Q_{n}^{(P-1)}=\left(C W C_{n}\right)^{-1}
$$

An updated value for the cell-to-well conductance that includes the effects of partial penetration can subsequently be calculated using equation 25 .

MODFLOW allows the simulation to include a quasithree-dimensional representation of a ground-water system; typically, in this mode, a confining unit is not represented explicitly, but instead is represented with an adjusted vertical conductance value connecting the overlying layer with the underlying layer. If a multi-node well passes through such a nonsimulated confining unit, MNW2 assumes that blank casing exists within that interval.

\section{Flow Routing in Borehole}

Flow magnitude, flow velocity, and solute concentration can vary within a long borehole in which inflows and outflows vary along the well screen or open interval. Borehole flow meter surveys and sampling devices (for example, see Izbicki and others, 1999; Paillet, 2001) can collect such data in the field. If the model could calculate these variables, it would provide another type of dataset against which observations could be compared and the reliability of the model assessed or demonstrated. Therefore, the capability to route flow and solute through a multi-node well has been added. Because MNW2 does not compute head losses within a borehole, flow is routed using a relatively simple mass-balance approach similar to that used in the Streamflow Routing Package to route flow downstream from one stream reach to the next (Prudic, 1989; Prudic and others, 2004). MODFLOW calculates the flux between the aquifer and the well at every node. After the numerical solution is obtained for a given time step, the flow from one well node to the next is determined from the net of the exchange with the aquifer and inflow from the previous node.

The MNW1 Package inherently assumes that if a pump is present in a long borehole, the pump intake is located above the first node of the multi-node well. The MNW2 Package adds the flexibility of specifying a pump intake (or discharge point for an injection well) location at any depth or associated with any single node of the multi-node well. This will not affect the calculated head in the well, but will, of course, affect how flow (and solute, if the GWT process is active) is routed through the borehole. Therefore, the net discharge from a well at the location of a pump intake represents another element that must be accounted for in the mass-balance approach to routing flow in the borehole.
The flow routing algorithm is relatively simple. For any node of a multi-node well, routing starts at the node furthest from the wellhead, where by definition there is no inflow from a previous node, so the flux to or from the next node must equal the exchange with the aquifer. In general, the flow from any given node $n$ to the next node closer to the wellhead $(n-1)$ equals the inflow from the further node $(n+1)$ plus or minus the flux between the aquifer and the well at that node (fig. 43). If the pump intake is located in that cell, the net discharge from the well must also be subtracted there. Expressed quantitatively, the flux between adjacent nodes is computed as

$$
Q_{n-1}=Q_{n+1}-Q_{G W}+Q_{n e t}
$$

where $Q$ is a volumetric flux $\left(\mathrm{L}^{3} / \mathrm{T}\right), Q_{n-1}$ is the flow from node $n$ to the next node closer to the wellhead (positive in sign for flow towards the wellhead - which is upwards in a vertical well), $Q_{n+1}$ is the flow from the further node to node $n, Q_{G W}$ is the flux between the aquifer and the well at that node (negative sign for discharge from the aquifer and inflow to the well), and $Q_{\text {net }}$ is the net external discharge directly from the well. Direct external discharge can occur only at the pump intake, which is located at either a user-specified node or (by default) above the first node closest to the wellhead (negative sign indicates discharge from the well).

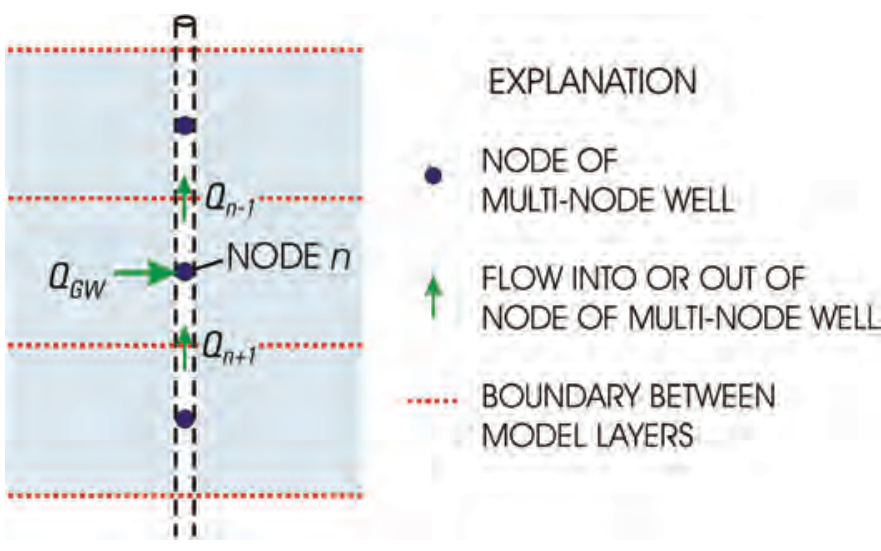

Figure 43. Schematic cross section illustrating components of flow into and out of well segments comprising a representative node (node n) of a multi-node well.

If the GWT process is active, solute mass is also routed between well nodes, and the concentration in a node is calculated using a simple mixing formula, as described by Konikow and Hornberger (2006b, p. 6-8). This approach assumes fluid and solute mass storage within the borehole is negligible over the duration of the time step.

\section{Solute Transport}

Because intraborehole flow can have a substantial effect on nearby ground-water hydraulics, it is logical to infer that it 
can therefore affect solute (or contaminant) distribution in an aquifer system (Konikow and Hornberger, 2006a). This effect has been previously recognized, primarily with respect to the difficulty of obtaining representative water-quality samples from boreholes or monitoring wells with long open intervals or long well screens. Church and Granato (1996) note that borehole flow redistributes water and solutes in the aquifer adjacent to the well, increasing the risk of bias in water-quality samples. Reilly and others (1989) used flow simulations to demonstrate that contaminant monitoring wells with long screens may completely fail to fulfill their purpose in many ground-water environments because of intraborehole flow. They conclude that significant borehole flow can occur in wells with long screens even if they are in relatively homogeneous aquifers with very small vertical head differences in the aquifer. Lacombe and others (1995) noted that abandoned and improperly sealed boreholes may act as conduits for contaminant transport from contaminated zones to previously uncontaminated strata.

Calculating such effects comprehensively requires that solute-transport processes in the ground-water system be simulated. To do this, Konikow and Hornberger (2006b) added the capability to represent multi-node wells to the GWT process of MODFLOW-2000. That capability has been extended to MNW2, and the code modified for the new flow-routing routines in MNW2, which allow a pump intake to be located in any node of the well.

The solute-transport capability was tested and demonstrated by Konikow and Hornberger (2006a,b) using a variant of the Reilly problem in which an initial mass of contaminant was placed in the cells in layer 1 immediately upgradient from the long nonpumping borehole. Solute transport was then simulated in a transport subgrid that included 20 rows, 40 columns, and all 41 layers of the primary MODFLOW grid. The test assumed transient transport for one year in a steady-state flow field. These results were replicated with the new code to assure that MNW2 is compatible with the GWT process.

In MNW2, if the GWT process is active and water is being injected into the well, the concentration in the injected fluid can be specified for the well for each stress period in dataset 4a. The Multi-Node Well Observation (MNWO) Package developed by Konikow and Hornberger (2006b) is now superseded by the MNWI Package documented in this report. This new output package for MNW2 controls the generation of additional separate output files listing detailed information about each multi-node well, including solute concentration information. These files can generate concentration profiles within a borehole and concentration changes over time at each node and in the net discharge of the well.

\section{Code Efficiency}

The features, processes, and options available for simulating multi-node wells offer the MODFLOW model user more flexibility and realistic conditions for simulating wells in ground-water systems. These advantages and additional calculations relative to the standard WEL Package, however, come with a price - specifically the potential for increased computational effort and time, as well as increased memory requirements. To provide a perspective on these computational costs, a range of test cases were run and timed to illustrate relative computational times.

The test cases were all variations of the Reilly problem described previously in this report and all tests included only one multi-node well having 12 nodes. The variants were designed to add small increments of complexity with each successive test case to provide a measure of the computational cost associated with selected features and processes documented in this report. All of these tests assume the properties listed in tables 2 and 3 . For consistency, however, all scenarios tested here use the value of $K_{S K I N}=12.5 \mathrm{ft} / \mathrm{d}$ as listed in table 3 . All tests were solved numerically using the Preconditioned Conjugate Gradient (PCG) method with a head change closure criterion of $1 \times 10^{-5}$, a residual change closure criterion of 0.10 , a maximum number of inner iterations of 30 , and a maximum number of outer iterations of 20 . All transient flow cases were run with an initial steady-state stress period followed by one 365-day transient flow stress period in which the desired discharge from the multi-node well was set at $Q=-4,400 \mathrm{ft}^{3} / \mathrm{d}$. The transient stress periods were always discretized into 20 time steps using a time-step multiplier of 1.1. All tests were run with both the MODFLOW-2000 and MODFLOW-2005 versions of the code on the same personal computer - a Dell workstation with a 3.6 gigahertz Intel Pentium 4 processor and 3 gigabytes of random access memory (RAM). The Fortran code was compiled under Intel Fortran Compiler Integration for Microsoft Visual Studio 2005, version 10.0.3718.2005.

The results of the computational efficiency tests are listed in table 4 . The first test is for the relatively simple case of steady-state flow, which requires just one time step and one stress period; the calculated heads are illustrated in figure 6 . In this case, there was no net discharge from the multi-node borehole, although intraborehole flow was allowed to occur. The solution converged after 393 iterations and required about 24 seconds of central processing unit (CPU) time (for an average computational time of 0.061 seconds per iteration) for both MODFLOW-2000 and MODFLOW-2005. One of the general findings of these tests is that MODFLOW-2005 is consistently slower than MODFLOW-2000 by an average of about 7 percent.

In the first test the intraborehole flow caused some small flux between the well and the aquifer at each of the 12 nodes of the well. When these identical fluxes are simulated using 12 single-node wells in the standard MODFLOW WEL Package rather than with one multi-node well, the numerical solution actually required about 12 percent more iterations and computational time. (The WEL Package input was easily generated using the WEL1 flag in the MNWI Package.)

The remaining cases tested assumed that a 365-day transient-flow stress period followed the steady-state stress period. In the first of these, the total cumulative number of 
Table 4. Computational effort for range of variations of Reilly test problem.

[Abbreviations used: central processing unit, CPU; cubic feet per day, $\mathrm{ft}^{3} / \mathrm{d}$; feet, $\mathrm{ft}$ ]

\begin{tabular}{|c|c|c|c|c|c|c|c|}
\hline \multirow[b]{2}{*}{ Test } & \multirow{2}{*}{ Description of variation of Reilly problem } & \multicolumn{2}{|c|}{ Cumulative iterations } & \multicolumn{2}{|c|}{ CPU time, in seconds } & \multicolumn{2}{|c|}{$\begin{array}{l}\text { Time per iteration, in } \\
\text { seconds }\end{array}$} \\
\hline & & $\begin{array}{c}\text { MODFLOW- } \\
2000\end{array}$ & $\begin{array}{c}\text { MODFLOW- } \\
2005\end{array}$ & $\begin{array}{c}\text { MODFLOW- } \\
2000\end{array}$ & $\begin{array}{c}\text { MODFLOW- } \\
2005\end{array}$ & $\begin{array}{l}\text { MODFLOW- } \\
2000 \\
\end{array}$ & $\begin{array}{l}\text { MODFLOW- } \\
2005\end{array}$ \\
\hline & Steady-state flow with MNW2 & 393 & 393 & 24 & 24 & 0.061 & 0.061 \\
\hline & Steady-state flow with WEL Package & 440 & 440 & 25 & 26 & 0.057 & 0.059 \\
\hline & Transient with MNW2, $\mathrm{Q}=-4,400 \mathrm{ft}^{3} / \mathrm{d}$ & 3,563 & 3,574 & 182 & 202 & 0.051 & 0.057 \\
\hline & Transient with well package & 3,505 & 3,455 & 187 & 212 & 0.053 & 0.061 \\
\hline & Transient, MNW2, three nearby wells $\left(\mathrm{Q}=-4,000 \mathrm{ft}^{3} / \mathrm{d}\right.$ each $)$ & 5,584 & 5,542 & 287 & 308 & 0.051 & 0.056 \\
\hline & Same, with partial penetration fraction $=0.2$ in node 1 & 5,442 & 5,437 & 270 & 303 & 0.050 & 0.056 \\
\hline 7 & Same as 5, with constraints and $h_{\text {lim }}=-7.5 \mathrm{ft}$, Qfrcmn $=0.10, Q \mathrm{frcmx}=0.20$ & 6,527 & 6,513 & 331 & 349 & 0.051 & 0.054 \\
\hline 8 & Same as 5 , with two lowest nodes offset vertically (nonvertical well) & 5,364 & 5,378 & 276 & 293 & 0.051 & 0.054 \\
\hline & Same as 5 , but pump capacity option active & 5,983 & 5,986 & 315 & 340 & 0.053 & 0.057 \\
\hline 10 & Same as 5 , with minimal output & 5,584 & 5,542 & 284 & 307 & 0.051 & 0.055 \\
\hline
\end{tabular}

iterations and the total computational time increased by nearly a factor of 10 (test 3 in table 4). When this test was rerun representing the 12 nodes of the multi-node well by 12 singlenode wells (test 4 ), the simulation ran slightly more efficiently (though it should be noted that the distribution of discharge values among the 12 nodes could not be predetermined using the standard WEL Package and that with MNW2 the flows at the nodes may change each time step whereas flows are fixed during a stress period with the standard WEL Package).

When three single-node pumping wells are added to the system close to the multi-node well, local drawdowns are increased and hydraulic gradients are somewhat steeper. This condition (test 5) resulted in substantially greater computational effort, although the time per iteration remained about the same. The next test (test 6) assessed the effects of partial penetration calculations by modifying test 5 by specifying the partial penetration fraction for the uppermost node of the multi-node well to 0.2 . This yielded a slight reduction in the cumulative number of iterations and total computational time. When test 5 was modified by adding constraints (test 7), the computational effort increased by 15 percent for MODFLOW-2000 and 13 percent for MODFLOW-2005. When test 5 was modified so that the multi-node well was not vertical (test 8 ), the total number of iterations and the total CPU time decreased slightly. When test 5 was modified by activating the pump capacity option and constraining discharge accordingly (test 9), the total cumulative number of iterations increased by about 7 percent and 8 percent for MODFLOW-2000 and MODFLOW-2005, respectively. When test 5 was rerun but output options were specified to eliminate writing optional output files, the total computational time was reduced by about 1 percent for MODFLOW-2000 and about 0.3 percent for MODFLOW-2005.

The results of these tests give a sense of the computational burden associated with use of the MNW2 Package. Of course, results will vary for different computers and for different problems.

\section{Summary and Conclusions}

The MNW2 Package allows MODFLOW to simulate long wells (or boreholes) that extend beyond a single model node, which allows more accurate and realistic representations of field conditions for minimal computational costs. Because long wells can be open or connected to different parts of a ground-water flow system that have differing heads, flow can occur within a borehole even if it is not pumped.

This update to the MNW1 Package simplifies the input data structure and allows the calculation of partial penetration effects in the borehole, the specification of the location of the pump intake, discharge to change during a time step in response to changes in pumping lift, improved conductance calculations for nonvertical wells, the presence of a seepage face in the borehole, and additional output options. The basic calculation procedure of Halford and Hanson (2002), which for simplification assumes no head loss within a borehole, remains unchanged. However, the MNW2 Package routes flow within the borehole, which facilitates comparisons with borehole flowmeter surveys and enables more accurate simulations of solute transport. The MNW2 Package is compatible with MODFLOW-2000 (Harbaugh and others, 2000) and MODFLOW-2005 (Harbaugh, 2005).

In some cases, intraborehole flow and solute transport through long boreholes can facilitate the movement of contaminants through a ground-water system and thereby need to be recognized when calculating changes in concentration in the system. The MNW2 Package is also compatible with the MODFLOW-GWT solute-transport model to facilitate such simulations. MNW2 routes solute, as well as flow, through the borehole when MODFLOW-GWT is active.

\section{Acknowledgments}

The authors appreciate the helpful review comments provided by USGS colleagues P.M. Barlow, C.E. Heywood, and 
C.D. Langevin. We also thank A.M. Provost of the USGS for his helpful discussions in developing the method to estimate conductance for nonvertical wells.

\section{References Cited}

Anderson, M.P., and Woessner, W.W., 1992, Applied groundwater modeling - Simulation of flow and advective transport: San Diego, Calif., Academic Press, 381 p.

Barlow, P.M., and Moench, A.F., 1999, WTAQ-A computer program for calculating drawdowns and estimating hydraulic properties for confined and water-table aquifers: U.S. Geological Survey Water-Resources Investigations Report 99-4225, $74 \mathrm{p}$.

Bennett, G.D., Kontis, A.L., and Larson, S.P., 1982, Representation of multiaquifer well effects in three-dimensional groundwater flow simulation: Ground Water, v. 20, no. 3 , p. 334-341.

Boonstra, Hans, and Soppe, Richard, 2007, Well design and construction, chap. 11 of Delleur, J.W., ed., The handbook of groundwater engineering ( $2^{\mathrm{d}}$ ed.): Boca Raton, Fla., CRC Press, p. 11.1-11.30.

Chenaf, Djaouida, and Chapuis, R.P., 2007, Seepage face height, water table position, and well efficiency at steady state: Ground Water, v. 45 , no. 2 , p. $168-177$, doi: 10.1111/j.1745-6584.2006.00277.x.

Church, P.E., and Granato, G.E., 1996, Bias in ground-water data caused by well-bore flow in long-screen wells: Ground Water, v. 34, no. 2, p. 262-273.

Cooley, R.L., and Cunningham, A.B., 1979, Consideration of energy loss in theory of flow to wells: Journal of Hydrology, v. 43 , p. $161-184$.

Dougherty, D.E., and Babu, D.K., 1984, Flow to a partially penetrating well in a double-porosity reservoir: Water Resources Research, v. 20, no. 8, p. 1116-1122.

Driscoll, F.G., 1986, Groundwater and wells (2 ed.): St. Paul, Minn., Johnson Filtration Systems, Inc., 1089 p.

Earlougher, R.C., Jr., 1977, Advances in well test analysis: Society of Petroleum Engineers of AIME, Dallas, Tex., $264 \mathrm{p}$.

Fanchi, J.R., Kennedy, J.E., and Dauben, D.L., 1987, BOAST II: A three-dimensional, three-phase black oil applied simulation tool: U.S. Department of Energy Report DOE/ BC/-88/2/SP.

Giddings, Todd, 1987, What is an adequate screen length for monitoring wells? Opinion I: Ground Water Monitoring Review, v. 7, no. 2, p. 96-97.
Halford, K.J., and Hanson, R.T., 2002, User guide for the drawdown-limited, Multi-Node Well (MNW) Package for the U.S. Geological Survey's modular three-dimensional ground-water flow model, versions MODFLOW-96 and MODFLOW-2000: U.S. Geological Survey Open-File Report 02-293, $33 \mathrm{p}$.

Hanson, R.T., Li, Zhen, and Faunt, C.C., 2004, Documentation of the Santa Clara Valley regional ground-water/ surface-water flow model, Santa Clara County, California: U.S. Geological Survey Scientific Investigations Report 2002-5231, 85 p.

Hanson, R.T., and Nishikawa, Tracy, 1996, Combined use of flowmeter and time-drawdown data to estimate hydraulic conductivities in layered aquifer systems: Ground Water, v. 34 , no. 1, p. $84-94$.

Harbaugh, A.W., 2005, MODFLOW-2005, The U.S. Geological Survey modular ground-water model-The groundwater flow process: U.S. Geological Survey Techniques and Methods 6-A16, $238 \mathrm{p}$.

Harbaugh, A.W., Banta, E.R., Hill, M.C., and McDonald, M.G., 2000, MODFLOW-2000, The U.S. Geological Survey modular ground-water model-User guide to modularization concepts and the ground-water flow process: U.S. Geological Survey Open-File Report 00-92, 121 p.

Harbaugh, A.W., and McDonald, M.G., 1996, User's documentation for MODFLOW-96, an update to the U.S. Geological Survey modular finite-difference ground-water flow model: U.S. Geological Survey Open-File Report 96-485, $56 \mathrm{p}$.

Izbicki, J.A., Christensen, A.H., and Hanson, R.T., 1999, U.S. Geological Survey combined well-bore flow and depthdependent water sampler: U.S. Geological Survey Fact Sheet 196-99, 2 p.

Jacob, C.E., 1947, Drawdown test to determine effective radius of artesian well: Transactions of the American Society of Civil Engineers, v. 112, p. 1047-1070.

Jacob, C.E., 1963, Correction of drawdowns caused by a pumped well tapping less than the full thickness of an aquifer, in Bentall, Ray, ed., Methods of determining permeability, transmissibility and drawdown: U.S. Geological Survey Water-Supply Paper 1536-I, p. 272-282.

Kaleris, Vasilios, 1989, Inflow into monitoring wells with long screens, in Kobus, H.E., and Kinzelbach, Wolfgang, eds., Contaminant transport in groundwater: Rotterdam, Netherlands, A.A. Balkema, p. 41-50.

Konikow, L.F., Goode, D.J., and Hornberger, G.Z., 1996, A three-dimensional method-of-characteristics solute-transport model (MOC3D): U.S. Geological Survey Water-Resources Investigations Report 96-4267, 87 p. 
Konikow, L.F., and Hornberger, G.Z., 2006a, Modeling effects of multi-node wells on solute transport: Ground Water, v. 44, no. 5, p. 648-660, doi: $10.1111 /$ j.17456584.2006.00231.x

Konikow, L.F., and Hornberger, G.Z., 2006b, Use of the Multi-Node Well (MNW) Package when simulating solute transport with the MODFLOW ground-water transport process: U.S. Geological Survey Techniques and Methods 6-A15, $34 \mathrm{p}$.

Kozeny, Josef, 1933, Theorie und berechnung der brunnen: Wasserkraft und Wasserwirtschaft, v. 28, p. 88-92, 101-105, 113-116.

Kruseman, G.P., and de Ridder, N.A., 1990, Analysis and evaluation of pumping test data ( $2^{\mathrm{d}} \mathrm{ed}$.): Wageningen, Netherlands, International Institute for Land Reclamation and Improvement Publication 47, $377 \mathrm{p}$.

Lacombe, S., Sudicky, E.A., Frape, S.K., and Unger, A.J.A., 1995, Influence of leaky boreholes on cross-formational groundwater flow and contaminant transport: Water Resources Research, v. 31, no. 8, p. 1871-1882.

Lohman, S.W., 1972, Ground-water hydraulics: U.S. Geological Survey Professional Paper 708, 70 p.

McDonald, M.G., 1984, Development of a multi-aquifer well option for a modular ground-water flow model, in Proceedings of the National Water Well Association Conference on Practical Applications of Ground Water Models: Columbus, Ohio, National Water Well Association, p. 786-796.

McDonald, M.G., and Harbaugh, A.W., 1988, A modular three-dimensional finite-difference ground-water flow model: U.S. Geological Survey Techniques of WaterResources Investigations Techniques and Methods 6-A1, $576 \mathrm{p}$.

Moench, A.F., 1993, Computation of type curves for flow to partially penetrating wells in water-table aquifers: Ground Water, v. 31, no. 6, p. 966-971.

Moench, A.F., 1997, Flow to a well of finite diameter in a homogeneous, anisotropic water table aquifer: Water Resources Research, v. 33, no. 6, p. 1397-1407.

Neville, C.J., and Tonkin, M.J., 2004, Modeling multiaquifer wells with MODFLOW: Ground Water, v. 42, no. 6, p. $910-919$.

Paillet, F.L., 2001, Hydraulic head applications of flow logs in the study of heterogeneous aquifers: Ground Water, v. 39, no. 5, p. 667-675.

Paillet, F.L., Williams, J.H., Oki, D.S., and Knutson, K.D., 2002, Comparison of formation and fluid-column logs in a heterogeneous basalt aquifer: Ground Water, v. 40, no. 6 , p. $577-585$.
Peaceman, D.W., 1983, Interpretation of well-block pressures in numerical reservoir simulation with nonsquare grid blocks and anisotropic permeability: Society of Petroleum Engineers Journal, v. 23, no. 3, p. 531-543.

Planert, Michael, 1997, Documentation of a computer program to estimate the head in a well of finite radius using the U.S. Geological Survey modular finite difference ground-water flow model: U.S. Geological Survey Open-File Report 96-651A, $11 \mathrm{p}$.

Pollock, D.W., 1994, User's Guide for MODPATH/MODPATH-PLOT, version 3: A particle tracking post-processing package for MODFLOW, the U. S. Geological Survey finite-difference ground-water flow model: U. S. Geological Survey Open-File Report 94-464, 248 p.

Prickett, T.A., 1967, Designing pumped well characteristics into electric analog models: Ground Water, v. 5, no. 4, p. $38-46$.

Prudic, D.E., 1989, Documentation of a computer program to simulate stream-aquifer relations using a modular, finite-difference, ground-water flow model: U.S. Geological Survey Open-File Report 88-729, 113 p.

Prudic, D.E., Konikow, L.F., and Banta, E.R., 2004, A new Streamflow-Routing (SFR1) Package to simulate streamaquifer interaction with MODFLOW-2000: U.S. Geological Survey Open-File Report 2004-1042, 95 p.

Ramey, H.J., Jr., 1982, Well-loss function and the skin effect-A review, in Narasimhan, T.N., ed., Recent trends in hydrogeology: Boulder, Colo., The Geological Society of America Special Paper 189, p. 265-271.

Reilly, T.E., Franke, O.L., and Bennett, G.D., 1989, Bias in groundwater samples caused by wellbore flow: Journal of Hydraulic Engineering, v. 115, no. 2, p. 270-276.

Rorabaugh, M.I., 1953, Graphical and theoretical analysis of step-drawdown test of artesian well: Transactions, American Society of Civil Engineers, v. 79, no. 362, 23 p.

Rutledge, A.T., 1991, An axisymmetric finite-difference flow model to simulate drawdown in and around a pumped well: U.S. Geological Survey Water-Resources Investigations Report 90-4098, 33 p.

Stehfest, Harald, 1970, Numerical inversion of Laplace transforms: Communications of the Association for Computing Machinery, v. 13, no. 1, p. 47-49.

Theis, C.V., 1935, The relation between the lowering of the piezometric surface and the rate and duration of discharge of a well using ground-water storage: Transactions, American Geophysical Union, v. 16, p. 519-524.

Thiem, Günther, 1906, Hydrologische methoden: Leipzig, Germany, J.M. Gebhart, 56 p. 
Trescott, P.C., Pinder, G.F., and Larson, S.P., 1976, Finitedifference model for aquifer simulation in two dimensions with results of numerical experiments: U.S. Geological Survey Techniques of Water-Resources Investigations, book 7 , chap. C1, $116 \mathrm{p}$.

Voss, C.I. and Provost, A.M., 2002, SUTRA, a model for saturated-unsaturated variable density ground-water flow with energy or solute transport: U.S. Geological Survey Open-File Report 02-4231, 250 p.

Walton, W.C., 1962, Selected analytical methods for well and aquifer evaluation: Illinois State Water Survey Bulletin 49, 81 p. 


\section{Appendix 1-Data Input Instructions for Multi-Node Well (MNW2) Package}

\section{MODFLOW Name File}

The MNW2 Package is activated by including a record in the MODFLOW name file using the file type (Ftype) "MNW2" to indicate that relevant calculations are to be made in the model and to specify the related input data file. The user can optionally specify that information calculated for specific multi-node wells are to be written to separate output files by including a record in the MODFLOW name file using the file type (Ftype) "MNWI" that specifies the relevant input data file giving selected well locations. The MNW2 and MNWI Packages are compatible with MODFLOW-2000 (Harbaugh and others, 2000) and MODFLOW-2005 (Harbaugh, 2005) and with compatible versions of the ground-water transport process, but not with earlier versions of MODFLOW.

\section{MNW2 Package Input Data}

The MNW2 input file consists of input items (datasets) numbered from 0 through 4, each consisting of one or more records, as described in detail below. These data are used to specify information about the locations, flows, physical and hydraulic properties of the wells, and possibly solute concentrations, as well as specifying certain output control options.

In the following description, input parameters are indicated as being optional by their enclosure in curly brackets. All input variables are read using free formats. In free format, variables are separated by one or more spaces or by a comma and optionally one or more spaces. Thus, in free format, a blank field cannot be used to set a variable value to zero.

\section{FOR EACH SIMULATION:}

0. Data: [\#Text]

Text A character variable (up to 199 characters) that is printed when the file is read. The "\#" character must be in column 1, and, accordingly, the variable starts in column 2 . Any characters can be included in Text.

Note 1: Item 0 can be repeated multiple times. Text will be printed to the MODFLOW listing (output) file.

1. Data: MNWMAX IWL2CB MNWPRNT \{OPTION\}

MNWMAX is the maximum number of multi-node wells (MNW) to be simulated.

IWL2CB is a flag and a unit number:

- if IWL2CB $>0$, then it is the unit number to which MNW cell-by-cell flow terms will be recorded whenever cell-by-cell budget data are written to a file (as determined by the output control options of MODFLOW).

- if IWL2CB $=0$, then MNW cell-by-cell flow terms will not be printed or recorded.

- if IWL $2 \mathrm{CB}<0$, then well injection or withdrawal rates and water levels in the well and its multiple cells will be printed in the main MODFLOW listing (output) file whenever cell-by-cell budget data are written to a file (as determined by the output control options of MODFLOW).

MNWPRNT is a flag controlling the level of detail of information about multi-node wells to be written to the main MODFLOW listing (output) file. If MNWPRNT = 0, then only basic well information will be printed in the main MODFLOW output file; increasing the value of MNWPRNT yields more information, up to a maximum level of detail corresponding with MNWPRNT $=2$. 
of dataset 4a. Up to five parameters can be specified, each of which must be preceded by "AUXILIARY" or "AUX." These parameters will not be used by the MNW2 Package, but they will be available for use by other packages.

\section{For each Multi-Node well (that is, repeat dataset 2 MNWMAX times):}

\section{2a. Data: WELLID NNODES}

WELLID

is the name of the well. This is a unique alphanumeric identification label for each well. The text string is limited to 20 alphanumeric characters. If the name of the well includes spaces, then enclose the name in quotes.

NNODES

is the number of cells (nodes) associated with this well. NNODES normally is $>0$, but for the case of a vertical borehole, setting NNODES $<0$ will allow the user to specify the elevations of the tops and bottoms of well screens or open intervals (rather than grid layer numbers), and the absolute value of NNODES equals the number of open intervals (or well screens) to be specified in dataset $2 \mathrm{~d}$. If this option is used, then the model will compute the layers in which the open intervals occur, the lengths of the open intervals, and the relative vertical position of the open interval within a model layer (for example, see figure 14 and related discussion).

Note 2: If NNODES $<0$ and elevations indicate multiple well screens or open intervals within a single model layer, then the model will assign a single equivalent composite well screen (see additional discussion in text).

\section{2b. Data: LOSSTYPE PUMPLOC Qlimit PPFLAG PUMPCAP}

LOSSTYPE is a character flag to determine the user-specified model for well loss (equation 2). Available options (that is, place one of the following approved words in this field) are:

NONE

THIEM

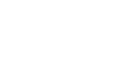

SKIN GENERAL

SPECIFYCWC there are no well corrections and the head in the well is assumed to equal the head in the cell. This option $\left(h_{W E L L}=h_{n}\right)$ is only valid for a single-node well (NNODES $\left.=1\right)$. (This is equivalent to using the original WEL Package of MODFLOW, but specifying the single-node well within the MNW2 Package enables the use of constraints.)

this option allows for only the cell-to-well correction at the well based on the Thiem (1906) equation; head in the well is determined from equation 2 as $\left(h_{W E L L}=h_{n}+A Q_{n}\right)$, and the model computes $A$ on the basis of the user-specified well radius (Rw) and previously defined values of cell transmissivity and grid spacing. Coefficients $\mathrm{B}$ and $\mathrm{C}$ in equation 2 are automatically set $=0.0$. User must define Rw in dataset $2 \mathrm{c}$ or $2 \mathrm{~d}$.

this option allows for formation damage or skin corrections at the well: $h_{W E L L}=h_{n}+$ $A Q_{n}+B Q_{n}$ (from equation 2), where $\mathrm{A}$ is determined by the model from the value of Rw, and B is determined by the model from Rskin and Kskin. User must define Rw, Rskin, and Kskin in dataset $2 \mathrm{c}$ or $2 \mathrm{~d}$.

head loss is defined with coefficients $A, B$, and $C$ and power exponent $P\left(h_{W E L L}=\right.$ $\left.h_{n}+A Q_{n}+B Q_{n}+C Q_{n}{ }^{\mathrm{P}}\right) . A$ is determined by the model from the value of Rw. User must define Rw, $B, C$, and $P$ in dataset $2 \mathrm{c}$ or $2 \mathrm{~d}$. A value of $\mathrm{P}=2.0$ is suggested if no other data are available (the model allows $1.0 \leq \mathrm{P} \leq 3.5$ ). Entering a value of $\mathrm{C}=0$ will result in a "linear" model in which the value of B is entered directly (rather than entering properties of the skin, as with the SKIN option).

the user specifies an effective conductance value (equivalent to the combined effects of the $A, B$, and $C$ well-loss coefficients expressed in equation 15) between the well and the cell representing the aquifer, $C W C$. User must define $C W C$ in dataset $2 \mathrm{c}$ or $2 \mathrm{~d}$. If there are multiple screens within the grid cell or if partial penetration corrections are to be made, then the effective value of $C W C$ for the node may be further adjusted 
automatically by MNW2.

PUMPLOC

Qlimit

PPFLAG

PUMPCAP is an integer flag pertaining to the location along the borehole of the pump intake (if any). If PUMPLOC $=0$, then either there is no pump or the intake location (or discharge point for an injection well) is assumed to occur above the first active node associated with the multinode well (that is, the node closest to the land surface or to the wellhead). If PUMPLOC $>0$, then the cell in which the intake (or outflow) is located will be specified in dataset $2 \mathrm{e}$ as a LAY-ROW-COL grid location. For a vertical well only, specifying PUMPLOC $<0$, will enable the option to define the vertical position of the pump intake (or outflow) as an elevation in dataset 2e (for the given spatial grid location [ROW-COL] defined for this well in $2 \mathrm{~d}$ ).

is an integer flag that indicates whether the water level (head) in the well will be used to constrain the pumping rate. If $Q$ limit $=0$, then there are no constraints for this well. If Qlimit $>0$, then pumpage will be limited (constrained) by the water level in the well, and relevant parameters are constant in time and defined below in dataset $2 \mathrm{f}$. If $\mathrm{Qlimit}<0$, then pumpage will be limited (constrained) by the water level in the well, and relevant parameters can vary with time and are defined for every stress period in dataset $4 \mathrm{~b}$.

is an integer flag that determines whether the calculated head in the well will be corrected for the effect of partial penetration of the well screen in the cell. If PPFLAG $=0$, then the head in the well will not be adjusted for the effects of partial penetration. If PPFLAG $>0$, then the head in the well will be adjusted for the effects of partial penetration if the section of well containing the well screen is vertical (as indicated by identical row-column locations in the grid). If NNODES $<0$ (that is, the open intervals of the well are defined by top and bottom elevations), then the model will automatically calculate the fraction of penetration for each node and the relative vertical position of the well screen. If NNODES $>0$, then the fraction of penetration for each node must be defined in dataset $2 \mathrm{~d}$ (see below) and the well screen will be assumed to be centered vertically within the thickness of the cell (except if the well is located in the uppermost model layer that is under unconfined conditions, in which case the bottom of the well screen will be assumed to be aligned with the bottom boundary of the cell and the assumed length of well screen will be based on the initial head in that cell).

is an integer flag and value that determines whether the discharge of a pumping (withdrawal) well $(Q<0.0)$ will be adjusted for changes in the lift (or total dynamic head) with time. If PUMPCAP $=0$, then the discharge from the well will not be adjusted on the basis of changes in lift. If PUMPCAP $>0$ for a withdrawal well, then the discharge from the well will be adjusted on the basis of the lift, as calculated from the most recent water level in the well. In this case, data describing the head-capacity relation for the pump must be listed in datasets $2 \mathrm{~g}$ and $2 \mathrm{~h}$, and the use of that relation can be switched on or off for each stress period using a flag in dataset $4 \mathrm{a}$. The number of entries (lines) in dataset $2 \mathrm{~h}$ corresponds to the value of PUMPCAP. If PUMPCAP does not equal 0 , it must be set to an integer value of between 1 and 25 , inclusive.

Note 3: Discharge is reduced under PUMPCAP independently from a reduction related to constraints (and Qlimit). If both are applied to the same well, then the most restrictive condition from the two criteria will take precedence. PUMPCAP is only applied for withdrawal wells (that is, if the specified pumping rate (Qdes in dataset 4a) is negative in sign).

\section{If LOSSTYPE $\neq$ NONE :}

2c. Data: $\{R w$ Rskin Kskin B C P CWC $\}$ Include the appropriate coefficients in 2c, as consistent with the specified LOSSTYPE defined in 2b, as summarized also in table A1-1.

- if LOSSTYPE = THIEM, then specify RW (the radius of the well).

- if LOSSTYPE = SKIN, then specify RW, RSkin (the radius to the outer limit of the skin), and 
Kskin (the hydraulic conductivity of the skin).

- if LOSSTYPE = GENERAL, then specify RW, B, C, and P, where the last three parameters are coefficients in the well-loss equation (equation 2). (See notes and suggestions for GENERAL option under $2 \mathrm{~b}$ above.)

- if LOSSTYPE = SPECIFYCWC, then specify CWC (the cell-to-well conductance; see equation 15).

Note 4: Any of the parameters in dataset $2 \mathrm{c}$ can be assumed to be constant for the entire length of the open interval of the well (in which case appropriate values are simply specified above), or it can be assumed that they vary along the length of the open interval of the well (in which case any negative value should be specified above and the actual values then specified for each node or open interval in dataset $2 \mathrm{~d}$ below). For example, if $\mathrm{Rw}_{\mathrm{w}}=-1$, then it is assumed that $\mathrm{Rw}$ varies along the length of the well and a real value of Rw must be defined for each node (or open interval) of this well in dataset $2 \mathrm{~d}$.

Table A1-1. Summary of parameter definition requirements for available well-loss options.

\begin{tabular}{lccccccc}
\hline \multirow{2}{*}{ Losstype } & \multicolumn{6}{c}{ Parameter definition requirements for datasets 2c and (or) 2d } \\
\cline { 2 - 7 } & RW & Rskin & Kskin & B & C & P & CWC \\
\hline NONE & - & - & - & - & - & - & - \\
THIEM & $\sqrt{ }$ & - & - & - & - & - & - \\
SKIN & $\sqrt{ }$ & $\sqrt{ }$ & $\sqrt{ }$ & - & - & - & - \\
GENERAL & $\sqrt{ }$ & - & - & $\sqrt{ }$ & $\sqrt{ }$ & $\sqrt{ }$ & - \\
SPECIFYCWC & - & - & - & - & - & - & $\sqrt{ }$ \\
\hline
\end{tabular}

For each node (or open interval) of this well the user must use either input format 1 or input format 2; in either case, dataset 2d must have |NNODES | records:

\section{Input format 1, for NNODES $>0$}

2d-1. Data: LAY ROW COL $\{$ Rw Rskin Kskin B C P CWC PP\}

\section{Input format 2, for NNODES $<0$}

2d-2. Data: Ztop Zbotm ROW COL \{RW Rskin Kskin B C P CWC PP\}

LAY, ROW, COL are the layer, row, and column numbers of each model cell (node) for the current well. If NNODES $>0$, then a total of NNODES model cells (nodes) must be specified for each well (and dataset $2 \mathrm{~d}$ must contain NNODES records). In the list of nodes defining the multi-node well, the data list must be constructed and ordered so that the first node listed represents the node closest to the wellhead, the last node listed represents the node furthest from the wellhead, and all nodes are listed in sequential order from the top to the bottom of the well (corresponding to the order of first to last well nodes). A particular node in the grid can be associated with more than one multi-node well.

Ztop, Zbotm are the top and bottom elevations of the open intervals (or screened intervals) of a vertical well. These values are only read if NNODES $<0$ in dataset $2 a$. The absolute value of NNODES indicates how many open intervals are to be defined, and so must correspond exactly to the number of records in dataset $2 \mathrm{~d}$ for this well. In the list of intervals defining the multi-node well, the data list must be constructed and ordered so that the first interval listed represents the shallowest one, the last interval listed represents the deepest one, and all intervals are listed in sequential order from the top to the bottom of the well. If an interval partially or fully intersects a model layer, then a node will be defined in that cell. If more than one open interval intersects a particular layer, then a length-weighted average of the cell-to-well conductances 
will be used to define the well-node characteristics; for purposes of calculating effects of partial penetration, the cumulative length of well screens will be assumed to be centered vertically within the thickness of the cell. If the well is a single-node well by definition of LOSSTYPE = NONE and the defined open interval straddles more than one model layer, then the well will be associated with the cell where the center of the open interval exists.

LOSSTYPE variables if the relevant variables were set to a negative value in dataset $2 \mathrm{c}$, then that means that they vary in value among nodes (or open intervals, if NNODES $<0$ ) and should be defined here in dataset $2 \mathrm{~d}$ according to the definitions given under dataset $2 \mathrm{c}$. Which values are specified here, if any, depends on which were set to a negative value in dataset $2 \mathrm{c}$. PPFLAG $>0$ and NNODES $>0$.

Note 5: If NNODES $<0$ and elevations indicate multiple well screens or open intervals within a single model layer, then the model will assign a single equivalent composite well screen for the node based on the ratio of the screen length to layer thickness (see additional discussion in text). However, if CWC values are specified explicitly by the user, then it is assumed that these values are already appropriate for the actual length of screen and are not further adjusted by this ratio (that is, equation 37 is not applied).

\section{If PUMPLOC $\neq 0$ :}

2e. Data: \{PUMPLAY PUMPROW PUMPCOL\} \{Zpump\}

PUMPLAY, PUMPROW, and PUMPCOL are the layer, row, and column numbers, respectively, of the cell (node) in this multi-node well where the pump intake (or outflow) is located. The location defined in dataset $2 \mathrm{e}$ should correspond with one of the nodes listed in $2 \mathrm{~d}$ for this multi-node well. These variables are only read if PUMPLOC $>0$ in $2 b$.

Zpump is the elevation of the pump intake (or discharge pipe location for an injection well). Zpump is read only if PUMPLOC $<0$; in this case, the model assumes that the borehole is vertical and will compute the layer of the grid in which the pump intake is located.

Note 6: If the intake location (or discharge point for an injection well) is specified by node and that node does not correspond with one of the nodes listed for the well, or if the intake location is specified by elevation and the elevation is above the top of the open interval, then the intake location will be assumed to occur above the first active node associated with the multinode well (that is, the node closest to the land surface or to the wellhead).

\section{If Qlimit > 0:}

\section{2f. Data: Hlim QCUT \{Qfremn Qfremx}

Hlim

QCUT

Qfrcmn

Qfremx is the limiting water level (head) in the well, which is a minimum for discharging wells and a maximum for injection wells. For example, in a discharging well, when $h_{W E L L}$ falls below $h_{\text {lim }}$, the flow from the well is constrained.

is an integer flag that indicates how pumping limits $Q \mathrm{frcmn}$ and $Q \mathrm{f} r \mathrm{~cm} x$ will be specified. If pumping limits are to be specified as a rate $\left(\mathrm{L}^{3} / \mathrm{T}\right)$, then set $\mathrm{QCUT}>0$; if pumping limits are to be specified as a fraction of the specified pumping rate (Qdes), then set QCUT $<0$. If there is not a minimum pumping rate below which the pump becomes inactive, then set QCUT $=0$.

is the minimum pumping rate or fraction of original pumping rate (a choice that depends on QCUT) that a well must exceed to remain active during a stress period. The absolute value of $Q f r c m n$ must be less than the absolute value of $Q f r c m x$ (defined next). Only specify if QCUT $\neq 0$.

is the minimum pumping rate or fraction of original pumping rate that must be exceeded to reactivate a well that had been shut off based on $Q$ f r $\mathrm{cmn}$ during a stress period. The 
absolute value of $Q f r c m x$ must be greater than the absolute value of $Q f r c m n$. Only specify if $\mathrm{QCUT} \neq 0$.

Note 7: Only specify dataset $2 \mathrm{f}$ if the value of $\mathrm{Qlimit}$ in dataset $2 \mathrm{~b}$ is positive. Do not enter fractions as percentages. For example, if QCUT $<0$, and the well must exceed 80 percent of the original pumping rate to remain active, then enter a value of " 0.8 " for Q $f r c m n$. If QCUT $>0$, then the rates specified for Qf $r \mathrm{cmn}$ and $\mathrm{Q} f r \mathrm{cmx}$ follow the sign convention for MODFLOW; that is, for discharging wells the rate should be negative, and for recharging (injection) wells the rate should be positive.

\section{If PUMPCAP > 0:}

2g. Data: Hlift LIFTq0 LIFTqmax HWtol

Hlift is the reference head (or elevation) corresponding to the discharge point for the well. This is typically at or above the land surface, and can be increased to account for additional head loss due to friction in pipes.

LIFTg0 is the value of lift (total dynamic head) that exceeds the capacity of the pump. If the calculated lift equals or exceeds this value, then the pump is shut off and discharge from the well ceases.

LIFTgmax is the value of lift (total dynamic head) corresponding to the maximum pumping (discharge) rate for the pump. If the calculated lift is less than or equal to LIFTqmax, then the pump will operate at its design capacity, assumed to equal the user-specified value of Qdes (in dataset 4a). LIFTqmax will be associated with the value of Qdes in the first stress period in which Qdes for the well is less than 0.0 .

HWtol is a minimum absolute value of change in the computed water level in the well allowed between successive iterations; if the value of $h_{W E L L}$ changes from one iteration to the next by a value smaller than this tolerance, then the value of discharge computed from the head capacity curves will be locked for the remainder of that time step. It is recommended that HWtol be set equal to a value approximately one or two orders of magnitude larger than the value of HCLOSE, but if the solution fails to converge, then this may have to be adjusted.

Note 8: LIFTq0 and LIFTgmax define the two end points of the performance curve (head-capacity curve) for the pump installed in the well. One or more additional intermediate points on the curve must be defined below in dataset $2 \mathrm{~h}$. The model will use linear interpolation to estimate values between defined data points. The number of additional data points on the curve (and lines in dataset $2 \mathrm{~h}$ ) must correspond to the value of PUMPCAP for this well (where PUMPCAP $\leq 25$ ). The data entered are typically provided by the pump manufacturer. The performance curves will only be applied for stress periods in which Qdes $<0.0$ and CapMult $>0$ (see dataset $4 a$ ).

\section{If PUMPCAP > 0:}

2h. Data: LIFTn Qn

LIFTn is a value of lift (total dynamic head) that corresponds to a known value of discharge (Qn) for the given pump, specified as the second value in this line.

Qn

is the value of discharge corresponding to the height of lift (total dynamic head) specified previously on this line. Sign (positive or negative) is ignored.

Note 9: Repeat $2 \mathrm{~h}$ PUMPCAP times. That is, the number of lines (records) in dataset $2 \mathrm{~h}$ must correspond to the value of PUMPCAP for this well. Enter data in order of decreasing lift (that is, start with the point corresponding to the highest value of total dynamic head) and increasing discharge. The discharge value for the last data point in the sequence must be less than the value of LIFT qmax. The data entered are typically provided by the pump manufacturer. These data provide intermediate values for a lookup table in which the end (limiting) values are derived from values specified earlier in dataset $2 \mathrm{~g}$. 


\section{FOR EACH STRESS PERIOD:}

3. Data: ITMP

ITMP

is an integer value for reusing or reading multi-node well data; it can change each stress period.

ITMP must be $\geq 0$ for the first stress period of a simulation.

- if ITMP $>0$, then ITMP is the total number of active multi-node wells simulated during the stress period, and only wells listed in dataset $4 \mathrm{a}$ will be active during the stress period. Characteristics of each well are defined in datasets 2 and 4.

- if $\operatorname{ITMP}=0$, then no multi-node wells are active for the stress period and the following dataset is skipped.

- if ITMP $<0$, then the same number of wells and well information will be reused from the previous stress period and dataset 4 is skipped.

IF ITMP > 0:

\section{For each multi-node well (that is, repeat dataset 4 ITMP times):}

\section{4a. Data: WELLID Qdes \{CapMult\} \{Cprime $\{$ xyz}

WELLID must correspond with one of the names defined in dataset 2a. Including WELLID in this dataset means it will be an active well during this stress period.

Qdes is the actual (or maximum desired, if constraints are to be applied) volumetric pumping rate (negative for withdrawal or positive for injection) at the well $\left(\mathrm{L}^{3} / \mathrm{T}\right)$. Qdes should be set to 0 for nonpumping wells. If constraints are applied, then the calculated volumetric withdrawal or injection rate may be adjusted to range from 0 to Qdes and is not allowed to switch directions between withdrawal and injection conditions during any stress period. When PUMPCAP $>0$, in the first stress period in which Qdes is specified with a negative value, Qdes represents the maximum operating discharge for the pump; in subsequent stress periods, any different negative values of Qdes are ignored, although values are subject to adjustment for CapMult. If Qdes $\geq 0.0$, then pump-capacity adjustments are not applied.

CapMult is a flag and multiplier for implementing head-capacity relations during a given stress period. Only specify if PUMPCAP $>0$ for this well. If CapMul $t \leq 0$, then head-capacity relations are ignored for this stress period. If CapMult $=1.0$, then head-capacity relations defined in datasets $2 \mathrm{~g}$ and $2 \mathrm{~h}$ are used. If CapMult equals any other positive value (for example, 0.6 or 1.1), then head-capacity relations are used but adjusted and shifted by multiplying the discharge value indicated by the head-capacity curve by the value of CapMult.

Cprime $\quad$ is the concentration in the injected fluid. Only specify if Qdes $>0$ and GWT process is active.

[xyz] represents a list of up to five auxiliary variables for a multi-node well that have been defined in dataset 1 . The auxiliary variables must be present in each repetition of dataset $4 \mathrm{a}$ if they are defined in dataset 1 .

\section{If Qlimit < 0:}

\section{4b. Data: Hlim QCUT \{Qfrcmn Qfremx}

Hlim

is the limiting water level (head) in the well, which is a minimum for discharging wells and a maximum for injection wells. For example, in a discharging well, when $h_{W E L L}$ falls below $h_{\text {lim }}$, the flow from the well is constrained.

is an integer flag that indicates how pumping limits $Q f r c m n$ and $Q f r c m x$ will be specified. If pumping limits are to be specified as a rate $\left(\mathrm{L}^{3} / \mathrm{T}\right)$, then set $\mathrm{QCUT}>0$; if pumping limits are 
to be specified as a fraction of the specified pumping rate (Qdes), then set QCUT $<0$. If there is not a minimum pumping rate below which the pump becomes inactive, then set $\mathrm{QCUT}=0$.

Qfremn is the minimum pumping rate or fraction of original pumping rate (a choice that depends on QCUT) that a well must exceed to remain active during a stress period. The absolute value of $Q f r c m n$ must be less than the absolute value of $Q f r c m x$ (defined next). Only specify if QCUT $\neq 0$.

Qfrcmx

is the minimum pumping rate or fraction of original pumping rate that must be exceeded to reactivate a well that had been shut off based on $Q$ f $r \mathrm{cmn}$ during a stress period. The absolute value of $Q f r c m x$ must be greater than the absolute value of $Q f r c m n$. Only specify if QCUT $\neq 0$.

Note 10: Only specify dataset $4 \mathrm{~b}$ if the value of Qlimit associated with the well defined by WELLID in dataset 4a is negative (where Qlimit is defined in dataset $2 b$ ). Do not enter fractions as percentages. For example, if QCUT $<0$, and the well must exceed 80 percent of the original pumping rate to remain active, then enter a value of " 0.8 " for $Q f r c m n$. If $Q C U T>0$, then the rates specified for $Q f r c m n$ and $Q f r c m x$ follow the sign convention for MODFLOW; that is, for discharging wells the rate should be negative, and for recharging (injection) wells the rate should be positive.

\section{Multi-Node Well Information (MNWI) Package}

Data calculated for multi-node wells can be recorded at every time increment using the MNWI Package. The specific nature of the recorded and written information depends on the selection of a number of options, as described below. Some options will save specific types of information for all multi-node wells to a single file, and other options will save certain information about an individual multi-node well to a single file. These output options can facilitate graphical postprocessing of the calculated data. The input file is read if the file type (Ftype) "MNWI" is included in the MODFLOW name file, and MNWI should only be used if the MNW2 Package is active.

In the following description, input parameters are indicated as being optional by their enclosure in curly brackets. All input data are read using free formats.

\section{FOR EACH SIMULATION:}

\section{Data: WELlflag QSUMflag BYNDflag}

WELIflag is an integer value indicating whether or not to create an output file in which the flows from every MNW node at the end of each stress period are written as single-cell fluxes in the format of the original MODFLOW Well Package (WEL1). This is equivalent to the "WEL1" option in the original MNW Package (Halford and Hanson, 2002). If WELIflag $=0$, then the WEL1 output file will not be created. If WELIflag $>0$, then the value of WELIflag is the unit number to which the WEL1 information will be saved.

QSUMflag is an integer value indicating whether or not to create an output file that lists the flow rates from each multi-node well for each time step. This is essentially equivalent to the "QSUM" option in the original MNW Package (Halford and Hanson, 2002). If QSUMflag $=0$, then the QSUM output file will not be created. If QSUMflag $>0$, then the value of QSUMflag is the unit number to which the QSUM information will be saved.

BYNDflag

is an integer value indicating whether or not to create an output file in which the flows and other information associated with every MNW node are written to a single file. This is essentially equivalent to the "BYNODE" option in the original MNW Package (Halford and Hanson, 2002). If BYNDflag $=0$, then the output file will not be created. If BYNDflag $>0$, then the value of BYNDflag is the unit number to which the nodal information will be saved.

Note 11: Unit numbers must be unique and matched to a DATA file type and file name in the MODFLOW name file. 
Note 12: As noted by Halford and Hanson (2002, p. 15), the WEL1 file can be used in post-processing programs, such as MODPATH (Pollock, 1994), that currently are not compatible with multi-node wells. Although flow rates for constrained wells can change during a stress period, only flow rates from the last time step of each stress period are reported because the WEL1 Package is limited to a pumping rate that is constant and uniform in a given well during each stress period. The WEL1 file will not include information about auxiliary variables or wells that were specified using the standard WEL Package of MODFLOW.

Note 13: The QSUM file will include a table of values for all multi-node wells for all times that consists: of the sum of all nodal inflows $(Q<0)$ from the aquifer to each well $\left(\mathrm{L}^{3} / \mathrm{T}\right)$, the sum of all nodal outflows (discharges; $\left.Q>0\right)$ to the aquifer from each well $\left(\mathrm{L}^{3} / \mathrm{T}\right)$, the net flow at the wellhead $\left(\mathrm{L}^{3} / \mathrm{T}\right)$, and the calculated head in the well $(\mathrm{L})$. If the GWT process is active, then calculated concentrations in the well will also be saved, with the exact information depending on the flow. For withdrawal wells $\left(Q_{n e t}<0\right)$, the MNWI Package will record the calculated concentration in the well discharge at the wellhead. For highrate injection wells ( $Q_{\text {net }}>0$ and no inflow at any nodes of the MNW), the MNWI Package will record the user-specified source concentration $\left(C_{I N J}^{\prime}\right)$. For nonpumping wells and low-rate injection wells (which include a mix of inflow and outflow nodes in the MNW), the MNWI Package will record the length-weighted average concentration in the borehole.

Note 14: The BYND file will include a table of values for all nodes of all multi-node wells for all times listing the flow between the node and the aquifer $(Q<0$ represents flow out of the aquifer into the well; $Q>0$ represents flow out of the well into the aquifer), and the calculated heads in both the cell and the well. If the GWT process is active, then the calculated concentration in the well at that nodal location will also be saved.

\section{FOR EACH SIMULATION:}

2. Data: MNWOBS

MNWOBS Number of multi-node wells for which detailed flow, head, and (if the GWT process is active) solute data are to be saved in a separate file for each multi-node well. MNWOBS must be $\geq 0$.

\section{IF MNWOBS > 0, THEN FOR EACH MULTI-NODE WELL TO BE MONITORED:}

\section{Data: WELLID UNIT QNDflag QBHflag \{CONCflag\}}

WELLID is the name of the multi-node well. This is an alphanumeric identification label for each well, as defined in dataset $2 \mathrm{a}$. The text string is limited to 20 alphanumeric characters.

UNIT

QNDflag

QBHflag is the unit number for the output file.

is an integer flag used to indicate whether additional flow information for every node in the $\mathrm{MNW}$ is written to this output file. If QNDflag $=0$, then nodal flow information is not written, resulting in a smaller file. If QNDflag $>0$, then the flow $\left(\mathrm{L}^{3} / \mathrm{T}\right)$ between the well node and the aquifer for all nodes of the MNW will be written (with a negative value indicating flow out of the aquifer and into the well). The additional data will not be written if the well contains only one node.

is an integer flag used to indicate whether additional flow information for the MNW borehole is written to this output file. If $Q B H f l a g=0$, then flows between adjacent nodes of the well are not written, resulting in a smaller file. If QBHflag $>0$, then the flow between each well node in the borehole will be written (with a negative value indicating downward flow and a positive value indicating upwards flow). For each well node, the intraborehole flow across the top face (closest to the wellhead) of the node is recorded, where the flow is a volumetric rate $\left(\mathrm{L}^{3} / \mathrm{T}\right)$ within the borehole. The flow across the top face of the first node equals $Q_{n e t}$ if the pump is located above the open interval. The flow across the bottom face of the last node is always 0.0 , though this value is not printed. These data can be used to conveniently analyze or plot a profile of flows or velocities down a borehole. The additional data will not be written if the well contains only one node. 
CONCflag

is an integer flag used to indicate what solute information for this particular multi-node well is written to its output file. Only specify if the GWT process is active. If CONCflag $=0$, then in addition to the flow and head information, the concentration in the well will also be saved (see "notes" below for more details about the concentration value to be saved). If CONCflag $=1$, then additional columns of information about mass flux will be printed. The mass flux removed from (or injected into) the ground-water system for the time increment and cumulatively will be written (these always equal 0.0 for a nonpumping well). Additionally, the mass flux into the well from the ground-water system during the time increment, the cumulative mass flux into the well, the mass flux out of the well and into the ground-water system during the time increment, and the cumulative mass flux out of the well will be written in successive columns. If CONCflag $=2$, then concentration in the well and the calculated concentration at every well node are saved (but no data on mass flux are recorded). If CONCflag $=3$, then all solute-related data are saved and written to the output file.

Note 15: A unique unit number must be specified for each multi-node well listed in record 3 and matched to a DATA file type and file name in the MODFLOW name file.

Note 16: For each well listed, the output file will record in tabular format the elapsed simulation time, the sum of all nodal inflows from the aquifer into the well $\left(\mathrm{L}^{3} / \mathrm{T}\right)$, the sum of all nodal outflows from the well into the aquifer $\left(\mathrm{L}^{3} / \mathrm{T}\right)$, the net flow rate into or out of the well at the wellhead $\left(Q_{n e t}\right)\left(\mathrm{L}^{3} / \mathrm{T}\right)$, the cumulative volume of flow into or out of the well at the wellhead over all time steps $\left(\mathrm{L}^{3}\right)$, and the calculated head in the well $(\mathrm{L})$. To this extent, the output file for each listed MNWOBS well is similar to that contained in the QSUM output file; however, the latter will contain information for multiple wells whereas the MNWOBS file will only contain information for a single well. Additional information on flows between the aquifer and the well at each node of the MNW will be written if QNDflag $>0$. If the GWT process is active, then the solute information to be written is determined by the specification of CONCflag. The type of calculated concentration value for the well that is saved depends on the well flow. For withdrawal wells $\left(Q_{n e t}<0\right)$, the MNWI Package will record the calculated concentration in the well discharge. For high-rate injection wells $\left(Q_{n e t}>0\right.$ and no inflow at any nodes of the MNW), the MNWI Package will record the user-specified source concentration $\left(C_{I N J}^{\prime}\right)$. For nonpumping wells and low-rate injection wells (which include a mix of inflow and outflow nodes in the MNW), the MNWI Package will record the length-weighted average concentration in the borehole.

Note 17: Although it is expected that a multi-node well will include more than one node in the grid, it is possible and allowable for a single-node well to be included in the list of multi-node wells read by the MNW2 Package. If a single-node injection well is specified for observation in the MNWI Package, then the software will simply record the user-specified source-fluid concentration, which is constant during a stress period. The software will not record the concentration in the aquifer; if those are desired, then concentrations calculated at specific nodes in the grid can be retrieved using the standard Observation Well (OBS) Package available for the MODFLOW-GWT model. Similarly, if a single-node withdrawal well is specified for observation in this package, then the software will record the values of aquifer concentration at the node corresponding to the location of this well [in this case, an identical record would be obtained using the OBS Package (see Konikow and others, 1996, p. 77)]. 


\section{Appendix 2-Selected Input Data and Printed Results for Sample Problem}

\section{Sample Problem}

A sample problem was selected to illustrate the input formats and specifications for the MNW2 Package, as well as output information and style in the main listing (output) file and in optional separate output files. The sample problem is a modification of the Reilly problem that includes two 150-day transient stress periods, three single-node withdrawal wells near the multi-node well, and constraints on pumping from the multi-node well linked to a limiting head of $-7.5 \mathrm{ft}$. The results of this problem are illustrated in figure 28 and described in the related discussion. The input and output files include information for an initial steady-state stress period, assumed to have a length of one day and used to establish internally consistent equilibrium conditions for the start of the transient stress periods (this initial steady-state stress period is not included in the discussion and illustration of the problem in the main text).

Selected sections of several key input and output data files are shown below-sometimes with annotations; gaps in the listings, if present, are indicated by an ellipsis. A complete set of these files is available for distribution on the Internet as discussed in the preface. The contents of some files are enclosed in a border and explanations are noted outside of the border; for other files, explanations are sometimes included as comments following a semicolon on the line being explained. Font sizes are sometimes reduced and (or) blank spaces deleted from the output files so that lines will fit within page margins. In the following listings, unless the entire file is related to MNW2, information and lines explicitly related to the MNW2 Package are highlighted by gray shading.

\section{Selected Input Files for Sample Problem}

Following (enclosed in a border) are the contents of the MODFLOW-2000 name file for the sample problem; explanations are noted outside of border:

File name: MNW2-Fig28 . nam

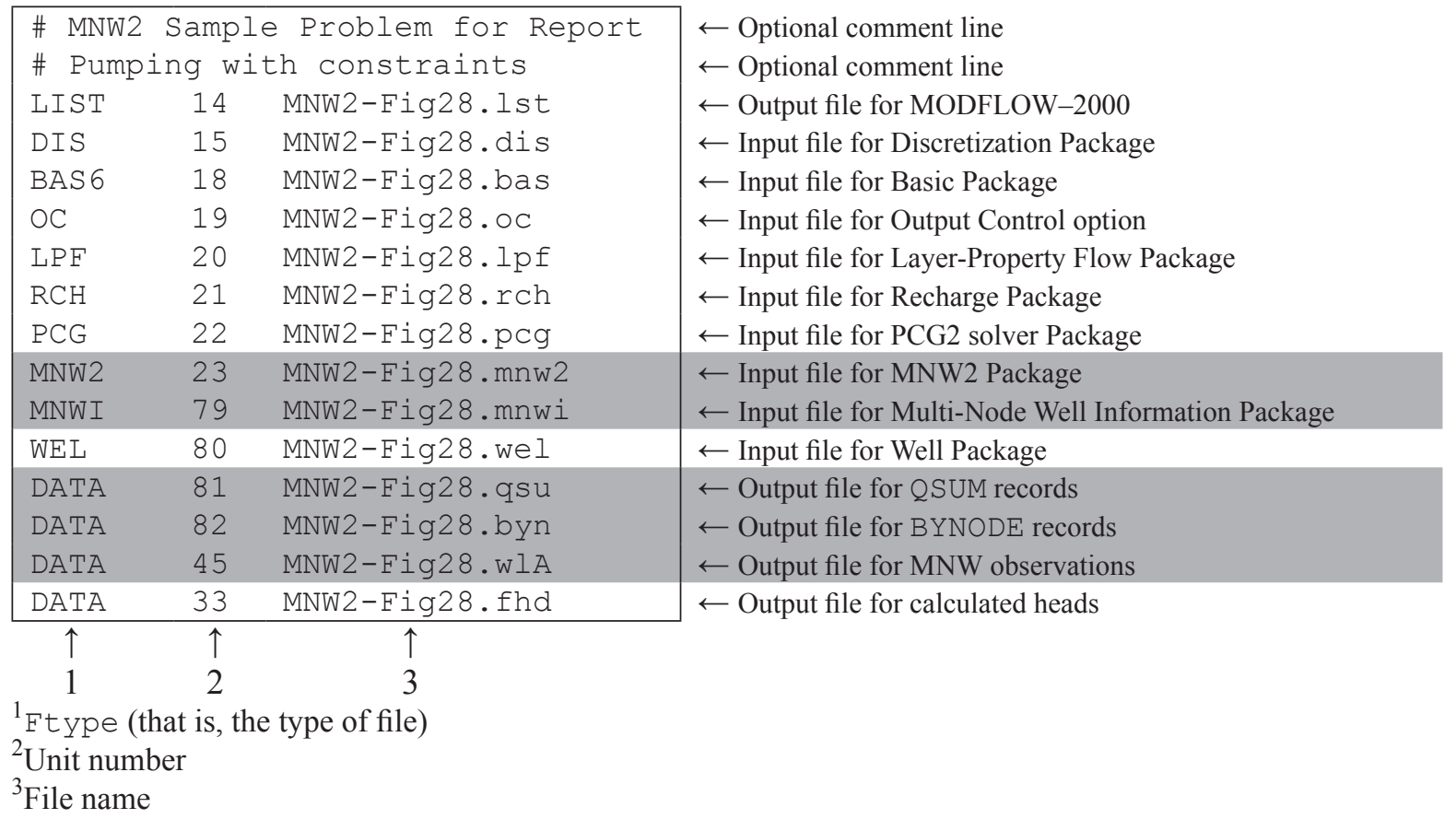


Following are the contents of the MNW2 Package input file for the sample problem; explanations are noted as comments at the end of each record, and the first field after the semicolon is the number of the dataset in the input instructions:

File name: MNW2-Fig28. mnw2

\begin{tabular}{|c|c|c|}
\hline $1-902$ & $; 1$. & MNWMAX, IMNWCB, MNWPRNT \\
\hline Well-A -1 & $; 2 \mathrm{a}$. & WELLID, NNODES \\
\hline SKIN 001100 & $; 2 \mathrm{~b}$. & LOSSTYPE, PUMPLOC, QLIMIT, PPFLAG, PUMPCAP \\
\hline $0.13331 .79471628 \quad 12.5$ & $; 2 \mathrm{C}$. & Rw, Rskin, Kskin \\
\hline$-5 \cdot-65 \cdot 3041$ & $; 2 \mathrm{~d}$. & ztop, zbotm, row, col \\
\hline $\begin{array}{llll}-7.5 & -1 & 0.10 & 0.15\end{array}$ & $; 2 \mathrm{f}$. & hlim, QCUT, Qfremn, Qfremx \\
\hline 1 & $; 3$. & ITMP (SP1; one well) \\
\hline Well-A 0.0 & $; 4$. & WELLID, Qdes(0.0 for initial steady-state SP) \\
\hline 1 & $; 3$. & $\operatorname{ITMP}$ (SP2; one well) \\
\hline Well-A -10000.0 & $; 4$. & WELLID, Qdes \\
\hline 1 & $; 3$. & ITMP (SP3; one well) \\
\hline Well-A -10000.0 & $; 4$. & WELLID, Qdes \\
\hline
\end{tabular}

Following are the contents of the MNWI Package input file for the sample problem; explanations are noted as comments at the end of each record:

File name: MNW2-Fig28. mnwi

\begin{tabular}{|c|c|c|}
\hline 08182 & $; 1$. & Wel 1flag, QSUMflag, BYNDflag \\
\hline 1 & $; 2$. & MNWOBS \\
\hline Well-A $45 \quad 0 \quad 0$ & $; 3$. & WELLID, Unit no., QNDflag, QBHflag \\
\hline
\end{tabular}

\section{Selected Output Files for Sample Problem}

Following are selected contents of the main MODFLOW output (listing) file for the sample problem; arrow symbol $(\rightarrow)$ indicates that a line is wrapped from a previous line in the listing. Note that the simulation includes three stress periods, including an initial 1-day steady-state period followed by two 150-day transient stress periods.

File name: MNW2-Fig28. Ist

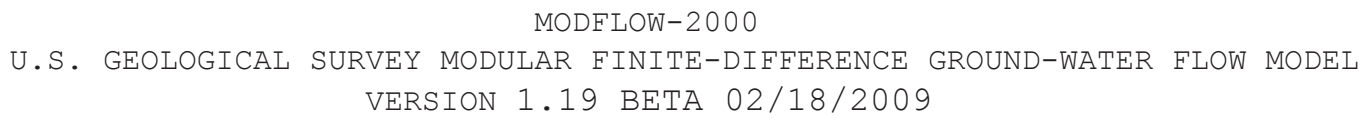




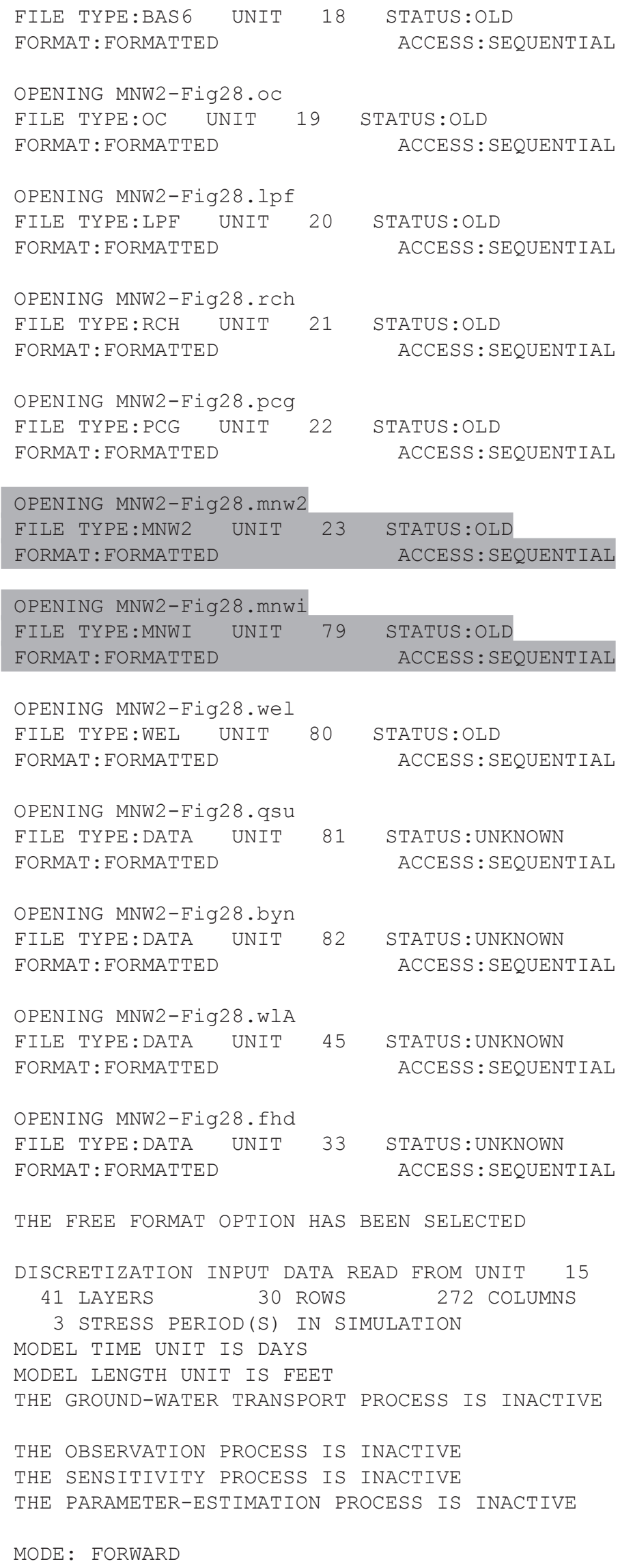




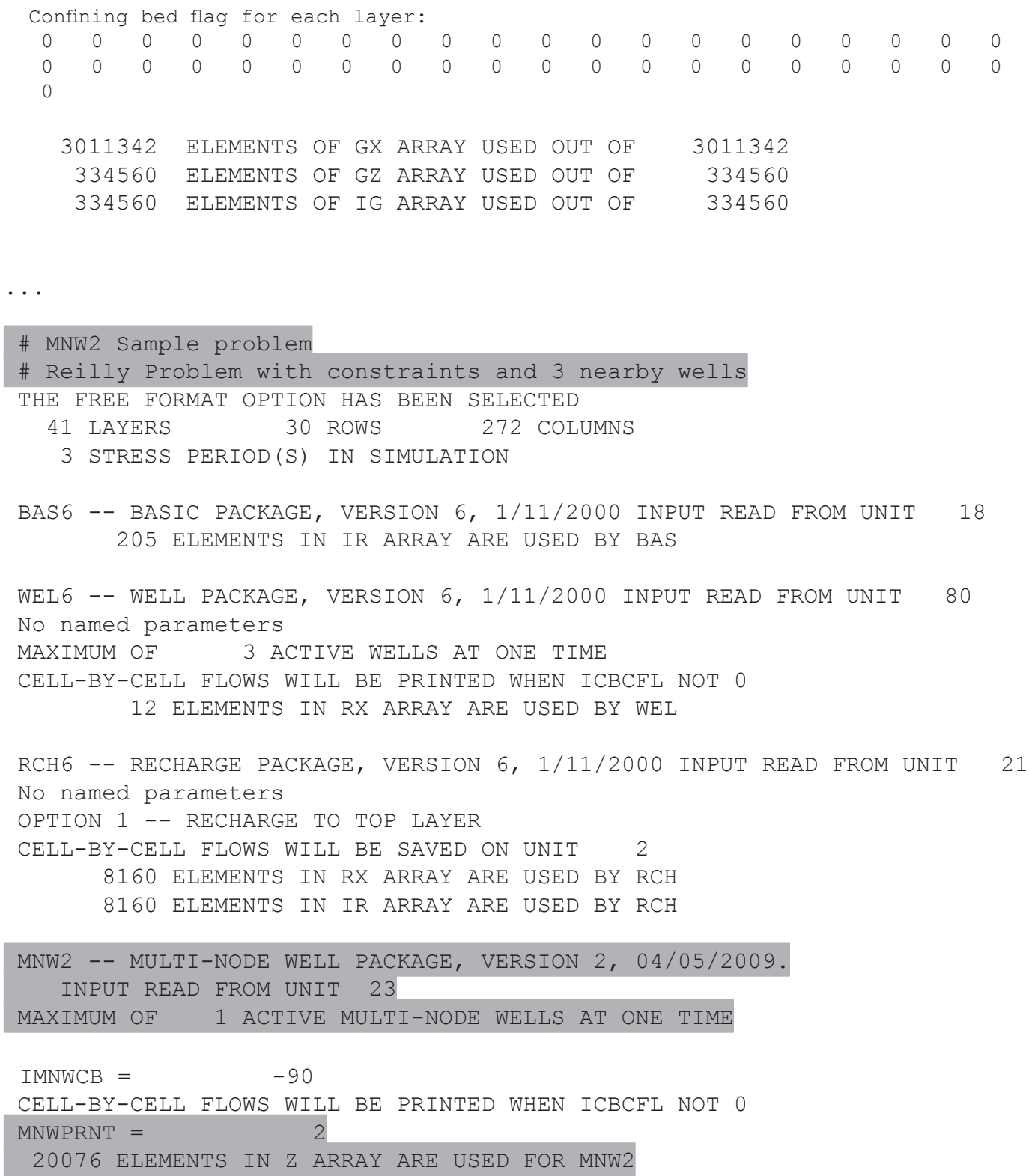




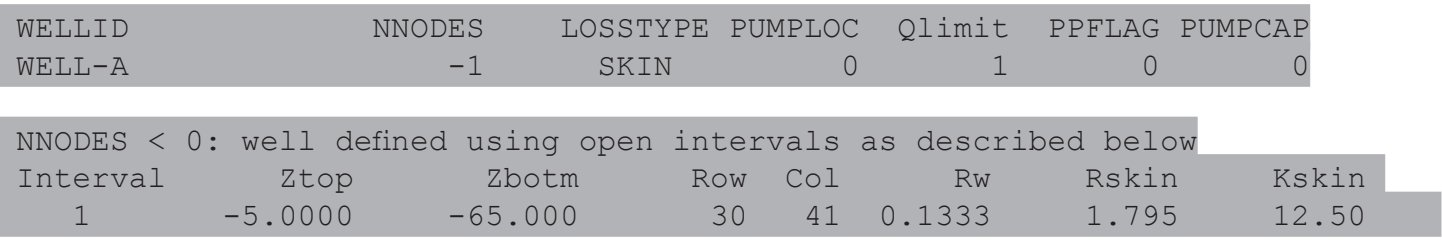
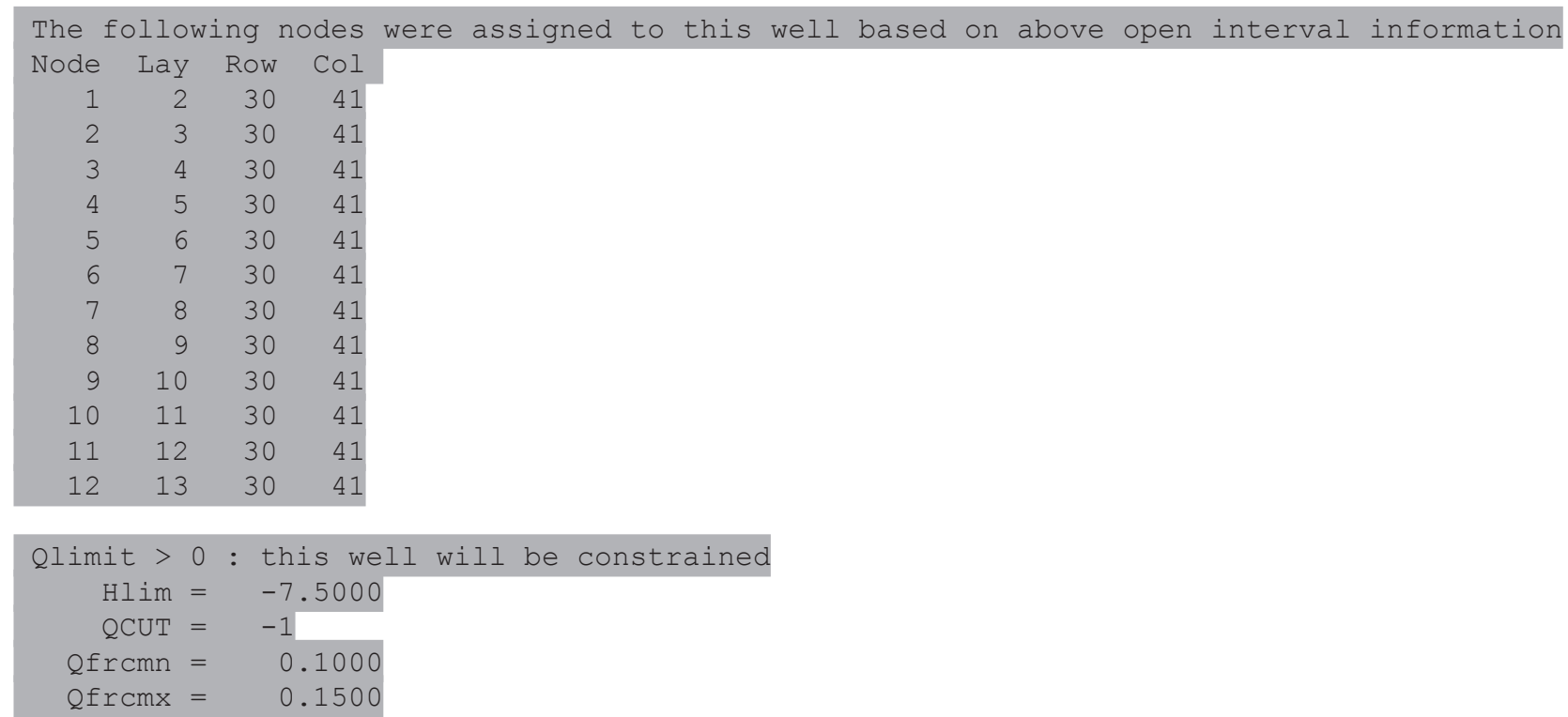

MNW2: $\quad 1$ active well in stress period

MNW2 Well Well-A

active, desired $\mathrm{Q}=0.0000 \mathrm{E}+00$ for next stress period

SITE ID FOR 1 MNW2 WELL DESIGNATED FOR OBSERVATION:

$\begin{array}{rrrrrl}\text { WELL \# } & \text { SITE ID } & \text { UNIT } & \text { QNDflag QBHflag } \\ 1 & \text { WELL-A } & 45 & 0 & 0 & \\ \text { DATA FOR } & \text { MNW WELLS } & \text { DESIGNATED } & \text { FOR } & \text { OBSERVATION } & \text { WILL BE WRITTEN ON UNIT NUMBERS }\end{array}$

$\rightarrow$ LISTED ABOVE

SOLVING FOR HEAD

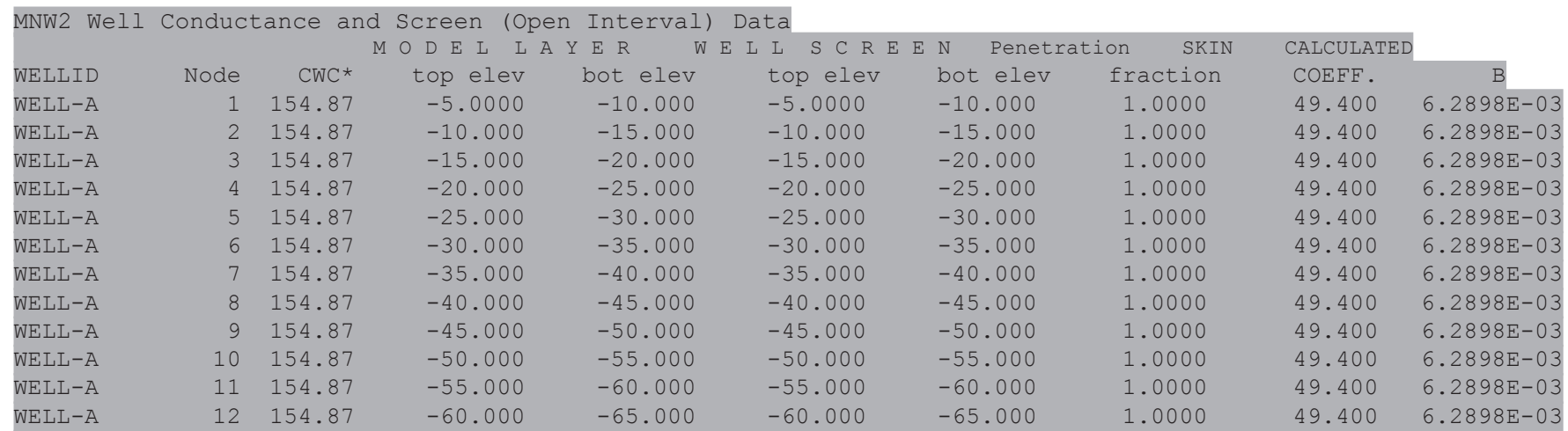

* Cell-to-well conductance values (CWC) may change during the course of a stress period

4 CALLS TO PCG ROUTINE FOR TIME STEP 1 IN STRESS PERIOD 1

240 TOTAL ITERATIONS 
OUTPUT CONTROL FOR STRESS PERIOD 1
PRINT BUDGET

SAVE HEAD FOR ALL LAYERS

HEAD WILL BE SAVED ON UNIT 33 AT END OF TIME STEP 1, STRESS PERIOD 1

1

VOLUMETRIC BUDGET FOR ENTIRE MODEL AT END OF TIME STEP 1 IN STRESS PERIOD 1

\begin{tabular}{|c|c|c|c|c|}
\hline CUMULATIVE VOLUMES & $L * \star 3$ & RATES FOR THIS TIME ST & & $\mathrm{L} * \star 3 / \mathrm{T}$ \\
\hline IN: & & IN : & & \\
\hline--- & & --- & & \\
\hline STORAGE $=$ & 0.0000 & STORAGE & & 0.0000 \\
\hline CONSTANT HEAD $=$ & 0.0000 & CONSTANT HEAD & $=$ & 0.0000 \\
\hline WELLS $=$ & 0.0000 & WELLS & $=$ & 0.0000 \\
\hline RECHARGE $=$ & 4501.0518 & RECHARGE & $=$ & 4501.0518 \\
\hline MNW2 $=$ & 0.9270 & MNW2 & $=$ & 0.9270 \\
\hline TOTAL IN $=$ & 4501.9790 & TOTAL IN & $=$ & 4501.9790 \\
\hline OUT: & & OUT: & & \\
\hline--- & & ---- & & \\
\hline STORAGE $=$ & 0.0000 & STORAGE & $=$ & 0.0000 \\
\hline CONSTANT HEAD = & 4500.9199 & CONSTANT HEAD & $=$ & 4500.9199 \\
\hline WELLS $=$ & 0.0000 & WELLS & $=$ & 0.0000 \\
\hline RECHARGE $=$ & 0.0000 & RECHARGE & $=$ & 0.0000 \\
\hline MNW2 $=$ & 0.9270 & MNW2 & $=$ & 0.9270 \\
\hline TOTAL OUT $=$ & 4501.8472 & TOTAL OUT & $=$ & 4501.8472 \\
\hline IN $-\mathrm{OUT}=$ & 0.1318 & IN - OUT & & 0.1318 \\
\hline EENT DISCREPANCY = & 0.00 & PERCENT DISCREPANCY & $=$ & 0.00 \\
\hline
\end{tabular}

SOLVING FOR HEAD

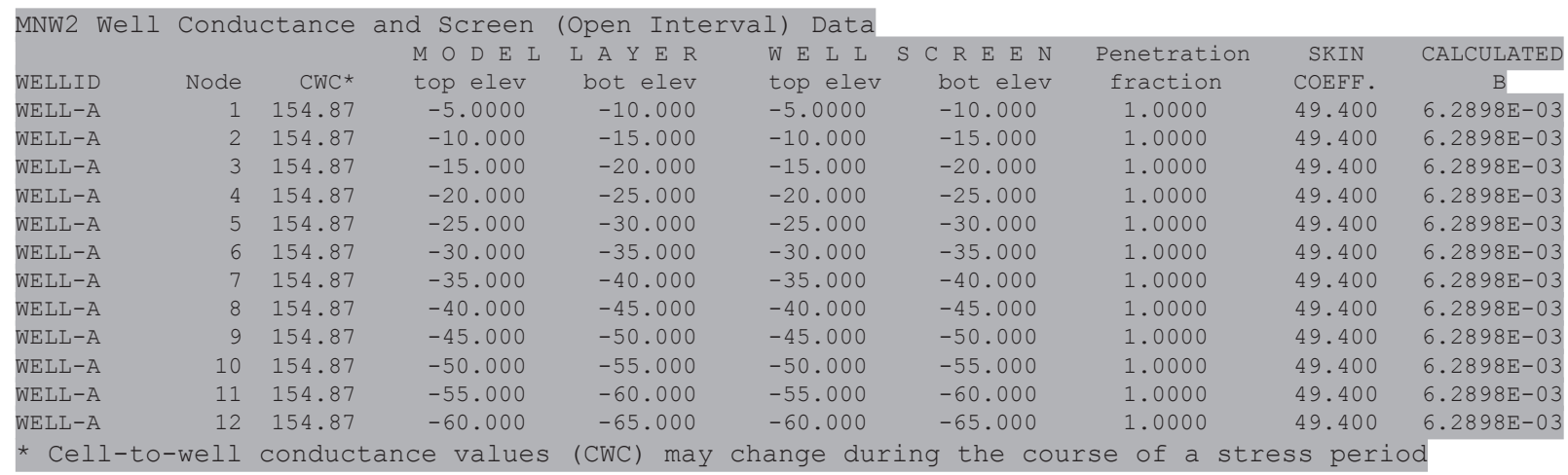

4 CALLS TO PCG ROUTINE FOR TIME STEP 12 IN STRESS PERIOD 3 238 TOTAL ITERATIONS

OUTPUT CONTROL FOR STRESS PERIOD 3 TIME STEP 12

PRINT BUDGET

SAVE HEAD FOR ALL LAYERS 


\section{because of Hlim constraint}

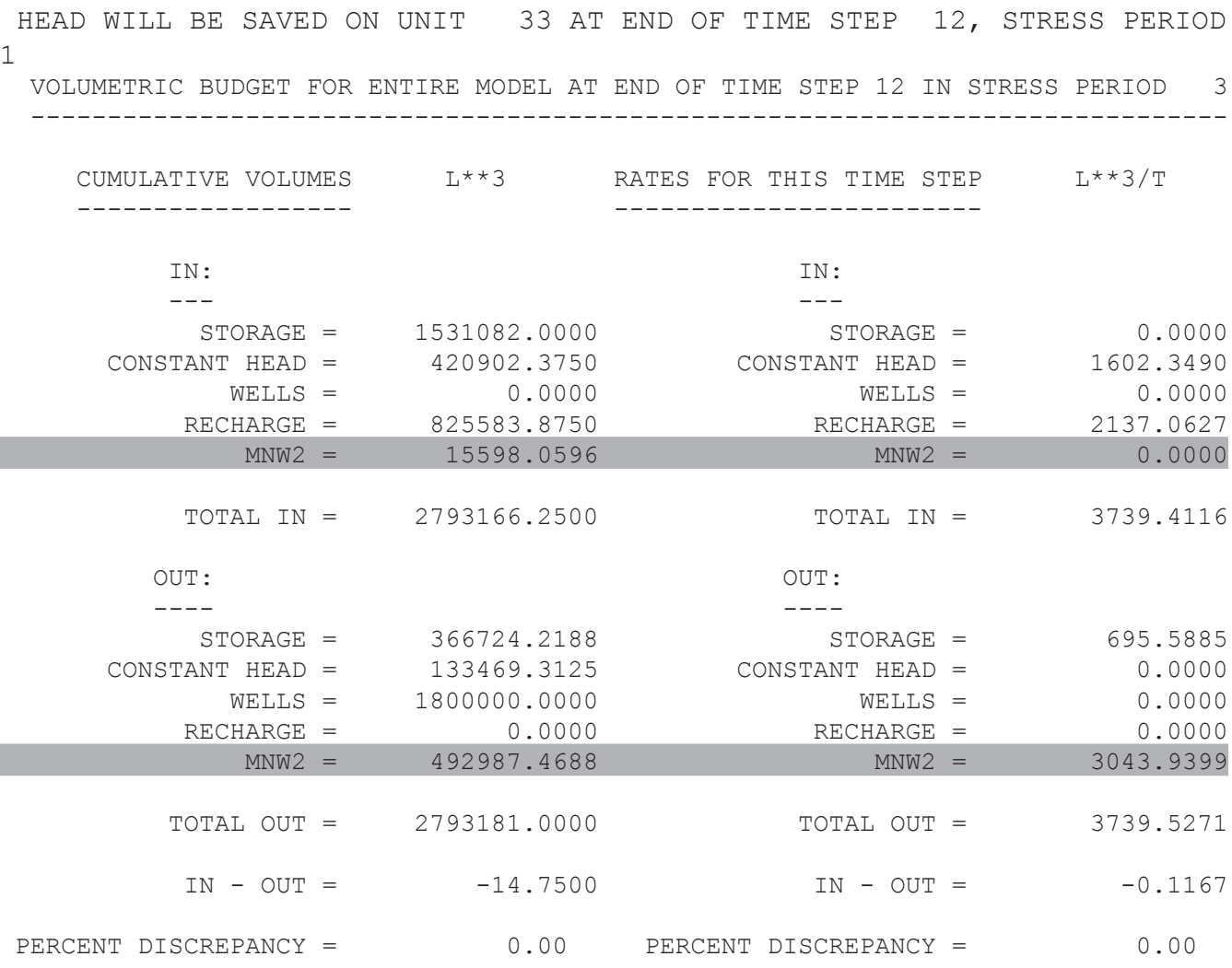

\begin{tabular}{|c|c|c|c|c|c|c|}
\hline & TIME SUMM & $\begin{array}{l}\text { ARY AT END O } \\
\text { SECONDS }\end{array}$ & $\begin{array}{l}\text { F TIME STEP } \\
\text { MINUTES }\end{array}$ & $\begin{array}{l}12 \text { IN STRESS } \\
\text { HOURS }\end{array}$ & $\begin{array}{l}\text { PERIOD } \\
\text { DAYS }\end{array}$ & YEARS \\
\hline TIME & STEP LENGTH & $3.12490 \mathrm{E}+06$ & 52082 . & 868.03 & 36.168 & $9.90220 \mathrm{E}-02$ \\
\hline STRESS & PERIOD TIME & $1.29600 \mathrm{E}+07$ & $2.16000 \mathrm{E}+05$ & 3600.0 & 150.00 & 0.41068 \\
\hline & TOTAL TIME & $2.60064 \mathrm{E}+07$ & $4.33440 \mathrm{E}+05$ & 7224.0 & 301.00 & 0.82409 \\
\hline
\end{tabular}

Following are the contents of the MNWI output file for the sample problem. The calculated data for Qnet and hwell included in this output file are also plotted in figure 28. Spaces have been deleted after the WELLID field.

File name: MNW2-Fig28,W1A

$\begin{array}{lrrrrrr}\text { WELLID } & \text { TOTIM } & \text { Qin } & \text { Qout } & \text { Qnet } & \text { Cum.Vol. } & \text { hwell } \\ \text { WELL-A } & 1.000000 \mathrm{E}+00 & -9.270180 \mathrm{E}-01 & 9.270180 \mathrm{E}-01 & -9.628964 \mathrm{E}-13 & -9.628964 \mathrm{E}-13 & 4.932257 \mathrm{E}+00 \\ \text { WELL-A } & 3.018111 \mathrm{E}+00 & -1.000000 \mathrm{E}+04 & 0.000000 \mathrm{E}+00 & -1.000000 \mathrm{E}+04 & -2.018111 \mathrm{E}+04 & -6.563526 \mathrm{E}+00 \\ \text { WELL-A } & 5.641656 \mathrm{E}+00 & -9.189964 \mathrm{E}+03 & 0.000000 \mathrm{E}+00 & -9.189964 \mathrm{E}+03 & -4.429139 \mathrm{E}+04 & -7.500000 \mathrm{E}+00 \\ \text { WELL-A } & 9.052263 \mathrm{E}+00 & -7.460323 \mathrm{E}+03 & 0.000000 \mathrm{E}+00 & -7.460323 \mathrm{E}+03 & -6.973563 \mathrm{E}+04 & -7.500000 \mathrm{E}+00 \\ \text { WELL-A } & 1.348605 \mathrm{E}+01 & -5.938876 \mathrm{E}+03 & 0.000000 \mathrm{E}+00 & -5.938876 \mathrm{E}+03 & -9.606735 \mathrm{E}+04 & -7.500000 \mathrm{E}+00 \\ \text { WELL-A } & 1.924998 \mathrm{E}+01 & -4.542198 \mathrm{E}+03 & 0.000000 \mathrm{E}+00 & -4.542198 \mathrm{E}+03 & -1.222482 \mathrm{E}+05 & -7.500000 \mathrm{E}+00 \\ \text { WELL-A } & 2.674308 \mathrm{E}+01 & -2.936396 \mathrm{E}+03 & 0.000000 \mathrm{E}+00 & -2.936396 \mathrm{E}+03 & -1.442510 \mathrm{E}+05 & -7.500000 \mathrm{E}+00 \\ \text { WELL-A } & 3.648412 \mathrm{E}+01 & -1.688785 \mathrm{E}+02 & 1.688785 \mathrm{E}+02 & 0.000000 \mathrm{E}+00 & -1.442510 \mathrm{E}+05 & -6.153597 \mathrm{E}+00 \\ \text { WELL-A } & 4.914746 \mathrm{E}+01 & -1.688848 \mathrm{E}+02 & 1.688848 \mathrm{E}+02 & -2.771117 \mathrm{E}-13 & -1.442510 \mathrm{E}+05 & -7.177913 \mathrm{E}+00 \\ \text { WELL-A } & 6.560981 \mathrm{E}+01 & -1.688863 \mathrm{E}+02 & 1.688863 \mathrm{E}+02 & -1.371347 \mathrm{E}-12 & -1.442510 \mathrm{E}+05 & -8.693682 \mathrm{E}+00 \\ \text { WELL-A } & 8.701086 \mathrm{E}+01 & -1.126887 \mathrm{E}+02 & 1.126887 \mathrm{E}+02 & -3.041123 \mathrm{E}-12 & -1.442510 \mathrm{E}+05 & -1.062797 \mathrm{E}+01 \\ \text { WELL-A } & 1.148322 \mathrm{E}+02 & -1.126888 \mathrm{E}+02 & 1.126888 \mathrm{E}+02 & -5.222489 \mathrm{E}-12 & -1.442510 \mathrm{E}+05 & -1.312928 \mathrm{E}+01 \\ \text { WELL-A } & 1.510000 \mathrm{E}+02 & -9.638431 \mathrm{E}+01 & 9.638431 \mathrm{E}+01 & 5.499601 \mathrm{E}-12 & -1.442510 \mathrm{E}+05 & -1.608294 \mathrm{E}+01 \\ \text { WELL-A } & 1.530181 \mathrm{E}+02 & -1.726025 \mathrm{E}-01 & 1.726025 \mathrm{E}-01 & -2.751133 \mathrm{E}-13 & -1.442510 \mathrm{E}+05 & -1.308487 \mathrm{E}+01\end{array}$


WELL-A 1.556417E+02 -1.056290E-03 WELL-A $1.590523 \mathrm{E}+02-6.993726 \mathrm{E}-05$ WELL-A 1.634861E+02 -1.324463E-04 WELL-A 1.692500E+02 -1.170383E-04 WELL-A 1.767431E+02 -1.560217E-04 WELL-A $1.864841 \mathrm{E}+02-1.675941 \mathrm{E}+03$ WELL-A $1.991475 \mathrm{E}+02-1.675941 \mathrm{E}+03$ WELL-A 2.156098E+02 -2.689814E+03 WELL-A 2.370109E+02 -2.793382E+03 WELL-A 2.648322E+02 -2.927088E+03 WELL-A 3.010000E+02 -3.043940E+03
$1.056290 \mathrm{E}-03-1.375562 \mathrm{E}-12-1.442510 \mathrm{E}+05-1.144114 \mathrm{E}+01$ $6.993726 \mathrm{E}-05-1.375562 \mathrm{E}-12-1.442510 \mathrm{E}+05-1.001580 \mathrm{E}+01$ $1.324463 \mathrm{E}-04-5.502248 \mathrm{E}-13-1.442510 \mathrm{E}+05-8.690089 \mathrm{E}+00$ $1.170383 \mathrm{E}-04 \quad 6.877810 \mathrm{E}-13-1.442510 \mathrm{E}+05-7.443020 \mathrm{E}+00$ $1.560217 \mathrm{E}-04-1.238006 \mathrm{E}-12-1.442510 \mathrm{E}+05-6.282333 \mathrm{E}+00$ $0.000000 \mathrm{E}+00-1.675941 \mathrm{E}+03-1.605764 \mathrm{E}+05-7.143954 \mathrm{E}+00$ $0.000000 \mathrm{E}+00-1.675941 \mathrm{E}+03-1.817994 \mathrm{E}+05-6.683726 \mathrm{E}+00$ $0.000000 \mathrm{E}+00-2.689814 \mathrm{E}+03-2.260800 \mathrm{E}+05-7.500000 \mathrm{E}+00$ $0.000000 \mathrm{E}+00-2.793382 \mathrm{E}+03-2.858614 \mathrm{E}+05-7.500000 \mathrm{E}+00$ $0.000000 \mathrm{E}+00-2.927088 \mathrm{E}+03-3.672970 \mathrm{E}+05-7.500000 \mathrm{E}+00$ $0.000000 \mathrm{E}+00-3.043940 \mathrm{E}+03-4.773895 \mathrm{E}+05-7.500000 \mathrm{E}+00$

Following are the abridged contents of the QSUM output file for the sample problem. Spaces have been deleted after the WELLID field.

File name: MNW2-Fig28. qsu

$\begin{array}{lccccr}\text { WELLID } & \text { Totim } & \text { Qin } & \text { Qout } & \text { Qnet } & \text { hwell } \\ \text { WELL-A } & 1.00000 & -0.927018 & 0.927018 & -9.628964 \mathrm{E}-13 & 4.93226 \\ \text { WELL-A } & 3.01811 & -10000.0 & 0.00000 & -10000.0 & -6.56353 \\ \text { WELL-A } & 5.64166 & -9189.96 & 0.00000 & -9189.96 & -7.50000 \\ \text { WELL-A } & 9.05226 & -7460.32 & 0.00000 & -7460.32 & -7.50000 \\ \text { WELL-A } & 13.4861 & -5938.88 & 0.00000 & -5938.88 & -7.50000 \\ \text { WELL-A } & 19.2500 & -4542.20 & 0.00000 & -4542.20 & -7.50000 \\ \text { WELL-A } & 26.7431 & -2936.40 & 0.00000 & -2936.40 & -7.50000 \\ \text { WELL-A } & 36.4841 & -168.879 & 168.879 & 0.00000 & -6.15360 \\ \text { WELL-A } & 49.1475 & -168.885 & 168.885 & -2.771117 \mathrm{E}-13 & -7.17791 \\ \text { WELL-A } & 65.6098 & -168.886 & 168.886 & -1.371347 \mathrm{E}-12 & -8.69368 \\ \text { WELL-A } & 87.0109 & -112.689 & 112.689 & -3.041123 \mathrm{E}-12 & -10.6280 \\ \text { WELL-A } & 114.832 & -112.689 & 112.689 & -5.222489 \mathrm{E}-12 & -13.1293 \\ \text { WELL-A } & 151.000 & -96.3843 & 96.3843 & 5.499601 \mathrm{E}-12 & -16.0829 \\ \text { WELL-A } & 153.018 & -0.172603 & 0.172603 & -2.751133 \mathrm{E}-13 & -13.0849 \\ \text { WELL-A } & 155.642 & -1.056290 \mathrm{E}-03 & 1.056290 \mathrm{E}-03 & -1.375562 \mathrm{E}-12 & -11.4411 \\ \text { WELL-A } & 159.052 & -6.993726 \mathrm{E}-05 & 6.993726 \mathrm{E}-05 & -1.375562 \mathrm{E}-12 & -10.0158 \\ \text { WELL-A } & 163.486 & -1.324463 \mathrm{E}-04 & 1.324463 \mathrm{E}-04 & -5.502248 \mathrm{E}-13 & -8.69009 \\ \text { WELL-A } & 169.250 & -1.170383 \mathrm{E}-04 & 1.170383 \mathrm{E}-04 & 6.877810 \mathrm{E}-13 & -7.44302 \\ \text { WELL-A } & 176.743 & -1.560217 \mathrm{E}-04 & 1.560217 \mathrm{E}-04 & -1.238006 \mathrm{E}-12 & -6.28233 \\ \text { WELL-A } & 186.484 & -1675.94 & 0.00000 & -1675.94 & -7.14395 \\ \text { WELL-A } & 199.147 & -1675.94 & 0.00000 & -1675.94 & -6.68373 \\ \text { WELL-A } & 215.610 & -2689.81 & 0.00000 & -2689.81 & -7.50000 \\ \text { WELL-A } & 237.011 & -2793.38 & 0.00000 & -2793.38 & -7.50000 \\ \text { WELL-A } & 264.832 & -2927.09 & 0.00000 & -2927.09 & -7.50000 \\ \text { WELL-A } & 301.000 & -3043.94 & 0.00000 & -3043.94 & -7.50000\end{array}$

Following are the abridged contents of the BYNODE output file for the sample problem. Spaces have been deleted after the WELLID field and the final column label ("seepage elev.") has been deleted below because it doesn't apply in this sample problem.

File name: MNW2-Fig28 . byn

$\begin{array}{lrrrrrrrr}\text { WELLID } & \text { NODE } & \text { Lay } & \text { Row } & \text { Col } & \text { Totim } & \text { Q-node } & \text { hwell } & \text { hcell } \\ \text { WELL-A } & 1 & 2 & 30 & 41 & 1.000000 \mathrm{E}+00 & -3.013586 \mathrm{E}-01 & 4.932257 \mathrm{E}+00 & 4.934203 \mathrm{E}+00 \\ \text { WELL-A } & 2 & 3 & 30 & 41 & 1.000000 \mathrm{E}+00 & -2.378125 \mathrm{E}-01 & 4.932257 \mathrm{E}+00 & 4.933793 \mathrm{E}+00 \\ \text { WELL-A } & 3 & 4 & 30 & 41 & 1.000000 \mathrm{E}+00 & -1.791428 \mathrm{E}-01 & 4.932257 \mathrm{E}+00 & 4.933414 \mathrm{E}+00 \\ \text { WELL-A } & 4 & 5 & 30 & 41 & 1.000000 \mathrm{E}+00 & -1.230621 \mathrm{E}-01 & 4.932257 \mathrm{E}+00 & 4.933052 \mathrm{E}+00\end{array}$




\begin{tabular}{|c|c|c|c|c|c|c|c|c|}
\hline WELL-A & 5 & 6 & 30 & 41 & $1.000000 \mathrm{E}+00$ & $-6.898905 E-02$ & $4.932257 \mathrm{E}+00$ & $4.932703 \mathrm{E}+00$ \\
\hline WELL-A & 6 & 7 & 30 & 41 & $1.000000 \mathrm{E}+00$ & $-1.665286 \mathrm{E}-02$ & $4.932257 \mathrm{E}+00$ & $4.932365 \mathrm{E}+00$ \\
\hline WELL-A & 7 & 8 & 30 & 41 & $1.000000 \mathrm{E}+00$ & $3.412860 \mathrm{E}-02$ & $4.932257 \mathrm{E}+00$ & $4.932037 \mathrm{E}+00$ \\
\hline WELL-A & 8 & 9 & 30 & 41 & $1.000000 \mathrm{E}+00$ & $8.350088 \mathrm{E}-02$ & $4.932257 \mathrm{E}+00$ & $4.931718 \mathrm{E}+00$ \\
\hline WELL-A & 9 & 10 & 30 & 41 & $1.000000 \mathrm{E}+00$ & $1.316186 \mathrm{E}-01$ & $4.932257 \mathrm{E}+00$ & $4.931407 \mathrm{E}+00$ \\
\hline WELL-A & 10 & 11 & 30 & 41 & $1.000000 \mathrm{E}+00$ & $1.787274 \mathrm{E}-01$ & $4.932257 \mathrm{E}+00$ & $4.931103 \mathrm{E}+00$ \\
\hline WELL-A & 11 & 12 & 30 & 41 & $1.000000 \mathrm{E}+00$ & $2.253779 \mathrm{E}-01$ & $4.932257 \mathrm{E}+00$ & $4.930802 \mathrm{E}+00$ \\
\hline WELL-A & 12 & 13 & 30 & 41 & $1.000000 \mathrm{E}+00$ & $2.736646 \mathrm{E}-01$ & $4.932257 \mathrm{E}+00$ & $4.930490 \mathrm{E}+00$ \\
\hline WELL-A & 1 & 2 & 30 & 41 & $3.018111 \mathrm{E}+00$ & $-7.791847 \mathrm{E}+02$ & $-6.563526 \mathrm{E}+00$ & $-1.532455 \mathrm{E}+00$ \\
\hline WELL-A & 2 & 3 & 30 & 41 & $3.018111 \mathrm{E}+00$ & $-8.214291 \mathrm{E}+02$ & $-6.563526 \mathrm{E}+00$ & $-1.259689 \mathrm{E}+00$ \\
\hline \multicolumn{9}{|l|}{$\cdots$} \\
\hline WELL-A & 11 & 12 & 30 & 41 & $2.648322 \mathrm{E}+02$ & $-2.481774 \mathrm{E}+02$ & $-7.500000 \mathrm{E}+00$ & $-5.897558 \mathrm{E}+00$ \\
\hline WELL-A & 12 & 13 & 30 & 41 & $2.648322 \mathrm{E}+02$ & $-2.526499 \mathrm{E}+02$ & $-7.500000 \mathrm{E}+00$ & $-5.868680 \mathrm{E}+00$ \\
\hline WELL-A & 1 & 2 & 30 & 41 & $3.010000 \mathrm{E}+02$ & $-2.506459 \mathrm{E}+02$ & $-7.500000 \mathrm{E}+00$ & $-5.881620 \mathrm{E}+00$ \\
\hline WELL-A & 2 & 3 & 30 & 41 & $3.010000 \mathrm{E}+02$ & $-2.507281 \mathrm{E}+02$ & $-7.500000 \mathrm{E}+00$ & $-5.881088 \mathrm{E}+00$ \\
\hline WELL-A & 3 & 4 & 30 & 41 & $3.010000 \mathrm{E}+02$ & $-2.508952 \mathrm{E}+02$ & $-7.500000 \mathrm{E}+00$ & $-5.880010 \mathrm{E}+00$ \\
\hline WELL-A & 4 & 5 & 30 & 41 & $3.010000 \mathrm{E}+02$ & $-2.511522 \mathrm{E}+02$ & $-7.500000 \mathrm{E}+00$ & $-5.878350 \mathrm{E}+00$ \\
\hline WELL-A & 5 & 6 & 30 & 41 & $3.010000 \mathrm{E}+02$ & $-2.515083 \mathrm{E}+02$ & $-7.500000 \mathrm{E}+00$ & $-5.876051 \mathrm{E}+00$ \\
\hline WELL-A & 6 & 7 & 30 & 41 & $3.010000 \mathrm{E}+02$ & $-2.519781 E+02$ & $-7.500000 \mathrm{E}+00$ & $-5.873017 \mathrm{E}+00$ \\
\hline WELL-A & 7 & 8 & 30 & 41 & $3.010000 \mathrm{E}+02$ & $-2.525855 E+02$ & $-7.500000 \mathrm{E}+00$ & $-5.869096 \mathrm{E}+00$ \\
\hline WELL-A & 8 & 9 & 30 & 41 & $3.010000 \mathrm{E}+02$ & $-2.533707 \mathrm{E}+02$ & $-7.500000 \mathrm{E}+00$ & $-5.864026 \mathrm{E}+00$ \\
\hline WELL-A & 9 & 10 & 30 & 41 & $3.010000 \mathrm{E}+02$ & $-2.544074 \mathrm{E}+02$ & $-7.500000 \mathrm{E}+00$ & $-5.857332 \mathrm{E}+00$ \\
\hline WELL-A & 10 & 11 & 30 & 41 & $3.010000 \mathrm{E}+02$ & $-2.558476 \mathrm{E}+02$ & $-7.500000 \mathrm{E}+00$ & $-5.848033 \mathrm{E}+00$ \\
\hline WELL-A & 11 & 12 & 30 & 41 & $3.010000 \mathrm{E}+02$ & $-2.580849 \mathrm{E}+02$ & $-7.500000 \mathrm{E}+00$ & $-5.833587 E+00$ \\
\hline WELL-A & 12 & 13 & 30 & 41 & $3.010000 \mathrm{E}+02$ & $-2.627360 \mathrm{E}+02$ & $-7.500000 \mathrm{E}+00$ & $-5.803555 E+00$ \\
\hline
\end{tabular}





\title{
Appendix 3-Program to Convert MNW1 Input Data to MNW2 Input Data
}

\author{
By A.W. Harbaugh
}

\section{Overview of Program}

The MNW2 Package will supercede the older MNW1 Package in new releases of MODFLOW. Therefore, model users who have input datasets compatible with MNW1 will have to edit and modify those datasets to use MNW2.

MNW1 to 2 is a utility program that automatically converts input data for the MNW1 Package to input data for the MNW2 Package. The overall capabilities of both packages are similar, but the organization of the input data differs, and a few incompatible features and processes exist between the two packages.

MNW1 reads all of the attributes for all of the nodes of a multi-node well every stress period the well is used. MNW2 defines most attributes for all multi-node wells up front, and then a well is activated within a stress period by indicating its name and pumping rate.

Both MNW1 and MNW2 allow a water-level limit to be specified for wells, but MNW2 does not support all the functionality of MNW1. The fundamental capability supported by both packages is an absolute water-level limit (input variable HIim in both MNW1 and MNW2). MNW1 also supports specifying the limit as a drawdown (or head build up for recharging wells) from a reference level (input variable Href in MNW1). Although MNW2 does not directly support specification of the limit as a drawdown, MNW1 to2 will compute HIim for use in MNW2 from the MNW1 HIim and Href values. MNW1 further allows the reference head to be specified as a water level computed during the simulation, and MNW1 to 2 does not have a way to deal with this, except that MNW1 to 2 notifies the user if the drawdown limit is being used. The user is then asked to choose to either deactivate the water-level limit for all wells with a drawdown limit or allow MNW1 to2 to compute Hlim from the specified Href.

MNW1 does not require well names, but MNW2 requires well names. MNW1 to2 generates well names if none exist. The name is generated in the following form:

WcccrrrL1L2...Lx,

where ccc is a 3-digit number that is the grid column of the first node of the well, rrr is a 3-digit number that is the grid row of the first node of the well, L1,L2 ...Lx is a series of 2-digit numbers that are the layers of the nodes in the well.

For example, if there is a multi-node well in nodes (column, row, layer) $(17,43,3),(17,43,4)$, and $(17,43,5)$, then the generated well number will be W017043030405.

MNW1 allows 32-character names, and MNW2 limits well names to 20 characters. If a name is longer than 20 characters, then MNW1 to 2 uses the first 16 characters of the MNW1 name and appends a 4-digit number to make 20 characters.

MNW1 does not require unique well names within a stress period as required by MNW2. MNW1 to 2 checks the wells defined for each stress period to make sure that the names are unique. If there are duplicate names, then the program writes an error message and stops.

Further, MNW1 allows many of the attributes of a well to change each stress period, and MNW2 does not allow those changes. The attributes that can change in MNW1 and not in MNW2 are LOSSTYPE, use of a water-level limit, the specific nodes incorporated in the well, well radius, and any of the well-loss constants. The well discharge (Qdes) and the value of the water-level limit are allowed to change every stress period in MNW2. MNW1 to2 checks for an invalid change in well attributes each stress period. If a change is detected, then those new attributes are represented by creating a new well by appending a single uppercase letter to the name of the well.

MNW2 implements five alternative models of well loss, which are specified using input variable LOSSTYPE. Table A3-1 describes how the value of LOSSTYPE for MNW2 is determined from MNW1 data. 
Table A3-1. Inferred equivalence in MNW1 to2 of LOSSTYPE options in MNW1 to those in MNW2.

\begin{tabular}{ll}
\hline \multicolumn{1}{c}{ MNW1 data } & MNW2 LOSSTYPE \\
\hline $\mathrm{RW}=0$ & NONE \\
$\mathrm{Rw}<0$ & SPECIFYCWC \\
$\mathrm{LOSSTYPE}=$ SKIN and Skin $\leq 0$ & THIEM \\
LOSSTYPE $=$ SKIN and Skin $>0$ & SKIN \\
LOSSTYPE=LINEAR & General, with $C=0$ \\
LOSSTYPE=NONLINEAR & General \\
\hline
\end{tabular}

When the MNW2 LOSSTYPE is Skin, MNW2 requires that the skin radius (Rskin) and the skin hydraulic conductivity (Kskin) be defined. MNW1 to2 computes these from MNW1 data. In MNW1 (Halford and Hanson, 2002, eq. 3), Skin is defined as

$$
\text { Skin }=\left(\frac{T}{T_{\text {Skin }}}-1\right) \ln \left(\frac{R_{\text {Skin }}}{R_{w}}\right),
$$

where $T$ is the aquifer transmissivity in the cell $\left(\mathrm{L}^{2} / \mathrm{T}\right)$ and $T_{\text {Skin }}$ is the transmissivity in the skin region $\left(\mathrm{L}^{2} / \mathrm{T}\right)$.

A node is assumed to be screened in the entire thickness of the cell, so

$$
\text { Skin }=\left(\frac{K}{K_{\text {Skin }}}-1\right) \ln \left(\frac{R_{\text {Skin }}}{R_{w}}\right),
$$

where $K$ is the aquifer hydraulic conductivity $(\mathrm{L} / \mathrm{T})$ and $K_{\text {Skin }}$ is the hydraulic conductivity in the area around the well $(\mathrm{L} / \mathrm{T})$.

Skin and $R_{w}$ are specified in the MNW1 data file, and $K$ is determined from data in the flow package file. MNW1 to 2 determines the flow package being used from the MODFLOW Name File. The two flow packages supported by MNW1 to 2 are the Block-Centered Flow (BCF) and Layer-Property Flow (LPF) Packages. When $K$ is different in the $x$ - and $y$-directions, $K$ is defined as $\sqrt{K_{x} K_{y}}$. Equation 2 can be used to determine either $K_{\text {Skin }}$ or $R_{\text {Skin }}$ if the other is known. To avoid having the user interactively enter one of the values, MNW1 to 2 assumes that $R_{\text {Skin }}=2 R_{w}$. Using equation $2, K_{\text {Skin }}$ is then computed to be

$$
K_{\text {Skin }}=\frac{\sqrt{K_{x} K_{y}}}{\frac{\text { Skin }}{\ln 2}+1}
$$

\section{Running MNW1to2}

When MNW1 to2 is started, it prompts for a MODFLOW Name File. The Name File is used to determine the MNW1 input file, the Discretization (DIS) File, and the flow package file. If the MNW1 option to compute waterlevel limits based on drawdown is used, then MNW1 to2 asks the user to specify whether or not to compute the MNW2 Hlim from the MNW1 Hlim and Href values. If the response is "No", then the MNW1 water-level limit is ignored for all wells for which a drawdown limit is specified.

MNW1 to2 writes two output files. Mnw1to2. Ist contains information about the conversion, including the original MNW1 input data. Mnw1to2. mnw is the converted MNW2 data file. The MNW2 data file has comments at the end of lines to indicate the input data contained on the lines.

MNW1 to 2 does not use dynamic memory allocation, which results in limits on the number of wells and the number of nodes associated with each well. The limits are 10,000 multi-node wells and 50 nodes per well. MNW1 to 2 also limits the number of stress periods to 100 .

Although MNW1 to2 will usually be successful in generating an equivalent dataset for MNW2 from a MNW1 dataset, the conversion is based on a number of implicit assumptions, as discussed above, and the conversion may not always be 100 percent complete nor be precisely as anticipated by the user. Thus, it is recommended that the 
user carefully inspect the MNW2 input file generated by this utility program. The user should also review the Mnw1 to2. Ist output file to see if any warning messages were generated during the conversion process.

The executable code for MNW1 to2 is available for downloading from a USGS software repository, which for ground-water models can be found at http://water.usgs.gov/software/ground_water.htm. 


